\title{
AN ANALYSIS OF BEST PRACTICES FOR INTERPRETATION DEVELOPMENT \\ AT PUBLIC GARDENS
}

by

Nathan M. Tschaenn

A thesis submitted to the Faculty of the University of Delaware in partial fulfillment of the requirements for the degree of Master of Science in Public Horticulture

Spring 2013

\author{
(C) 2013 Nathan M. Tschaenn \\ All Rights Reserved
}




\section{AN ANALYSIS OF BEST PRACTICES FOR INTERPRETATION DEVELOPMENT AT PUBLIC GARDENS}

by

Nathan M. Tschaenn

Approved:

Robert E. Lyons, Ph.D.

Professor in charge of thesis on behalf of the Advisory Committee

Approved:

Blake C. Meyers, Ph.D.

Chair of the Department of Plant and Soil Sciences

Approved:

Mark Rieger, Ph.D.

Dean of the College of Agriculture and Natural Resources

Approved:

James G. Richards, Ph.D.

Vice Provost for Graduate and Professional Education 


\section{ACKNOWLEDGMENTS}

I would like to express my great appreciation for the members of my thesis advisory committee, Dr. Robert Lyons, Dr. Jules Bruck, and Ms. Dottie Miles, for their support and guidance in the completion of this thesis project. Your knowledge and expertise was much appreciated.

I would like to thank all the organizations that contributed to my research, as well as Longwood Gardens, the Longwood Foundation, and the University of Delaware for making this research possible. I would also like to thank my classmates for their friendship and support during these past two years.

Finally, I would like to thank my wife, son, and family for their continual support and encouragement. 


\section{TABLE OF CONTENTS}

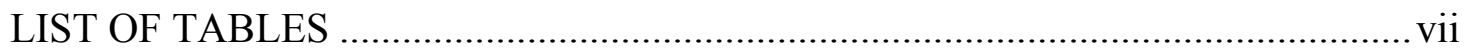

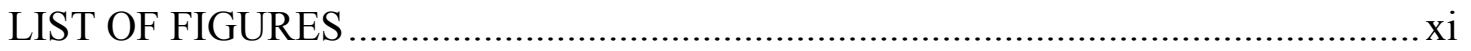

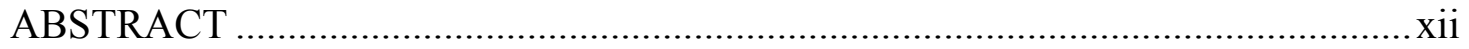

Chapter

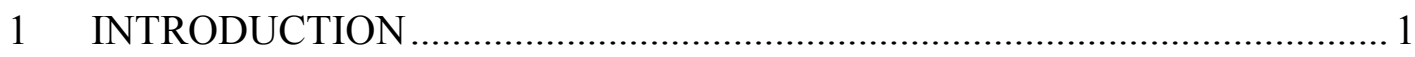

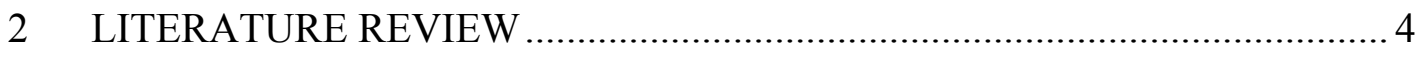

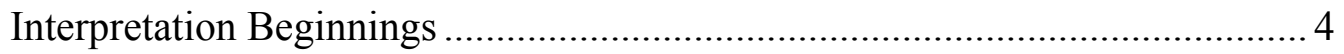

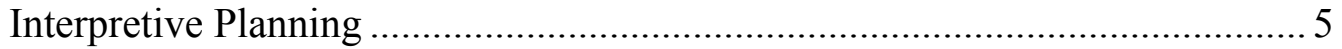

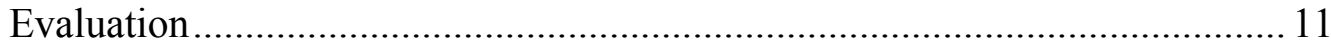

Interpretation and Audience Types ........................................................... 13

Understanding the Audience .............................................................. 16

3 MATERIALS AND METHODS ................................................................. 19

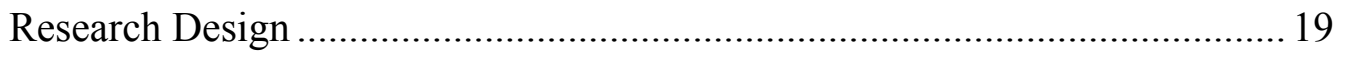

Human Subjects Review Board ............................................................. 19

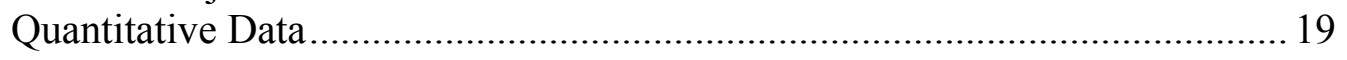

Survey 1: Preliminary Survey ........................................................ 20

Survey 2: Interpretation Development at Public Gardens .................. 20

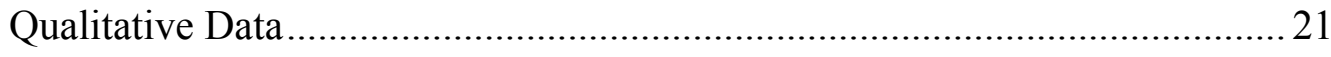

Case Study Site Selection ........................................................... 21

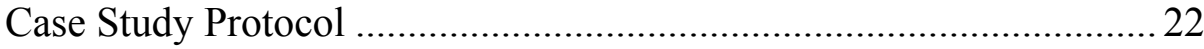

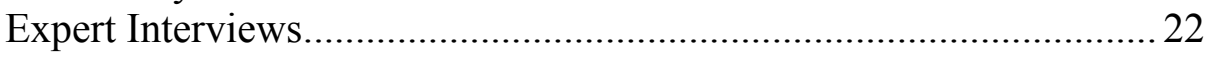

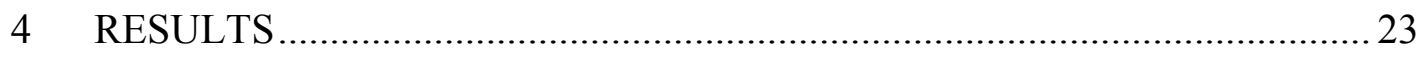

Survey: Interpretation Development at Public Gardens .............................. 23

Background Data ...................................................................... 23

Educational Background and Staff Training ................................. 26

Interpretive Planning Documents ................................................ 31 
Interpretation Development and Evaluation Practices 41

Barriers to Interpretation Development............................................... 47

Professional Development Organizations ........................................ 49

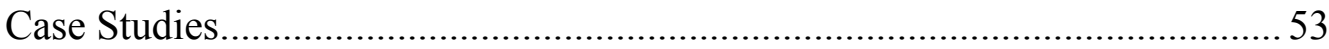

Monterey Bay Aquarium ............................................................... 53

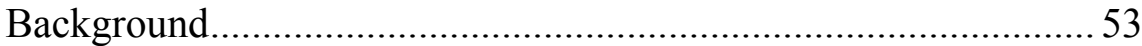

Volunteer Program and Training ............................................... 53

Exhibit Development and Planning Documents.......................... 54

Interpretive Sign Development at UC Davis Arboretum ................... 55

United Stated Botanic Garden ........................................................ 56

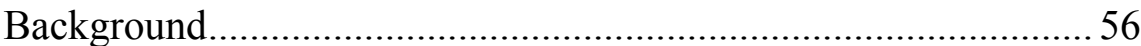

Interpretive Planning Documents .............................................. 57

Volunteer/Docent and Staff Training ....................................... 58

Chicago Botanic Garden................................................................. 59

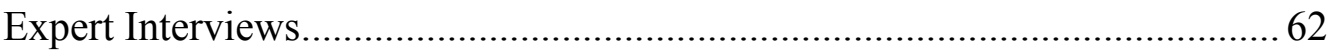

Interview with Jennifer Rigby, Director of The Acorn Group ............. 62

Interview with Casey Sclar, Executive Director of the American

Public Gardens Association................................................................ 63

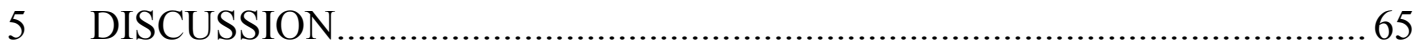

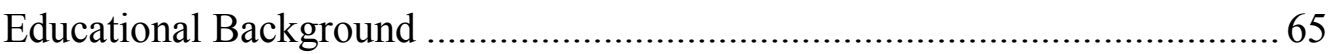

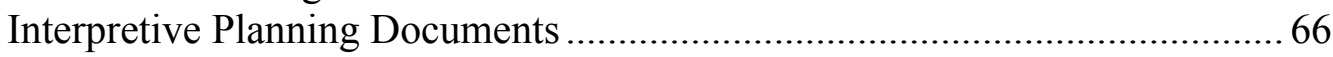

Interpretive Master Plans and Interpretive Plans for Individual

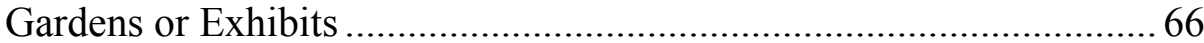

Interpretive Planning Consultants ................................................... 70

Interpretive Planning for Events and Daily Programing .................... 71

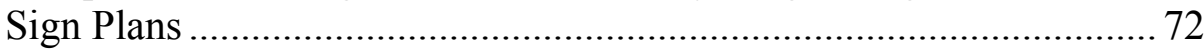

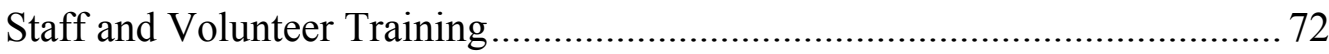

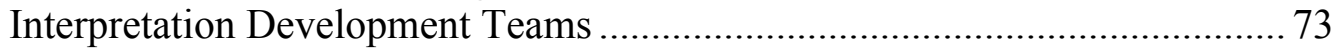

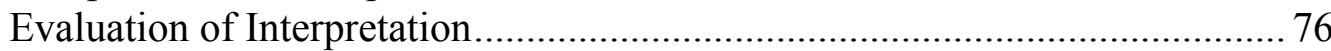

Insufficient Budget and Resources as Barriers to Interpretation

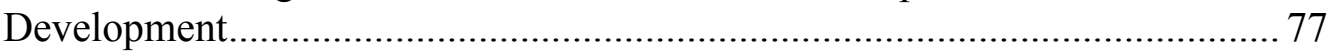

Professional Development Organizations ................................................. 79 


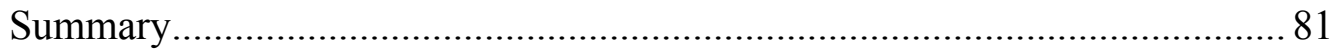

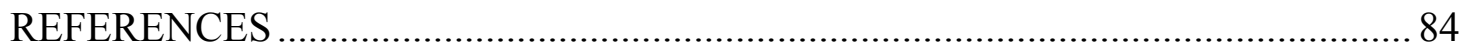

Appendix

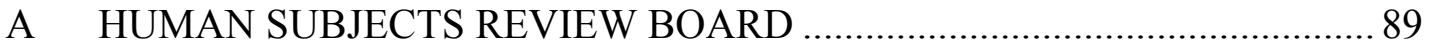

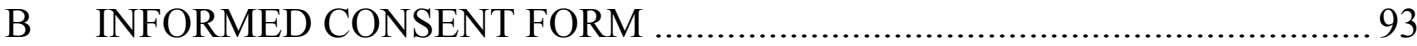

C PRELIMINARY SURVEY RESULTS .................................................... 95

D ADDITIONAL RESULTS FROM INTERPRETATION DEVELOPMENT

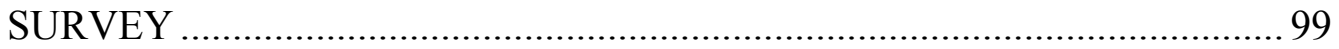

E MONTEREY BAY AQUARIUM DOCUMENTS .................................... 125

F UNITED STATES BOTANIC GARDEN INTERVIEW AND

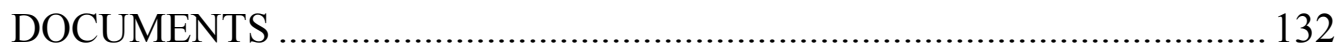




\section{LIST OF TABLES}

Table 1 Characteristics of formal and informal learning environments .............. 14

Table 2 Interpretive media provided by the public gardens of 284 survey participants

Table 3 Degree to which survey respondents agreed or disagreed with specific statements regarding interpretation development at their organization. . 25

Table 4 Percent of survey respondents indicating degree status or formal education in the fields of Education, Museum Studies or Interpretation.

Table 5 Survey respondents' degree of feeling adequately trained in their specific responsibilities in interpretation relative to their having a degree or formal training in fields of Education, Museums Studies, or Interpretation.

Table 6 Responses to the survey question, "Does your organization encourage horticulture staff to interact with visitors?"

Table $7 \quad$ Percent of survey respondents indicating training in personal interpretation is provided for horticultural staff and volunteers or docents.

Table 8 Degree to which survey respondents agreed or disagreed with the statement, "I am satisfied with the overall quality of interpretation at my organization," with regards to whether or not training is provided in personal interpretation for staff and volunteers or docents.

Table 9 Organizational interpretive planning documents created or amended in the past 15 years as indicated by 275 survey respondents.

Table 10 Degree to which survey respondents agreed or disagreed with specific statements regarding interpretation development at their organization (mean) with respect to whether or not they indicated having an interpretive master plan or prospectus or a document(s) outlining desired messages and/or goals for individual gardens or exhibits. 
Table 11 Usefulness ratings of an interpretive master plan or interpretive prospectus in developing interpretation as indicated by 98 survey respondents.

Table 12 Responses to the survey question, "Did you consult with a professional planning firm when developing the interpretive master plan or interpretive prospectus?".

Table 13 Usefulness ratings of a document(s) that outlines desired messages and/or goals for individual gardens or exhibits as indicated by 115 survey respondents.

Table 14 Responses to the survey question "Did you consult with a professional planning firm when developing documents outlining desired messages and/or goals for individual gardens or exhibits."

Table 15 How 94 survey respondents rated the usefulness of the document(s) outlining desired goals and/or messages for individual gardens or exhibits with respect to their decision to consult with a professional planning firm. 36

Table 16 How useful 92 survey respondents indicated the usefulness of a sign plan for the development of interpretive media.

Table 17 Usefulness ratings of documents outlining desired messages and/or goals for events and daily programming in developing interpretation as indicated by 72 survey respondents.

Table 18 Degree to which survey respondents agreed or disagreed with specific statements regarding interpretation development (mean) with respect to whether or not the survey respondent indicated having documents outlining desired messages and/or goals for events and daily programming.

Table 19 Responses to the survey question "Have you ever funded a planning document through a grant?"

Table 20 Responses to the survey question "Have you ever used an interpretive planning document to successfully secure a grant or financial donation?"

Table 21 Response to the question, "Is there a team specifically dedicated to interpretation development at your organization?" 
Table 22 Degree to which survey respondents agreed or disagreed with specific statements regarding interpretation development at their organization (mean) with respect to whether or not they indicated having a team dedicated to interpretation development at their organization.

Table 23 Responses to the question, "Does your organization routinely evaluate interpretive messages or devices (media)?"

Table 24 Types of evaluation used in evaluating interpretive messages or devices (media) as indicated by 80 survey respondents from organizations that routinely evaluate interpretive messages of devices. . 44

Table 25 How evaluation is conducted at 82 survey respondents' organizations where interpretive messages or devices (media) are routinely evaluated.

Table 26 Types of interpretive media that are routinely evaluated at 83 survey respondents' organizations where interpretive messages or devices (media) are routinely evaluated.

Table 27 Degree to which 194 survey respondents agreed or disagreed with the statement, "I am satisfied with the overall quality of interpretive signage at my organization," with respect to whether or not they indicated that interpretive signage was routinely evaluated.

Table 28 Degree to which 190 survey respondents agreed or disagreed with the statement, "I am satisfied with the overall quality of the guided tours provided by my organization," with respect to whether or not they indicated that guided tours were routinely evaluated.

Table 29 Challenges faced by survey respondents in interpretation development.

Table 30 Biggest challenges faced by survey respondents in interpretation development.

Table 31 Professional development organizations related to interpretation in which 281 survey respondents are actively involved.

Table 32 How valuable survey respondents rated their involvement in APGA with regards to professional development in the field of interpretation.. 51

Table 33 How valuable survey respondents rated their involvement in AAM with regards to professional development in the field of interpretation.. 52 
Table 34 How valuable survey respondents rated their involvement in NAI with regards to professional development in the field of interpretation...........52 


\section{LIST OF FIGURES}

Figure 1 The best interpretive message comes from an overlap of the management desires, visitor interests, and resource stories

Figure 2 Hierarchal system of interpretive message arrangement....................... 8

Figure 3 Example of interpretive planning levels......................................... 10

Figure 4 The sign at the entrance to the Heritage Garden at Chicago Botanic Garden explains the intent of the garden and introduces the concept of grouping plants for scientific study, the major theme of the garden...... 60

Figure 5 Plants within the Heritage Garden at Chicago Botanic Garden are arranged by geographic origins, medicinal benefits, or plant families. Interpretive signs identify each of the plant families displayed here and provide information about the shared characteristics of plants in that family

Figure 6 Multiple handwritten signs are placed throughout a garden at Chicago Botanic Garden with common themes. 


\begin{abstract}
Interpretation can be the most effective way for public gardens to communicate with their audiences by connecting their interests with the mission and resources of the organization. As the messages that public gardens strive to communicate become more complex and the interests and backgrounds of visitors become increasingly diverse, interpretation is more important than ever to fulfilling the mission of many public gardens. However, the importance of interpretation is easily overlooked, and many public gardens struggle to understand interpretation, its role in public horticulture, and how to best develop it.

This research compares and contrasts a variety of approaches to interpretation development at public gardens using surveys, case studies, and expert interviews. Different approaches are analyzed, including the organization's perceived value of an approach and staff satisfaction with various aspects of their own interpretation and development processes. Staff and volunteer training, interpretive planning documents, professional development organizations, evaluation, staff composition, and barriers faced in the interpretation development process are all factors included in this analysis.

Survey results revealed many interpretive development practices that are yielding significant benefits for public gardens. The data also revealed that the majority of public gardens have significant room for improvement with regard to interpretation planning and development. For instance, organizations were more likely to be satisfied with the interpretive media that they routinely evaluated, but few organizations routinely conducted evaluation of interpretive media or messages. This
\end{abstract}


research led to the development of a set of recommendations for public gardens that will help guide decision-making related to interpretation development practices. 
Chapter 1

\section{INTRODUCTION}

Public gardens along with zoos, aquariums, parks, and nature centers are important destinations where children and adults alike are put in contact with valuable natural resources. (Brochu and Merriman, 2002). In the case of public gardens, this resource is mainly plants. One of the ways public gardens benefit the general public is by providing information about their resources and helping them understand it. When communicating with their audiences, public gardens will often use an artful form of communication known as interpretation. Experts in the field of public horticulture often have common interests, knowledge bases, and sometimes backgrounds that allow them to easily communicate with one another about their resources, but the same communication approach would not be effective with audiences outside of the field. When communicating with an audience who has limited knowledge and interest in the resource, interpretation is often required in order to facilitate comprehension and understanding (Ward and Wilkenson, 2006).

Interpretation, as defined by the National Association for Interpretation, is "a mission-based communication process that forges intellectual and emotional connections between the interests of the audience and the meanings inherent in the resource" (2009). Interpretation differs from information in that it goes beyond facts and figures to convey the meaning of something, through exposition or explanation (Grater, 1976; Brochu and Merriman, 2002). The aim of interpretation is to translate 
ideas, concepts, or facts into a format that captures, engages, entertains, and inspires audiences and uses many of the same strategies as in marketing (Veverka, 2011a). Information must be given to a visitor in a way that the visitor can understand and appreciate it so that interpretation can take place. Understanding a resource may stimulate a desire to learn more, and with understanding and a desire to learn more, comes an appreciation of the resource (Grater, 1976).

Most public gardens feel that interpretation is important to their organizations' mission and it is their intention to provide information about their valuable natural resources in an understandable way to foster appreciation by visitors. Unfortunately, many "interpretive" signs or other media provided by public gardens and other museums are informational rather than interpretive because they do not follow principals of interpretive communication (Veverka, 2011b). Additionally, research has shown that visitors to botanical gardens are less motivated to learn when compared to visitors to similar organizations like zoos, aquariums, and museums, making interpretation even more challenging (Ballantyne et al., 2008).

The objective of this research was to analyze the current interpretive planning and development practices utilized by public gardens. Specifically, this research addressed:

- To what extent are public gardens following best practices for interpretation planning and development as described in literature and past research?

- What methods of interpretive planning are most valued by public gardens? 
- What are the interpretive planning and development strategies utilized by gardens who are most satisfied with the quality of their interpretation and development practices?

The results of this research aim to aid public gardens' decision-making regarding interpretive development practices so as to provide more meaningful interpretation for their visitors. 
Chapter 2

\section{LITERATURE REVIEW}

\section{Interpretation Beginnings}

The concept of interpreting natural and cultural resources has its beginnings in the National Parks. Enos Mills, one of the earliest natural resource interpreters (Gross and Zimmerman, 2002), started interpreting in 1889 in what would become Rocky Mountain National Park. Mills was inspired to become an interpretive guide after a chance meeting with John Muir, celebrated conservationist and founder of the Sierra Club, on a San Francisco beach. Mills started one of the first programs in the country to train interpreters and was one of the first to recognize and exploit the relationship between how much visitors know about a resource and how much they want to protect the resource (Ward and Wilkinson, 2006).

In the early 1950 's, the National Parks Service hired writer, playwright, and publisher Freeman Tilden to study and write about interpretation (Brochu and Merriman, 2002). Tilden is considered by many to be the founder of the discipline of interpretation (Leftridge, 2006; Ward and Wilkinson, 2006). Tilden (1957) defined interpretation as "an education activity, which aims to reveal meanings and relationships through the use of objects, by firsthand experience, and by illustrative

media, rather than simply to communicate factual information." His definition became the standard in the field for decades (Brochu and Merriman, 2002). In his book Interpreting Our Heritage, Tilden (1957) outlined six principals of interpretation: 
- Any interpretation that does not somehow relate what is being displayed or being described to something within the personality or experience of the visitor will be sterile.

- Information, as such, is not interpretation. Interpretation is revelation based upon information. But they are entirely different things. However, all interpretation includes information.

- Interpretation is an art, which combines many arts whether the materials presented are scientific, historical or architectural. Any art is in some degree teachable.

- The chief aim of interpretation is not instruction, but provocation.

- Interpretation should aim to present a whole rather than a part and must address itself to the whole man rather than any phase.

- Interpretation addressed to children should not be a dilution of the presentation to adults, but should follow a fundamentally different approach. To be at its best it will require a separate program.

These principals of interpretation are still widely used, adapted, and referenced today and can be used to differentiate between what is interpretation and what is just information (Veverka, 2011b).

\section{Interpretive Planning}

There is no one-size-fits-all approach to interpretation (Brochu, 2003). Public gardens widely vary in their resource considerations, management needs, messages, and target audiences. Interpretive planning is a decision-making process that takes into account all these variables in order to determine the most effective method of communicating a unified message to a target audience (Brochu, 2003). An interpretive 
plan is the documentation of this thoughtful decision-making process (National Association for Interpretation, 2009).

Interpretive plans provide numerous benefits to organizations. A welldeveloped planning document is extremely appealing to donors and can assist in fundraising (Brochu, 2003). Planning will help identify issues of concern and help find solutions to problems that allow for the most efficient allocation of resources. Planning can revitalize existing interpretive media with updated text and graphics, and can help organizations develop a collections policy that will avert the acquisition of specimens that don't fit an organization's mission. Finally, and perhaps most importantly, an effective interpretive plan can help create a more enjoyable visitor experience.

There are a variety of factors that must be considered or defined when planning for interpretation. One such factor is the management objectives for the organization, including the mission statement of the organization. Interpretation must help in achieving the mission of the organization (Brochu and Merriman, 2002); if it does not, there is little reason to spend money on it (Brochu, 2003). The mission statement can also be useful in developing themes and subthemes, i.e., core messages and supporting messages (Brochu and Merriman, 2002), a key step in developing an interpretive plan (Moscardo et al., 2007, Brochu and Merriman, 2002, Brochu, 2003).

Key factors that must be considered in interpretive planning but are often forgotten or ignored are the interests, needs, and knowledge of the visitor (Moscardo et al., 2007). The second quality of interpretation in Ham's (1992) interpretive approach is that interpretation is relevant. Information that is relevant is both meaningful and personal, i.e., will be understood by the visitor and promote 
connectivity with something they already know. Understanding and connectivity can be achieved through the use of examples, analogies, and comparisons. Even if visitors understand information perfectly, they will likely ignore it if they do not find it applicable (Ham, 1992). As Tilden's (1977) first principal states, interpretation must relate to the visitor in some way. Information about the interests, needs, and knowledge of the visitor can be gained through audience analysis and front-end evaluation (Moscardo et al., 2007; Hein, 1998).

Brochu (2003) suggests that the best message or messages to communicate will come from an overlap of the management objectives of the site, the visitor interests, and the meanings inherent in the resources (Figure 1). It is possible for planning to be so focused on any one of these elements that it neglects or ignores one or both of the other elements. Once the messages that fit each of these three elements have been identified, they should be organized and prioritized into a hierarchal system, which is accomplished through the development of a theme, supporting subthemes, and more detailed storylines that support the subthemes and theme (Figure 2). The theme may also be referred to as the core message. 


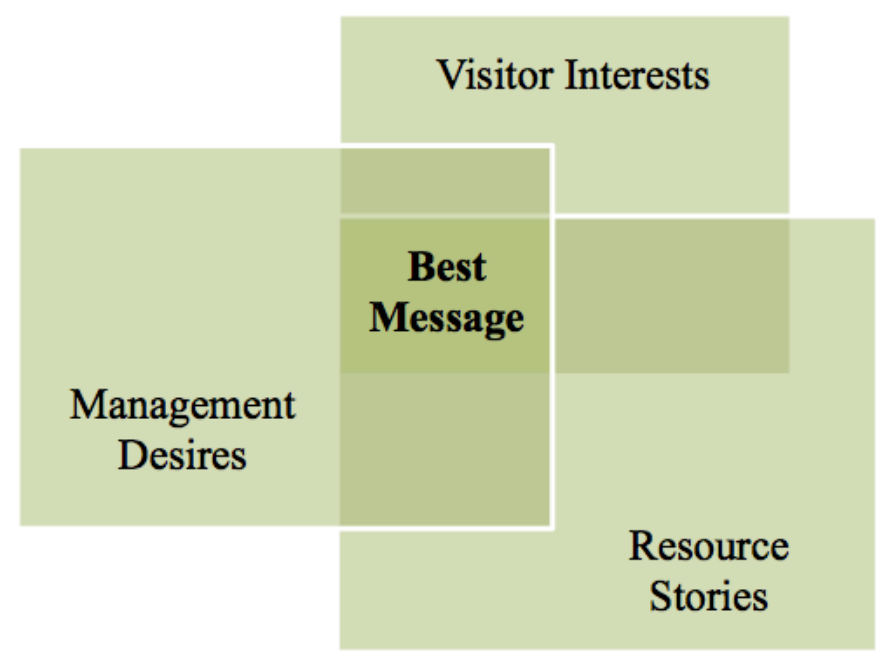

Adapted from: Brochu, L., and National Association for Interpretation 2003, Interpretive Planning: The 5-M Model for Successful Planning Projects. InterpPress, Fort Collins, CO.

Figure 1 The best interpretive message comes from an overlap of the management desires, visitor interests, and resource stories.

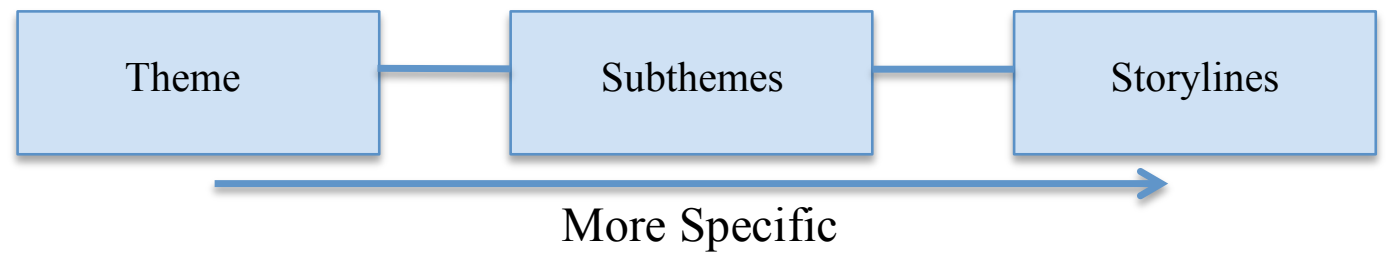

Figure 2 Hierarchal system of interpretive message arrangement.

Developing interpretation into themes and subthemes is a way of maximizing the effectiveness of interpretation (Brochu and Merriman, 2002). Ham (1992) describes the theme as "the main point or message a communicator is trying to convey about the topic." Themes go beyond stating the subject of the interpretation and 
instead tell something about the subject and reveal the overall purpose of the interpretation (Veverka, 2011a). Visitors to public gardens should leave knowing something about the organization and its cultural and natural heritage (Connolly, 2011). The theme should be a summary of the knowledge with which the visitors leave. Often a planning document will have one overarching or main theme with three to five supporting subthemes (Brochu, 2003). Themes may never appear in writing anywhere except the planning document but will serve as the guiding principles for the interpretive plans (Brochu, 2003).

Themes can either be very specific or broad depending on the type of interpretive planning that is taking place (Veverka, 2011a). For an interpretive master plan, the theme would be broad and cover the overall interpretive message of an entire site. When creating an interpretive plan for a particular exhibit, more specific themes would be required. Interpretive planning for interpretive programs or presentations also requires more specific themes that summarize the key idea of the program. More specific themes should flow from broader themes (Figure 3). 


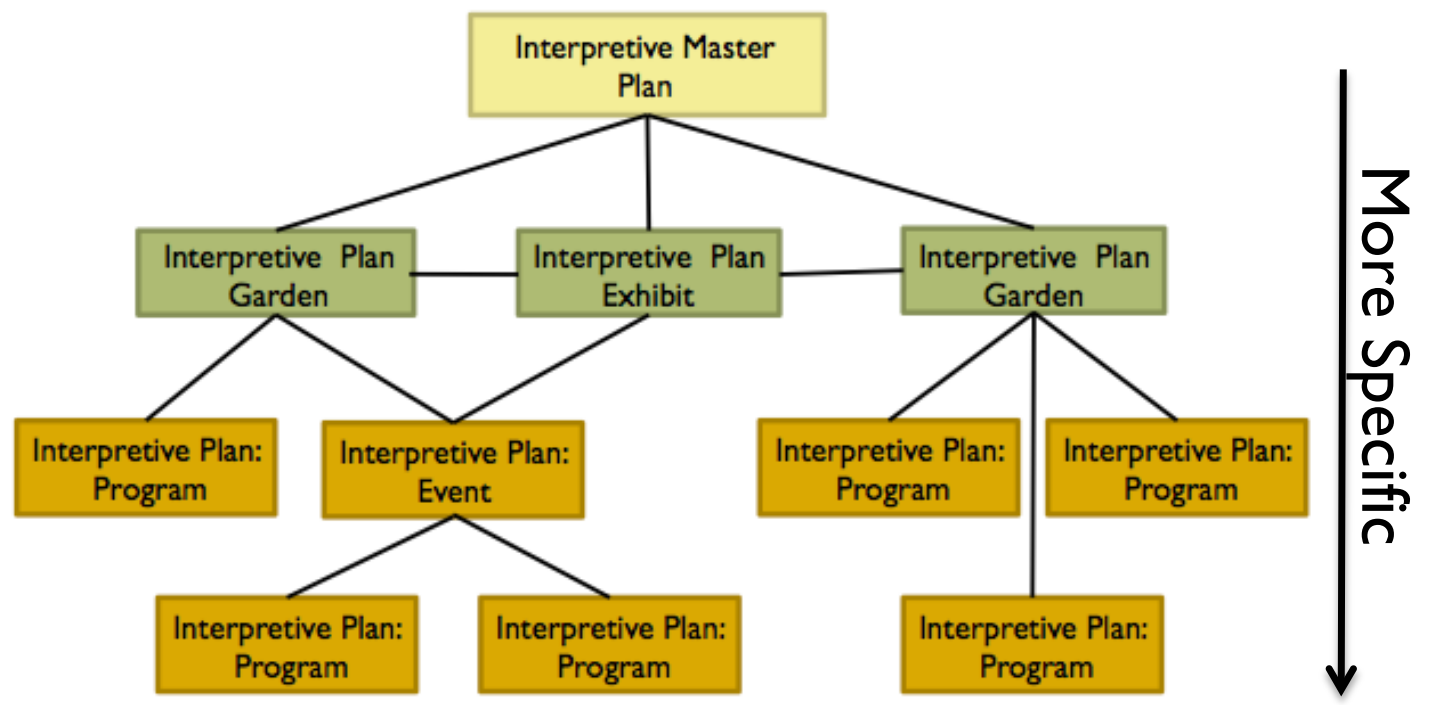

Figure 3 Example of interpretive planning levels.

Brochu's (2003) concept of developing three to five subthemes is based on the knowledge that there is a limit to the amount of information a person can store in short-term memory. Specifically, about seven chunks of information can be stored in short-term memory, with up to nine for some and just about five for most (Miller, 1956). More recently, Cowan (2001) reported that people can store four chunks of information in their short-term memory, with a chunk defined as "a collection of concepts that have strong associations to one another and much weaker associations to other chunks currently in use" (Cowan 2001). Therefore, interpretation should focus information into a common theme so visitors can better remember and understand it (Veverka, 2011a). 
Interpretive planning should also include the development of goals and objectives that provide direction for interpretive services and help define content (Veverka, 2011a). Goals state what an organization would like to have happen through their interpretation and aren't very specific. Objectives are measurable and useful for evaluation. John Veverka (2011a) defines three basic kinds of objectives: learning, behavioral, and emotional. Learning objectives are the most common and define what a visitor should learn or remember. Behavioral objectives, which Veverka believes are the most important, define what you would like the visitor to do with the information given them. Emotional objectives are the "driving force," that create emotional reactions which help visitors remember and help elicit behavioral changes.

Like interpretive themes, there are varying levels of goals and objectives that should be used by an organization (Veverka 2011a). The overall goals and objectives will define the anticipated accomplishments of the interpretive programs and services offered by an organization. Goals and objectives for each site or exhibit would be more specific but still align with the overall goals and objectives. Finally, individual interpretive programs would have even more specific and detailed goals and objectives, defining what is to be accomplished through the program.

\section{Evaluation}

Evaluation is an essential aspect of any interpretive activity and should be factored into every interpretive plan. Evaluation is instrumental in determining the effectiveness of specific interpretive elements; exploring visitor expectations, experiences, and satisfaction; and measuring the interpretive media's effectiveness in meeting the objectives or goals of the organization (Moscardo et al., 2007). There are three primary types of visitor evaluation methods are used to evaluate interpretation: 
front-end evaluation (i.e. preliminary), formative evaluation, and summative evaluation (Moscardo et al., 2007).

Front-end evaluation includes audience analysis and is used in the beginning stages of planning interpretation. It will help identify the needs, interests, knowledge, and attitudes of the target audience as well as pinpoint common misconceptions needing attention (Bitgood et al., 1997; Rand and Kiihne, 2010), which should help shape the content and scope of the selected interpretive media (Moscardo et al., 2007). Considerable time and effort can be wasted when developing interpretation around a topic of which visitors are already aware or show no interest (Woods and Moscardo, 1998). Focus groups are generally the best way to conduct front-end evaluation (Moscardo et al., 2007).

Formative evaluation assesses the effectiveness of interpretation media while still under development (Moscardo et al., 2007). For nonpersonal media this likely involves the testing, revision, and retesting of inexpensive mock-ups until they effectively communicate the intended message (Bitgood et al., 1997). Formative evaluation can be used to test a variety of design issues such as text length and readability, clarity of explanations, visual appeal of graphics, and the visitors' interests in interactive elements (Moscardo et al., 2007).

Summative evaluation applies to real exhibits and real visitors (Miles, 1993). It can and should include a variety of formal and informal techniques, such as questionnaires, interviews, and observation (Moscardo et al., 2007; Hein, 1998). Observing visitors and their frequency of reading interpretive text is just one summative evaluation method often used for interpretive signs and exhibits. This method, however, can be potentially flawed when visitors who do not appear to be 
reading may in fact be doing so (McManus, 1994). It has also been shown that the period of time that the visitor is at in their visit may have an impact on the amount of text they read, e.g., visitors pay the most attention to exhibits and labels in the first twenty to thirty minutes of their visit (Falk et al., 2010). Summative evaluation could also include personal interviews or feedback forms.

\section{Interpretation and Audience Types}

Ham (1992) identified visitors to interpretive sites such a public gardens as noncaptive audiences. Noncaptive audiences, unlike captive audiences, are a voluntary audience; they do not have to pay attention, expect an informal learning environment and a nonacademic approach, will switch attention if bored, and are motivated by factors such as interest, fun, entertainment, and self-enrichment (Table 1). Heimlich and Storksdieck (2007) describe this type of learning where an audience has its own motivations and drives their own outcomes as free-choice learning. In order to reach a noncaptive audience, Ham (1992) defined four qualities that distinguish interpretation from other forms of communication in what he called the "interpretive approach." These qualities are that interpretation is pleasurable, relevant, organized, and thematic. Veverka (2011b) uses a similar set of guidelines based on Tilden's principles (1957) to

distinguish interpretation from information. He stated that interpretation should provoke by gaining visitors attention or stimulating interest, relate, reveal, address the whole through a unifying theme, and strive for message unity. 
Table 1 Characteristics of formal and informal learning environments

\begin{tabular}{|c|c|}
\hline $\begin{array}{c}\text { Formal Learning } \\
\text { Environment }\end{array}$ & $\begin{array}{l}\text { Informal Learning } \\
\text { Environment }\end{array}$ \\
\hline $\begin{array}{l}\text { Learner stays in class, sits at } \\
\text { desk, listens to teacher, } \\
\text { completes assignments }\end{array}$ & $\begin{array}{l}\text { Learner chooses pathways (self- } \\
\text { paced), leisurely moves from one } \\
\text { exhibit to the next; stops, looks, } \\
\text { touches, talks, etc. }\end{array}$ \\
\hline $\begin{array}{l}\text { Learners have sustained } \\
\text { exposure to learning material }\end{array}$ & $\begin{array}{l}\text { Learners have short exposure to } \\
\text { learning materials }\end{array}$ \\
\hline $\begin{array}{l}\text { Focus is on classroom } \\
\text { instruction and material - } \\
\text { lecture, textbook, units, etc. }\end{array}$ & $\begin{array}{l}\text { Focus is on displays, exhibits, } \\
\text { discovery games, hands-on } \\
\text { activities, (multi-sensory) }\end{array}$ \\
\hline Exposure to subject is symbolic & $\begin{array}{l}\text { Exposure to subject is direct (in } \\
\text { environment) }\end{array}$ \\
\hline $\begin{array}{l}\text { Audience is restricted by age } \\
\text { and academic achievement - } \\
\text { peer contacts are common }\end{array}$ & $\begin{array}{l}\text { Audience is a mixture of ages and } \\
\text { academic achievement - family } \\
\text { social interaction is common }\end{array}$ \\
\hline Learning is primarily non-social & Learning is a more social event \\
\hline $\begin{array}{l}\text { Motivation is external }- \text { grades, } \\
\text { punishment, certificates }\end{array}$ & $\begin{array}{l}\text { Motivation is intrinsic - curiosity, } \\
\text { enjoyment, exploration, social, } \\
\text { interaction, fantasy, manipulation }\end{array}$ \\
\hline $\begin{array}{l}\text { Quality of learning is } \\
\text { emphasized }\end{array}$ & $\begin{array}{l}\text { Quality of experience is } \\
\text { emphasized }\end{array}$ \\
\hline
\end{tabular}

Adapted from: Bitgood, S. 1988, "A Comparison of Formal and Informal Learning". Technical Report No. 88-10. Center for Social Design, Jacksonville, AL 36265. (as cited by Desert Botanical Garden. 1999, Phoenix. AZ.) 
Interpretation can also be divided into two forms: personal, which is delivered from one person to another person or group of people, and nonpersonal, which is delivered by some media that does not require another person to be present. Personal interpretation can be in the form of docents, tour guides, presentations, or simply chatting with visitors and answering their questions. Nonpersonal interpretation includes media devices such as brochures, interpretive signs, labels, and audiovisual shows (Brochu et al., 2002).

There are numerous advantages and disadvantages to both forms of interpretation. Personal interpretation is generally regarded as the more powerful of the two, with its greatest strength lying in the ability of the interpreter to adapt to different audiences and situations (Brochu and Merriman, 2002). Disadvantages of personal interpretation include limited availability of the interpreter, a relatively higher cost to implement per visitor compared to nonpersonal interpretation, and variability in quality of interpretation based on the skill and even the mood of the interpreter (Brochu and Merriman, 2002). Nonpersonal interpretation reaches a larger audience, is always available, requires less manpower, is self-pacing and self-editable by the visitor, and is available in remote areas where it would be impractical to have personal interpreters (Grater, 1976; Brochu and Merriman, 2002; Moscardo et al. 2007). On the other hand, nonpersonal interpretation cannot adapt to changes in audience or environment, can be intrusive, must be concise and cannot be complex, requires more effort from the visitor, and may not be read, heard, or seen in entirety by the visitor (Brochu and Merrimman, 2002; Moscardo et al., 2007).

Public gardens often provide nonpersonal interpretation via interpretive signage, which should provide information about a place, object, or event that will 
enhance a visitor's appreciation, understanding, and enjoyment (Moscardo et al., 2007). Well-written interpretive signs are an essential part of the educational efforts of many sites, and also desired by visitors to natural sites to help make meaning of the resources and increase their enjoyment (Moscardo et al., 2007). This does not mean that interpretive signs or other forms of nonpersonal interpretation should be seen as a replacement for personal interpretation, rather they should be viewed as a supplement (Grater, 1976).

\section{Understanding the Audience}

When planning and developing interpretive media, it may be tempting to determine the perspective of the "average visitor." In fact, there is no such thing as an “average visitor" (Brochu and Merriman, 2002); rather there are groups of visitors who may have certain commonalities and other unique differences (Falk and Dierking, 1992). Falk and Dierking (1992) attempt to explain the variables that affect visitors' experiences at museums (including public gardens) with a model they call the Interactive Experience Model. The basic principle of this model is that no two users have an identical experience (Tofield et al., 2003). Visitors experience an exhibit through their own unique set of personal, social, and physical contexts, and the model helps to make sense of the commonalities and unique differences of visitors' museum experiences (Falk and Dierking, 1992).

All three contexts of the Interactive Experience Model (personal, social, and physical) contribute to the visitor experience but not necessarily proportionally. A visitor's personal context, which includes his or her personal beliefs, preconceptions, and previous knowledge and experiences, has an impact on that visitor's experience and ability to learn both at the conscious and subconscious levels. Visitors to museums 
are often part of social groups, and understanding the social context of the visitor can help make sense of the variations in behavioral patterns of visitors (Falk and Dierking, 1992). The composition of a visitor's group has been shown to affect how much interpretive text the visitors read and how visitors discuss and interact with exhibits (Graf, 1994; McManus, 1994). The physical context of the visitor's experience includes anything the visitor sees, hears, or even smells. It is generally assumed the objects and labels on exhibits have the greatest influence on the physical context of a visitor's experience. Visitors are affected differently by physical components and are selective in what they look at and interact with while moving through a museum, making each experience unique (Falk and Dierking, 1992).

Understanding what motivates visitors to visit free choice learning organizations is another useful tool in developing strategies for reaching the audience (Helmich, 1997). Falk and Storksdieck (2005) found that individuals' motivations for visiting free-choice organizations were primarily identity related, and later, Falk (2006) identified five distinct categories into which these identity-related motivations could be categorized:

- Explorers are curiosity driven and seek to learn about whatever they might encounter at the organization;

- Facilitators are focused primarily on enabling the experience and learning of others in their social group;

- Professional/Hobbyists feel a close tie between the organization's resources and their professional or hobbyist passions;

- Experience Seekers derive satisfaction primarily from visiting an important site; and 
- Spiritual Pilgrims are primarily seeking a contemplative and/or restorative experience.

A study done by the American Zoo and Aquarium Association confirmed that it was possible categorize visitor motivations for visiting zoos and aquariums in this way and that these motivations directly impacted how a visitors conducted their visit and what meaning they made from the experience (Falk et al., 2007). Approximately half of visitors in this study had a single identity-related motivation for visiting and the other half possessed multiple motivations. These identity-related motivations can be a useful tool for public gardens to use to create a variety of experiences in order to satisfy the needs of a broad audience (Meriman, 2010). 
Chapter 3

\section{MATERIALS AND METHODS}

\section{Research Design}

This research followed a mixed methods approach utilizing quantitative and qualitative data (Creswell, 2009). Research included two surveys, four case studies, and two expert interviews.

\section{Human Subjects Review Board}

All research methods used in the completion of this thesis followed the guidelines, regulations, and procedures set forth by the University of Delaware's Human Subjects Review Board (HSRB). The researcher attended an institutional training session on the use of human subjects in research on September 1, 2011 and received HSRB certification (Appendix A). All questions and documents for surveys and case studies were reviewed by HSRB and given exempt status.

\section{Quantitative Data}

Two surveys with audiences of public horticulture professionals were conducted. Both surveys were created and administered using Qualtrics ${ }^{\mathrm{TM}}$, an online survey tool licensed by the University of Delaware. Emails containing links to the surveys were distributed to the American Public Garden Association (APGA) member mailing list provided by the APGA. The Graduate Committee and HSRB reviewed all 
survey questions, and current Longwood Graduate Program students assisted in betatesting the surveys.

\section{Survey 1: Preliminary Survey}

The 10 question preliminary survey targeted professionals at public gardens who make decisions regarding the development of interpretive signage. Recipients of the email containing the survey link were asked to self-select whether the survey applied to them or not. The first question of the survey also served to filter out anyone who did not make decisions regarding the development of interpretation at a public garden.

The preliminary survey aimed to help determine the direction of the thesis research by gaining insight into interpretation development processes used by public gardens.

\section{Survey 2: Interpretation Development at Public Gardens}

This survey targeted professionals at public gardens involved in the process of developing interpretation at public gardens. For the purpose of this survey, formal education opportunities, such as continuing education classes or K-12 classes, were not included in the definition of interpretation. Recipients of the email containing the link to the survey were asked to self-select whether the survey applied to them or not. The first question also served to filter out anyone who received the survey but was not involved in the process of developing interpretation.

The survey aimed to provide insight into the various interpretive development processes used by public gardens by determining the extent to which various methods of planning and development were implemented and the perceived value or 
effectiveness of those methods. Difference of means tests were conducted to demonstrate relationships between survey respondents' answers to various questions and how they responded to Likert scale questions.

\section{Qualitative Data}

Qualitative research methods included four case studies and two expert interviews. Case studies and expert interviews were conducted between July 2012 and December 2012.

\section{Case Study Site Selection}

Case study sites were purposely selected from public gardens identified by respondents in the preliminary survey as doing interpretation well and from organizations recommended by the thesis steering committee members. Potential case study sites were contacted via email and interviewed over the phone. The following are example topics included in interviews with potential case study sites:

- Organization size and budget

- Size and skill set of interpretation development team

- Interpretation evaluation processes

- Interpretive planning documents

- Staff and volunteer training in the field of interpretation

- Satisfaction with the organization's overall interpretation and processes by which the interpretation is developed

Organizations with a variety of processes for interpretive development and interpretive planning were selected for case studies. Organizations selected must also 
have been satisfied with these processes and with the overall interpretation at their organization.

\section{Case Study Protocol}

Case studies consisted of onsite visits to selected institutions over periods of one or two days. Interviews with members of staff responsible for interpretation development and planning were conducted in person, and data from interviews was collected in the form of notes and digital audio recordings. Interviewees were asked to sign a consent form prior to interviews (Appendix B). Additional data was collected in the form of digital photographs, field observations made by researcher, and relevant documents provided by the organization.

\section{Expert Interviews}

In order to add additional professional insight to the research, two expert interviews were conducted. Interviews were purposely selected for their personal experiences and expertise. Dr. Casey Sclar, Director of American Public Garden Association, was selected for his experience as the director of an organization that provides professional development opportunities to public gardens. Jenny Rigby, Director of The Acorn Group/Acorn Naturalists, was selected for her experience in interpretive planning and design projects and for her experience working with public gardens. 
Chapter 4

\section{RESULTS}

\section{Survey: Interpretation Development at Public Gardens}

The survey was distributed through the APGA mailing list, and responses were collected between October 1, 2012 and November 7, 2012. Incomplete responses were removed from analysis, as were those where the responder was not responsible for some aspect of the interpretation development process. 289 completed responses from 174 different organizations were included in analysis.

\section{Background Data}

Participants identified different forms of interpretive media provided by their organizations from a list provided within the survey (Table 2). Respondents were able to make multiple selections for this question. The most frequent selections were guided tours (95.4\%), interpretive signage (95.1\%), and interpretive handouts $(93.7 \%)$.

Respondents were asked to what degree they agreed or disagreed with specific statements (Table 3). For the purpose of statistical analysis, each Likert Scale choice was assigned a numerical value ranging from 1 (strongly disagree) to 5 (strongly agree). These responses informed the research about the current state of interpretation development at public gardens and helped demonstrate relationships with responses to other survey questions. 
Table 2 Interpretive media provided by the public gardens of 284 survey participants

\begin{tabular}{|c|c|}
\hline Survey Choices & $\begin{array}{c}\text { Number of Responses } \\
\text { (overall percentage) }\end{array}$ \\
\hline Guided tours & $\begin{array}{c}271 \\
(95.4 \%)\end{array}$ \\
\hline Interpretive signage & $\begin{array}{c}270 \\
(95.1 \%)\end{array}$ \\
\hline Interpretive handouts (e.g. brochures) & $\begin{array}{c}266 \\
(93.7 \%)\end{array}$ \\
\hline Self-guided tours & $\begin{array}{c}237 \\
(83.4 \%)\end{array}$ \\
\hline Online engagement (i.e. social media) & $\begin{array}{c}211 \\
(74.3 \%)\end{array}$ \\
\hline $\begin{array}{l}\text { Adult, family, or K-12 programs (where } \\
\text { registration is not required) }\end{array}$ & $\begin{array}{c}207 \\
(72.9 \%)\end{array}$ \\
\hline Interpretive displays or carts & $\begin{array}{c}178 \\
(62.7 \%)\end{array}$ \\
\hline Exhibitions & $\begin{array}{c}173 \\
(60.9 \%)\end{array}$ \\
\hline Docents assigned to targeted areas & $\begin{array}{c}158 \\
(55.6 \%)\end{array}$ \\
\hline Audio tours & $\begin{array}{c}93 \\
(32.8 \%)\end{array}$ \\
\hline Mobile technology (e.g. app or mobile site) & $\begin{array}{c}89 \\
(31.3 \%)\end{array}$ \\
\hline Multimedia & $\begin{array}{c}82 \\
(28.9 \%)\end{array}$ \\
\hline Other & $\begin{array}{c}15 \\
(5.3 \%)\end{array}$ \\
\hline
\end{tabular}


Table 3 Degree to which survey respondents agreed or disagreed with specific statements regarding interpretation development at their organization.

\begin{tabular}{|c|c|c|c|c|c|c|c|}
\hline \multirow{2}{*}{ Survey Statement } & \multicolumn{7}{|c|}{$\begin{array}{c}\text { Survey Choices } \\
\text { (numerical designation) }\end{array}$} \\
\hline & $\begin{array}{l}\text { Strongly } \\
\text { disagree } \\
\text { (1) }\end{array}$ & $\begin{array}{l}\text { Disagree } \\
\text { (2) }\end{array}$ & $\begin{array}{l}\text { Neither } \\
\text { Agree nor } \\
\text { Disagree } \\
\text { (3) }\end{array}$ & $\underset{\text { (4) }}{\text { Agree }}$ & $\begin{array}{l}\text { Strongly } \\
\text { Agree } \\
\text { (5) }\end{array}$ & Total & Mean \\
\hline $\begin{array}{c}\text { I am satisfied with the process by which } \\
\text { interpretation is developed at my } \\
\text { organization. }\end{array}$ & 9 & 73 & 60 & 123 & 17 & 282 & 3.23 \\
\hline $\begin{array}{l}\text { The interpretive messages that my } \\
\text { organization strives to communicate are } \\
\text { clearly defined }\end{array}$ & 9 & 58 & 59 & 122 & 34 & 282 & 3.40 \\
\hline $\begin{array}{l}\text { The interpretation at my organization is } \\
\text { clear and concise. }\end{array}$ & 7 & 53 & 69 & 125 & 27 & 281 & 3.40 \\
\hline $\begin{array}{l}\text { My budget sufficiently supports } \\
\text { interpretation. }\end{array}$ & 50 & 106 & 61 & 51 & 9 & 281 & 2.48 \\
\hline $\begin{array}{l}\text { The interpretation at my organization is } \\
\text { created using themes and supporting sub- } \\
\text { themes (i.e. core message and supporting } \\
\text { messages). }\end{array}$ & 10 & 34 & 60 & 132 & 44 & 280 & 3.59 \\
\hline $\begin{array}{l}\text { I feel that I am adequately trained in best } \\
\text { practices for my specific responsibilities } \\
\text { in interpretation. }\end{array}$ & 5 & 71 & 68 & 103 & 34 & 281 & 3.32 \\
\hline $\begin{array}{l}\text { My organization provides sufficient } \\
\text { training and/or professional development } \\
\text { in the field of interpretation for related } \\
\text { staff and volunteers. }\end{array}$ & 31 & 88 & 82 & 68 & 12 & 281 & 2.79 \\
\hline $\begin{array}{l}\text { The interpretation at my organization } \\
\text { effectively connects the interests of our } \\
\text { visitors to the resources of our } \\
\text { organization. }\end{array}$ & 10 & 40 & 79 & 127 & 24 & 280 & 3.41 \\
\hline $\begin{array}{l}\text { Interpretation is important to the mission } \\
\text { of our organization. }\end{array}$ & 5 & 7 & 26 & 106 & 137 & 281 & 4.29 \\
\hline $\begin{array}{l}\text { I struggle with ways to interpret complex } \\
\text { issues like global climate change, invasive } \\
\text { species, etc. }\end{array}$ & 16 & 65 & 91 & 86 & 21 & 279 & 3.11 \\
\hline $\begin{array}{l}\text { I am satisfied with the overall quality of } \\
\text { interpretation at my organization. }\end{array}$ & 15 & 78 & 70 & 100 & 15 & 278 & 3.08 \\
\hline $\begin{array}{l}\text { I am satisfied with the overall quality of } \\
\text { interpretive signage at my organization. }\end{array}$ & 22 & 64 & 34 & 62 & 12 & 194 & 2.89 \\
\hline $\begin{array}{l}\text { I am satisfied with the quality of the } \\
\text { guided tours provided by my } \\
\text { organization. }\end{array}$ & 2 & 19 & 40 & 95 & 34 & 190 & 3.74 \\
\hline
\end{tabular}




\section{Educational Background and Staff Training}

The majority of respondents did not have a degree or formal education in the professional fields of Education, Museum Studies, or Interpretation (Table 4).

Although the mean score in the response to the statement "I feel that I am adequately trained in best practices for my specific responsibilities in interpretation" was higher for those who indicated they had a degree in Education than those who did not, the difference was not significant (Table 5). However, there was a significant difference between those who indicated they had a degree or formal training in the field of Museum Studies or Interpretation and those who did not.

Table 4 Percent of survey respondents indicating degree status or formal education in the fields of Education, Museum Studies or Interpretation.

\begin{tabular}{|c|c|c|c|}
\hline \multicolumn{1}{|c|}{ Survey Question } & \multicolumn{2}{|c|}{ Survey Response } & \\
\hline & Yes & No & Total \\
\hline \begin{tabular}{c|c|c|}
\hline Do you have a degree or formal education in the field \\
of Education?
\end{tabular} & 62 & 222 & 284 \\
\hline $\begin{array}{c}\text { Do you have a degree or formal education in the field } \\
\text { of Museum Studies or Interpretation? }\end{array}$ & $21.8 \%$ & $78.2 \%$ & $100 \%$ \\
\hline & $15.6 \%$ & $84.4 \%$ & $100 \%$ \\
\hline
\end{tabular}


Table 5 Survey respondents' degree of feeling adequately trained in their specific responsibilities in interpretation relative to their having a degree or formal training in fields of Education, Museums Studies, or Interpretation.

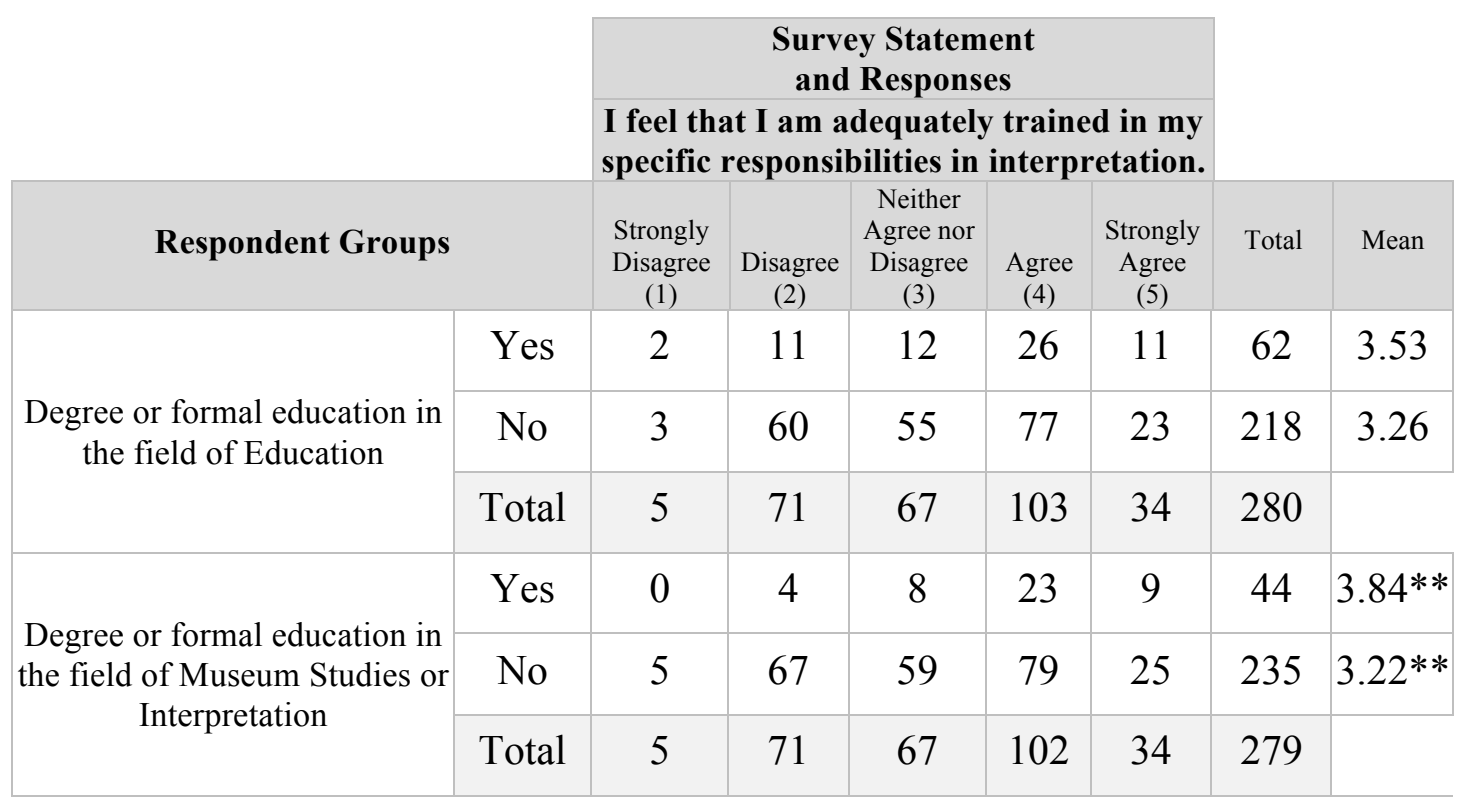

**Significant difference within column at $99 \%$ confidence interval in two-tailed difference of means test.

The vast majority of survey respondents answered "Yes" when asked if their organization encouraged horticulture staff to interact with visitors (Table 6). Few survey respondents indicated that their organization provided training in personal interpretation techniques to horticultural staff in order to help them communicate more effectively with guests (Table 7), but $68.0 \%$ of survey respondents indicated that their organization provided volunteers and docents with training in personal interpretation.

Respondents who indicated their organization provided training in personal interpretation to horticulture staff were more likely to agree with the statement "I am satisfied with the overall quality of interpretation at my organization" than those who did not indicate they had received training (Table 8). Respondents who indicated their 
organization provided training in personal interpretation to volunteers or docents also were more likely to agree with the statement "I am satisfied with the overall quality of interpretation at my organization" than those who did not.

Table 6 Responses to the survey question, "Does your organization encourage horticulture staff to interact with visitors?"

\begin{tabular}{|c|c|}
\hline Answer & $\begin{array}{c}\text { Number of Responses } \\
\text { (overall percentage) }\end{array}$ \\
\hline Yes & 230 \\
$(83.5 \%)$ \\
\hline \multirow{2}{*}{ No } & 31 \\
& $(10.9 \%)$ \\
\hline Not sure & 16 \\
& $(5.6 \%)$ \\
\hline Total & 284 \\
& $(100 \%)$ \\
\hline
\end{tabular}


Table 7 Percent of survey respondents indicating training in personal interpretation is provided for horticultural staff and volunteers or docents.

\begin{tabular}{|c|c|c|}
\hline Survey Question & Answer & $\begin{array}{c}\text { Number of } \\
\text { Responses } \\
\text { (percentage) }\end{array}$ \\
\hline \multirow{4}{*}{$\begin{array}{l}\text { Does your organization provide training in } \\
\text { personal interpretation techniques to } \\
\text { horticulture staff in order to help them } \\
\text { communicate more effectively with guests? }\end{array}$} & Yes & $\begin{array}{c}53 \\
(18.7 \%)\end{array}$ \\
\hline & No & $\begin{array}{c}205 \\
(72.2 \%)\end{array}$ \\
\hline & Not sure & $\begin{array}{c}26 \\
(9.2 \%)\end{array}$ \\
\hline & Total & 284 \\
\hline \multirow{4}{*}{$\begin{array}{l}\text { Does your organization provide training in } \\
\text { personal interpretation techniques to volunteers } \\
\text { or docents? }\end{array}$} & Yes & $\begin{array}{c}193 \\
(68.0 \%)\end{array}$ \\
\hline & No & $\begin{array}{c}62 \\
(21.8 \%)\end{array}$ \\
\hline & Not sure & $\begin{array}{c}29 \\
(10.2 \%)\end{array}$ \\
\hline & Total & 284 \\
\hline
\end{tabular}


Table 8 Degree to which survey respondents agreed or disagreed with the statement, "I am satisfied with the overall quality of interpretation at my organization," with regards to whether or not training is provided in personal interpretation for staff and volunteers or docents.

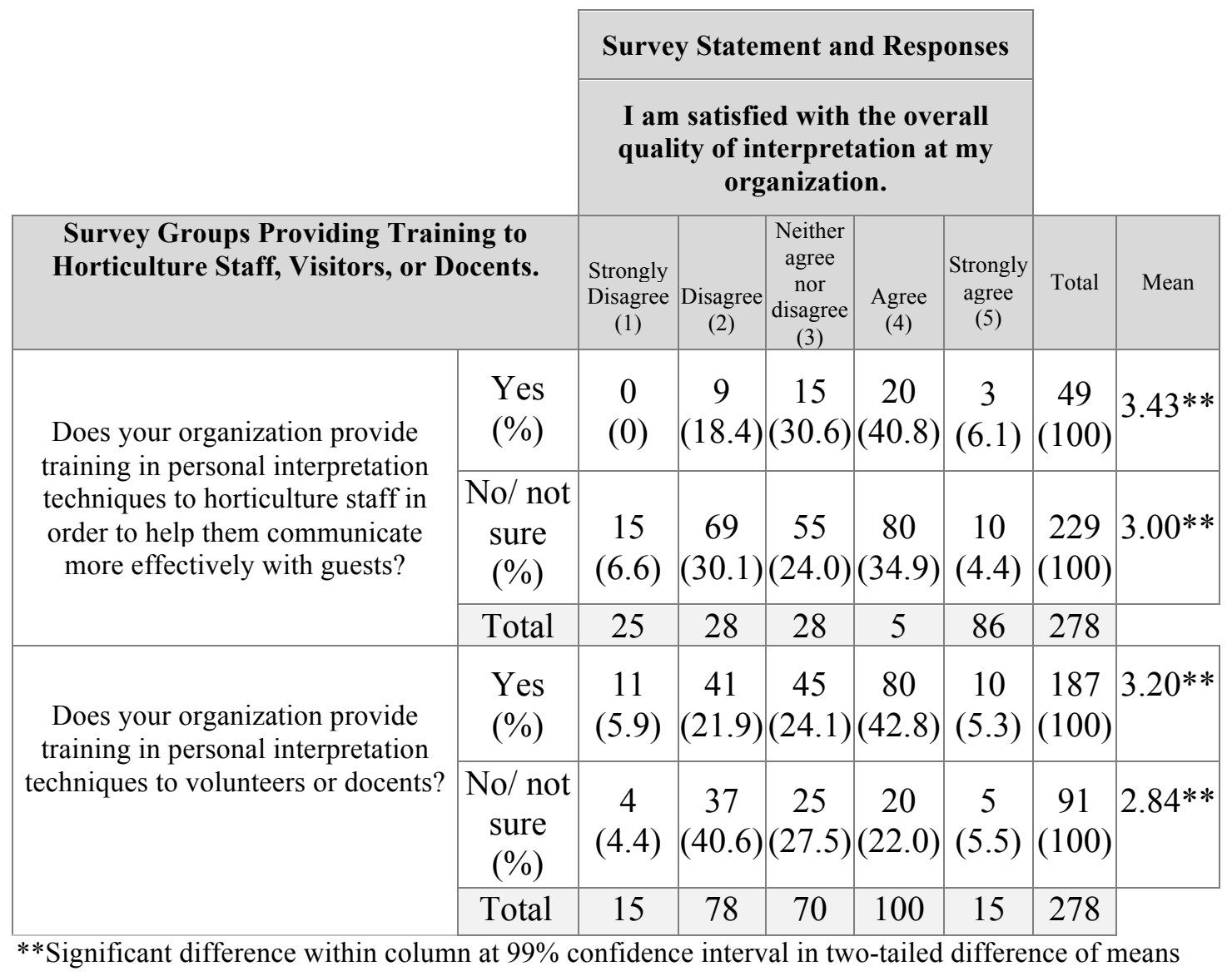
test. 


\section{Interpretive Planning Documents}

Survey respondents were asked to identify interpretive planning documents that their organization had created or updated in the past 15 years (Table 9). The most common response (47.3\%) was “ Documents outlining desired messages and/or goals for individual gardens or exhibits," followed by "Sign plan" (39.6\%), and lacking any interpretive planning documents as indicated by 63 (22.9\%) respondents.

Table 9 Organizational interpretive planning documents created or amended in the past 15 years as indicated by 275 survey respondents.

\begin{tabular}{|c|c|}
\hline Survey Choice & $\begin{array}{c}\text { Number of Responses } \\
\text { (overall percentage) }\end{array}$ \\
\hline $\begin{array}{c}\text { Interpretive master plan or interpretive prospectus } \\
100 \\
(36.4 \%)\end{array}$ \\
\hline $\begin{array}{c}\text { Documents outlining desired messages and/or goals for } \\
\text { individual gardens or exhibits }\end{array}$ & 130 \\
\hline Sign plan & $(47.3 \%)$ \\
\hline $\begin{array}{c}\text { Documents outlining desired messages and/or goals and } \\
\text { objectives for events and daily programming }\end{array}$ & 109 \\
\hline None & $(39.6 \%)$ \\
\hline
\end{tabular}

Whether or not the survey respondent indicated they had an interpretive master plan or prospectus or a document or documents that outlined desired messages and/or goals for individual gardens or exhibits had a significant impact on their responses to a number of statements from Table 3 (Table 10). 
Table 10 Degree to which survey respondents agreed or disagreed with specific statements regarding interpretation development at their organization (mean) with respect to whether or not they indicated having an interpretive master plan or prospectus or a document(s) outlining desired messages and/or goals for individual gardens or exhibits.

\begin{tabular}{|c|c|c|c|c|c|c|c|}
\hline \multirow{3}{*}{\multicolumn{2}{|c|}{ Survey Statements }} & \multicolumn{6}{|c|}{ Respondent Groups } \\
\hline & & \multicolumn{2}{|c|}{$\begin{array}{l}\text { Interpretive } \\
\text { master plan or } \\
\text { interpretive } \\
\text { prospectus }\end{array}$} & \multicolumn{2}{|c|}{$\begin{array}{c}\text { Document(s) } \\
\text { outlining } \\
\text { desired } \\
\text { messages } \\
\text { and/or goals for } \\
\text { individual } \\
\text { gardens or } \\
\text { exhibits. }\end{array}$} & \multirow[t]{2}{*}{ Both } & \multirow[t]{2}{*}{ Neither } \\
\hline & & Yes & No & Yes & No & & \\
\hline \multirow{2}{*}{$\begin{array}{l}\text { I am satisfied with the } \\
\text { process by which } \\
\text { interpretation is developed at } \\
\text { my organization. }\end{array}$} & Mean & $3.40^{*}$ & $3.14 *$ & $3.53 * *$ & $2.99 * *$ & $3.61 * *$ & $2.95 * *$ \\
\hline & Responses & 100 & 182 & 128 & 154 & 59 & 113 \\
\hline \multirow{2}{*}{$\begin{array}{l}\text { The interpretive messages } \\
\text { that my organization strives } \\
\text { to communicate are clearly } \\
\text { defined }\end{array}$} & Mean & $3.63 * *$ & $\begin{array}{c}3.28 * \\
*\end{array}$ & $3.70 * *$ & $3.16^{* *}$ & $3.83 * *$ & $3.11 * *$ \\
\hline & Responses & 99 & 183 & 128 & 154 & 59 & 114 \\
\hline \multirow[t]{2}{*}{$\begin{array}{l}\text { My budget sufficiently } \\
\text { supports interpretation }\end{array}$} & Mean & 2.62 & 2.41 & $2.65^{*}$ & $2.34^{*}$ & $2.71^{*}$ & $2.29 *$ \\
\hline & Responses & 99 & 182 & 127 & 154 & 58 & 113 \\
\hline \multirow{2}{*}{$\begin{array}{l}\text { The interpretation at my } \\
\text { organization is created using } \\
\text { themes and supporting sub- } \\
\text { themes (i.e. core message } \\
\text { and supporting messages). }\end{array}$} & Mean & $3.86^{* *}$ & $\begin{array}{c}3.45^{*} \\
*\end{array}$ & $3.90 * *$ & $3.34 * *$ & $3.98 * *$ & $3.21 * *$ \\
\hline & Responses & 99 & 181 & 127 & 153 & 58 & 112 \\
\hline \multirow{2}{*}{$\begin{array}{l}\text { I am satisfied with the } \\
\text { overall quality of } \\
\text { interpretation at my } \\
\text { organization. }\end{array}$} & Mean & $3.29 * *$ & $\begin{array}{c}2.96^{*} \\
*\end{array}$ & $3.32 * *$ & $2.87 * *$ & $3.46^{* *}$ & $2.81 * *$ \\
\hline & Responses & 100 & 178 & 127 & 151 & 59 & 110 \\
\hline \multirow[t]{2}{*}{$\begin{array}{l}\text { I am satisfied with the } \\
\text { overall quality of } \\
\text { interpretive signage at my } \\
\text { organization. }\end{array}$} & Mean & 3.03 & 2.81 & $3.15 * *$ & $2.68 * *$ & $3.25^{* *}$ & $2.66 * *$ \\
\hline & Responses & 69 & 125 & 85 & 109 & 40 & 80 \\
\hline
\end{tabular}


Survey respondents who indicated that they had an interpretive master plan or prospectus were asked to rate the usefulness of these documents in developing interpretation. For the purpose of statistical analysis, numerical values of 1 (very useful) to 4 (useless) were assigned to the responses. There was a mean rating of 2.17 from 98 responses. This was the highest (least useful) mean rating of the four types of interpretive planning documents that were rated (Table 11).

Survey respondents who rated the plan as "Very useful" or "Useful" were asked to elaborate on their response, commonly using words or phrases like, consistency, clarity, and focus on mission and goals, as well as providing direction or starting point (Appendix D). Those rating the plan as "Somewhat useful" or "Useless" were asked how the plan could be more useful. Common responses included updating the plan, making the plan more available or shared more broadly across organization, having a budget to support the plan, and problems resulting from staff changes.

Table 11 Usefulness ratings of an interpretive master plan or interpretive prospectus in developing interpretation as indicated by 98 survey respondents.

\begin{tabular}{|c|c|}
\hline $\begin{array}{c}\text { Survey Choices } \\
\text { (numerical value) }\end{array}$ & $\begin{array}{c}\text { Number of Responses } \\
\text { (overall percentage) }\end{array}$ \\
\hline Very useful (1) & $\begin{array}{c}27 \\
(27.6 \%)\end{array}$ \\
\hline Useful (2) & 33 \\
$(33.7 \%)$ \\
\hline Somewhat useful (3) \\
Useless (4) & $\begin{array}{c}32 \\
(32.6 \%)\end{array}$ \\
\hline & 6 \\
$(6.1 \%)$ \\
\hline
\end{tabular}


Fifty-four survey respondents $(55.1 \%)$ consulted with a professional planning firm to develop their interpretive master plan or interpretive prospectus and 33 (33.7\%) did not (Table 12). While the difference is not statistically significant, the interpretive master plan or prospectus is the only one of the three types of interpretive plans compared this way where the mean for those that consulted (2.19) was higher, rated less useful, than those who did not (2.09).

Table 12 Responses to the survey question, "Did you consult with a professional planning firm when developing the interpretive master plan or interpretive prospectus?"

\begin{tabular}{|c|c|}
\hline Survey Choices & $\begin{array}{c}\text { Number of Responses } \\
\text { (overall percentage) }\end{array}$ \\
\hline Yes & 54 \\
& $(55.1 \%)$ \\
\hline No & 33 \\
\hline Not sure & $(33.7 \%)$ \\
\hline Total & 11 \\
& $(11.2 \%)$ \\
& $(100 \%)$ \\
\hline
\end{tabular}


The mean rating for 115 respondents who rated the usefulness of a document or documents outlining desired messages and/or goals for individual gardens or exhibits in developing interpretation was 1.63 (Table 13). This was the lowest mean rating (most useful) of the four types of interpretive planning documents that were rated. Common, supportive feedback for such document(s) included keeping focus, providing direction, and keeping everyone on the same page (Appendix D).

Respondents also stated that these documents could be more useful with an accompanied larger budget, more personnel, an update, or more specifics.

There were $23(19.8 \%)$ respondents who consulted with a professional planning firm to develop the document(s) that outlined messages and/or goals for individual gardens or exhibits (Table 14) and 73 (62.9\%) did not. Those who did consult rated the plans significantly better than those that did not (Table 15).

Table 13 Usefulness ratings of a document(s) that outlines desired messages and/or goals for individual gardens or exhibits as indicated by 115 survey respondents.

\begin{tabular}{|c|c|c|}
\hline $\begin{array}{c}\text { Survey Choices } \\
\text { (numerical value) }\end{array}$ & \multicolumn{2}{|c|}{$\begin{array}{c}\text { Number of Responses } \\
\text { (overall percentage) }\end{array}$} \\
\hline Very useful (1) & \multicolumn{2}{|c|}{$\begin{array}{c}61 \\
(53 \%)\end{array}$} \\
\hline Useful (2) & \multicolumn{2}{|c|}{$\begin{array}{c}36 \\
(31.3 \%)\end{array}$} \\
\hline Somewhat useful (3) & \multicolumn{2}{|c|}{$\begin{array}{c}17 \\
(14.8 \%)\end{array}$} \\
\hline \multirow[t]{3}{*}{ Useless (4) } & \multicolumn{2}{|c|}{$\begin{array}{c}1 \\
(.9 \%)\end{array}$} \\
\hline & Total responses & Mean \\
\hline & 115 & 1.63 \\
\hline
\end{tabular}


Table 14 Responses to the survey question "Did you consult with a professional planning firm when developing documents outlining desired messages and/or goals for individual gardens or exhibits."

\begin{tabular}{|c|c|}
\hline Survey Choices & $\begin{array}{c}\text { Number of Responses } \\
\text { (overall percentage) }\end{array}$ \\
\hline Yes & $23(19.8 \%)$ \\
\hline No & $73(62.9 \%)$ \\
\hline Not sure & $20(17.2 \%)$ \\
\hline Total & $116(100 \%)$ \\
\hline
\end{tabular}

Table 15 How 94 survey respondents rated the usefulness of the document(s) outlining desired goals and/or messages for individual gardens or exhibits with respect to their decision to consult with a professional planning firm.

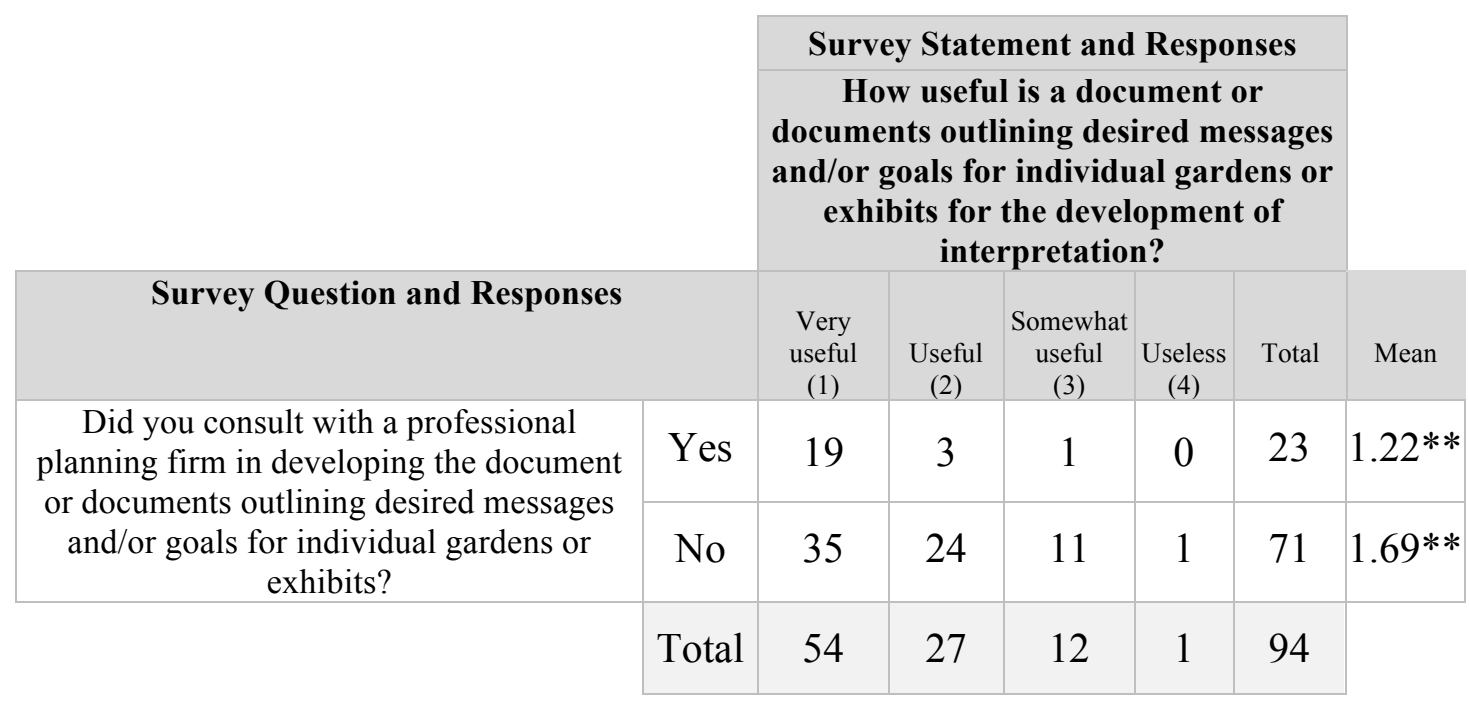

$* *$ Significant difference within column at $99 \%$ confidence interval in two-tailed difference of means test. 
The mean score for survey respondents rating the usefulness of a sign plan in interpretation development was 1.82 with 92 responses (Table 16). The mean showing how strongly respondents agreed or disagreed with the statement "I am satisfied with the overall quality of interpretive signage at my organization" for those indicating that they did have a sign plan was 3.01 and those that did not, 2.81 . The difference between these means is not significantly different.

Table 16 How useful 92 survey respondents indicated the usefulness of a sign plan for the development of interpretive media.

\begin{tabular}{|c|c|}
\hline $\begin{array}{c}\text { Survey Choices } \\
\text { (numerical value) }\end{array}$ & $\begin{array}{c}\text { Number of Responses } \\
\text { (overall percentage) }\end{array}$ \\
\hline Very useful (1) & $\begin{array}{c}39 \\
(42.4 \%)\end{array}$ \\
\hline Useful (2) & 33 \\
$(35.9 \%)$ \\
\hline Somewhat useful (3) & 18 \\
\hline Useless (4) & $(19.6 \%)$ \\
\hline & 2 \\
& $(2.2 \%)$ \\
\hline
\end{tabular}


Survey participants who indicated that they had documents outlining desired messages and/or goals for events and daily programming rated these documents very favorably with a mean of 1.72 (Table 17). This was the second best rated, second lowest mean, of the four types of interpretive plans rated. No one responded "Useless." $86.1 \%$ rated the plan as "Useful" or "Very useful," the highest percentage of any of the four planning documents. There were significant differences in the responses to numerous statements regarding interpretation development from Table 3 between survey participants that indicated that they had documents outlining desired messages and/or goals for events and daily programming and those that did not (Table $18)$.

Table 17 Usefulness ratings of documents outlining desired messages and/or goals for events and daily programming in developing interpretation as indicated by 72 survey respondents.

\begin{tabular}{|c|c|c|}
\hline $\begin{array}{l}\text { Survey Choices } \\
\text { (numerical value) }\end{array}$ & \multicolumn{2}{|c|}{$\begin{array}{l}\text { Number of Responses } \\
\text { (overall percentage }\end{array}$} \\
\hline Very useful (1) & \multicolumn{2}{|c|}{$\begin{array}{c}30 \\
(41.7 \%)\end{array}$} \\
\hline Useful (2) & \multicolumn{2}{|c|}{$\begin{array}{c}32 \\
(44.4 \%)\end{array}$} \\
\hline Somewhat useful (3) & \multicolumn{2}{|c|}{$\begin{array}{c}10 \\
(13.9 \%)\end{array}$} \\
\hline \multirow[t]{3}{*}{ Useless (4) } & \multicolumn{2}{|c|}{$\begin{array}{c}0 \\
(0 \%)\end{array}$} \\
\hline & Total responses & Mean \\
\hline & 72 & 1.72 \\
\hline
\end{tabular}


Table 18 Degree to which survey respondents agreed or disagreed with specific statements regarding interpretation development (mean) with respect to whether or not the survey respondent indicated having documents outlining desired messages and/or goals for events and daily programming.

\begin{tabular}{|c|c|c|c|c|}
\hline \multirow{2}{*}{\multicolumn{2}{|c|}{ Survey Statements }} & \multicolumn{3}{|c|}{$\begin{array}{c}\text { Survey Groups } \\
\text { Documents outlining desired messages } \\
\text { and/or goals for events and daily } \\
\text { programming }\end{array}$} \\
\hline & & \multirow{2}{*}{$\begin{array}{l}\text { Yes } \\
3.56\end{array}$} & \multirow{2}{*}{$\begin{array}{l}\text { No } \\
3.08\end{array}$} & \multirow{2}{*}{$\begin{array}{l}\text { Difference } \\
0.48 * *\end{array}$} \\
\hline $\begin{array}{l}\text { I am satisfied with the process by } \\
\text { which interpretation is developed at } \\
\text { my organization. }\end{array}$ & Mean & & & \\
\hline & Responses & 90 & 192 & \\
\hline \multirow[t]{2}{*}{$\begin{array}{l}\text { The interpretive messages that my } \\
\text { organization strives to communicate } \\
\text { are clearly defined }\end{array}$} & Mean & 3.77 & 3.23 & $0.54 * *$ \\
\hline & Responses & 90 & 192 & \\
\hline \multirow[t]{2}{*}{$\begin{array}{l}\text { The interpretation at my organization } \\
\text { is clear and concise. }\end{array}$} & Mean & 3.67 & 3.27 & $0.40 * *$ \\
\hline & Responses & 90 & 191 & \\
\hline \multirow[t]{2}{*}{$\begin{array}{l}\text { My budget sufficiently supports } \\
\text { interpretation }\end{array}$} & Mean & 2.73 & 2.37 & $0.36^{* *}$ \\
\hline & Responses & 90 & 191 & \\
\hline \multirow[t]{2}{*}{$\begin{array}{l}\text { The interpretation at my organization } \\
\text { is created using themes and supporting } \\
\text { sub-themes (i.e. core message and } \\
\text { supporting messages). }\end{array}$} & Mean & 4.04 & 3.38 & $0.66 * *$ \\
\hline & Responses & 90 & 190 & \\
\hline \multirow[t]{2}{*}{$\begin{array}{l}\text { I am satisfied with the overall quality } \\
\text { of interpretation at my organization. }\end{array}$} & Mean & 3.38 & 2.94 & $0.44 * *$ \\
\hline & Responses & 90 & 188 & \\
\hline
\end{tabular}


Of the survey respondents who indicated an interpretive planning document had been created or amended in the past 15 years, $23.8 \%$ also indicated that they had funded a planning document through a grant (Table 19). Forty-seven (21.0\%) indicated that they had used an interpretive planning document to secure a grant or financial donation (Table 20). Eighty-three of these survey respondents (37.0\%) answered yes to at least one of these two questions and $27(12.0 \%)$ answered yes to both.

Table 19 Responses to the survey question "Have you ever funded a planning document through a grant?"

\begin{tabular}{|c|c|}
\hline Survey Choices & $\begin{array}{c}\text { Number of Responses } \\
\text { (overall percentage) }\end{array}$ \\
\hline Yes & $53(23.8 \%)$ \\
\hline No & $107(48.0 \%)$ \\
\hline Not sure & $63(28.2 \%)$ \\
\hline Total & $223(100 \%)$ \\
\hline
\end{tabular}

Table 20 Responses to the survey question "Have you ever used an interpretive planning document to successfully secure a grant or financial donation?"

\begin{tabular}{|c|c|}
\hline Survey Choices & $\begin{array}{c}\text { Number of Responses } \\
\text { (overall percentage) }\end{array}$ \\
\hline Yes & $47(21.0 \%)$ \\
\hline No & $101(45.1 \%)$ \\
\hline Not sure & $76(33.9 \%)$ \\
\hline Total & $224(100 \%)$ \\
\hline
\end{tabular}




\section{Interpretation Development and Evaluation Practices}

Survey participants were asked if there was a team specifically dedicated to interpretation development at their organization, to which $132(46.5 \%)$ responded "Yes" and $152(53.5 \%)$ responded "No" or "Not sure" (Table 21).

Whether or not the survey participants had a team dedicated to horticulture at their organization had significant impact on their responses to many of specific statements regarding interpretation from Table 3 (Table 22). The biggest difference in means as how participants responded to the statement, "I am satisfied with the overall quality of interpretive signage at my organization."

Table 21 Response to the question, "Is there a team specifically dedicated to interpretation development at your organization?"

\begin{tabular}{|c|c|}
\hline Survey Choices & $\begin{array}{c}\text { Number of Responses } \\
\text { (overall percentage) }\end{array}$ \\
\hline Yes & $132(46.5 \%)$ \\
\hline No & $144(50.7 \%)$ \\
\hline Not sure & $8(2.8 \%)$ \\
\hline Total & $284(100 \%)$ \\
\hline
\end{tabular}


Table 22 Degree to which survey respondents agreed or disagreed with specific statements regarding interpretation development at their organization (mean) with respect to whether or not they indicated having a team dedicated to interpretation development at their organization.

\begin{tabular}{|c|c|c|c|c|}
\hline \multirow{2}{*}{\multicolumn{2}{|c|}{ Survey Statements }} & \multicolumn{3}{|c|}{$\begin{array}{l}\text { Survey Question and Responses } \\
\text { Is there a team specifically dedicated } \\
\text { to interpretation development at } \\
\text { your organization? }\end{array}$} \\
\hline & & \multirow{2}{*}{$\begin{array}{l}\text { Yes } \\
3.56\end{array}$} & \multirow{2}{*}{$\begin{array}{c}\begin{array}{c}\text { No or not } \\
\text { sure }\end{array} \\
\\
2.96\end{array}$} & \multirow{2}{*}{$\begin{array}{l}\text { Difference } \\
0.60^{* *}\end{array}$} \\
\hline $\begin{array}{l}\text { I am satisfied with the process by which } \\
\text { interpretation is developed at my } \\
\text { organization. }\end{array}$ & Mean & & & \\
\hline & Responses & 129 & 153 & \\
\hline \multirow{2}{*}{$\begin{array}{l}\text { The interpretive messages that my } \\
\text { organization strives to communicate are } \\
\text { clearly defined }\end{array}$} & Mean & 3.65 & 3.19 & $0.46^{* *}$ \\
\hline & Responses & 130 & 152 & \\
\hline \multirow[t]{2}{*}{$\begin{array}{l}\text { My budget sufficiently supports } \\
\text { interpretation }\end{array}$} & Mean & 2.76 & 2.27 & $0.49 * *$ \\
\hline & Responses & 128 & 153 & \\
\hline \multirow{2}{*}{$\begin{array}{l}\text { The interpretation at my organization is } \\
\text { created using themes and supporting } \\
\text { sub-themes (i.e. core message and } \\
\text { supporting messages). }\end{array}$} & Mean & 3.95 & 3.28 & $0.67 * *$ \\
\hline & Responses & 191 & 151 & \\
\hline \multirow{2}{*}{$\begin{array}{l}\text { The interpretation at my organization } \\
\text { effectively connects the interests of our } \\
\text { organization the resources of our } \\
\text { organization. }\end{array}$} & Mean & 3.66 & 3.19 & $0.47 * *$ \\
\hline & Responses & 130 & 150 & \\
\hline \multirow[t]{2}{*}{$\begin{array}{l}\text { I am satisfied with the overall quality of } \\
\text { interpretation at my organization. }\end{array}$} & Mean & 3.38 & 2.82 & $0.44 * *$ \\
\hline & Responses & 128 & 150 & \\
\hline \multirow[t]{2}{*}{$\begin{array}{l}\text { I am satisfied with the overall quality of } \\
\text { interpretive signage at my organization. }\end{array}$} & Mean & 3.30 & 2.53 & $0.77 * *$ \\
\hline & Responses & 90 & 104 & \\
\hline
\end{tabular}

**Significant at $99 \%$ C.I. in two-tailed difference of means test. 
When asked about interpretation evaluation, 85 (30.0\%) respondents indicated that they routinely evaluate interpretive messages or devices/media (Table 23). Those 85 respondents were then asked what types of evaluation method they used (Table 24). Preliminary or front-end evaluation was most common type of evaluation used followed by summative. Visitor observations was the most common response for how evaluation was conducted (Table 25). Interpretive signs (71.1\%) and guided tours $(69.9 \%)$ were the most common types of interpretive media that were evaluated (Table 26).

There was a relationship between the responses to the statement, "I am satisfied with the overall quality of interpretive signage at my organization," and whether or not interpretive signage was evaluated (Table 27). There was also a relationship between the responses to the statement, "I am satisfied with the quality of the guided tours provided by my organization," and whether or not guided tours were evaluated (Table 28).

Table 23 Responses to the question, "Does your organization routinely evaluate interpretive messages or devices (media)?"

\begin{tabular}{|c|c|}
\hline Survey Choices & $\begin{array}{c}\text { Number of Responses } \\
\text { (overall percentage) }\end{array}$ \\
\hline Yes & $85(30.0 \%)$ \\
\hline No & $131(46.3 \%)$ \\
\hline Not sure & $67(23.7 \%)$ \\
\hline Total & $283(100 \%)$ \\
\hline
\end{tabular}


Table 24 Types of evaluation used in evaluating interpretive messages or devices (media) as indicated by 80 survey respondents from organizations that routinely evaluate interpretive messages of devices.

\begin{tabular}{|c|c|}
\hline Survey Choices & $\begin{array}{c}\text { Number of Responses } \\
\text { (overall percentage) }\end{array}$ \\
\hline Preliminary/Front-end & $57(71.2 \%)$ \\
\hline Formative & $41(51.2 \%$ \\
\hline Remedial & $31(38.8 \%)$ \\
\hline Summative & $48(60 \%)$ \\
\hline
\end{tabular}

Table 25 How evaluation is conducted at 82 survey respondents' organizations where interpretive messages or devices (media) are routinely evaluated.

\begin{tabular}{|c|c|}
\hline Survey Choices & $\begin{array}{c}\text { Number of Responses } \\
\text { (overall percentage) }\end{array}$ \\
\hline Visitor observations & $63(76.8 \%)$ \\
\hline Written surveys & $40(48.8 \%)$ \\
\hline Personal interviews & $39(47.7 \%)$ \\
\hline Focus groups & $25(30.5 \%)$ \\
\hline Using mock-ups for visitor testing (i.e. prototyping) & $23(28.0 \%)$ \\
\hline Other & $7(8.5 \%)$ \\
\hline None & $5(6.1 \%)$ \\
\hline
\end{tabular}


Table 26 Types of interpretive media that are routinely evaluated at 83 survey respondents' organizations where interpretive messages or devices (media) are routinely evaluated.

\begin{tabular}{|c|c|}
\hline Survey Choices & $\begin{array}{c}\text { Number of Responses } \\
\text { (overall percentage) }\end{array}$ \\
\hline Interpretive signs & $59(71.1 \%)$ \\
\hline Guided tours & $58(69.9 \%$ \\
\hline Volunteers or docents & $50(60.2 \%)$ \\
\hline Interpretive exhibit or display & $46(55.4 \%)$ \\
\hline Self-guided tours (i.e. audio and brochure) & $38(45.8 \%)$ \\
\hline Interpretive programs & $36(43.4 \%)$ \\
\hline Multimedia & $27(32.5 \%)$ \\
\hline Exhibitions & $27(32.5 \%)$ \\
\hline Mobile technology based interpretation & $22(26.5 \%)$ \\
\hline (e.g. smartphones) & $17(20.5 \%)$ \\
\hline Interpretive carts & $1(1.2 \%)$ \\
\hline None of the above & \\
\hline
\end{tabular}


Table 27 Degree to which 194 survey respondents agreed or disagreed with the statement, "I am satisfied with the overall quality of interpretive signage at my organization," with respect to whether or not they indicated that interpretive signage was routinely evaluated.

\begin{tabular}{|c|c|c|c|c|c|c|}
\cline { 2 - 8 } \multicolumn{1}{c|}{} & \multicolumn{6}{c|}{ Survey Statement and Choices } \\
\cline { 2 - 9 } \multicolumn{1}{c|}{ I am satisfied with the overall quality of interpretive } \\
signage at my organization.
\end{tabular}

Table 28 Degree to which 190 survey respondents agreed or disagreed with the statement, "I am satisfied with the overall quality of the guided tours provided by my organization," with respect to whether or not they indicated that guided tours were routinely evaluated.

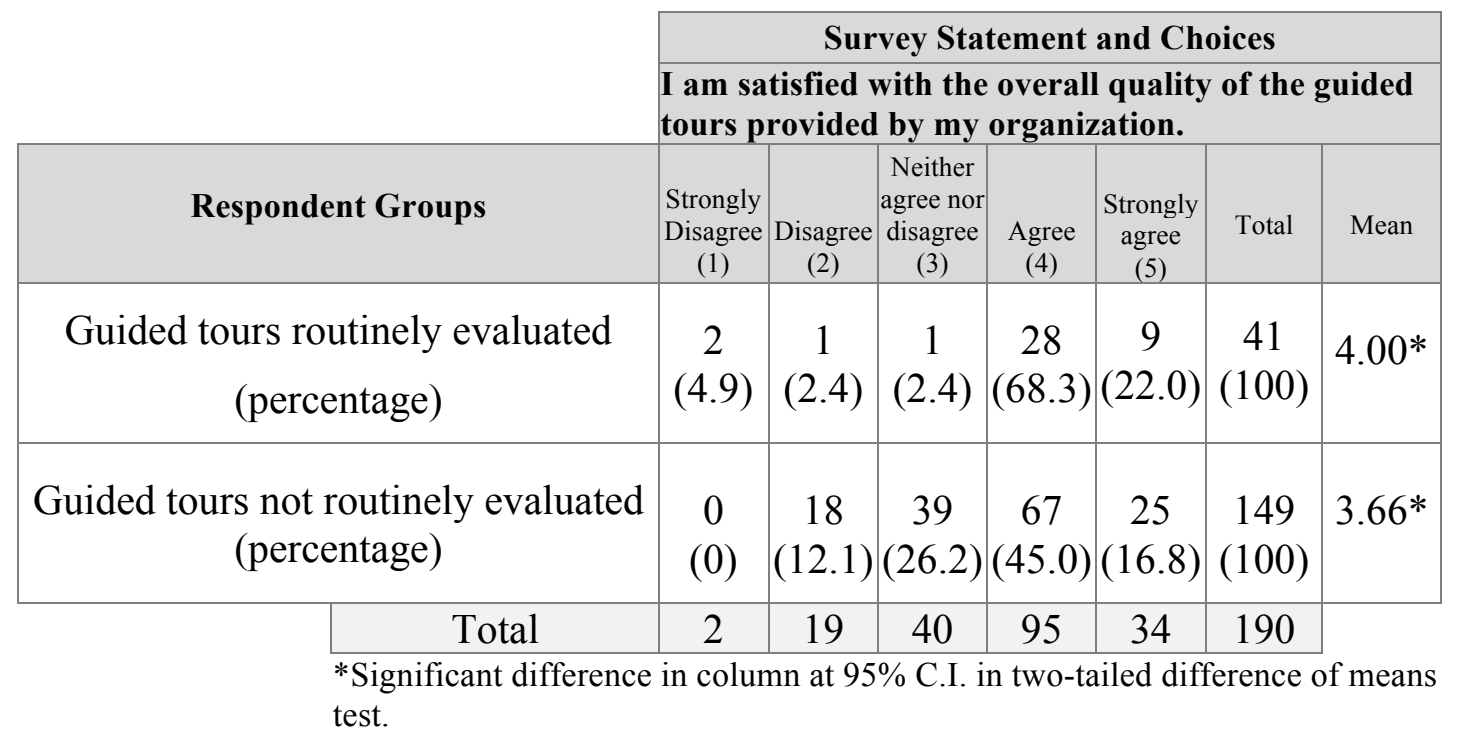




\section{Barriers to Interpretation Development}

Survey participants were asked to identify what barriers they faced in developing effective interpretation (Table 29). "Insufficient budget or resources" was the most common answer with 217 participants (79.2\%) indicating it was a challenge followed by "No staff dedicated to interpretation" with 100 participants (36.5\%).

Survey participants were then asked to identify the biggest challenge they faced in developing effective interpretation (Table 30). "Insufficient budget or resources" was again the most common selection with 126 participants $(46.5 \%)$ indicating it was their biggest challenge. "Interpretation is not a priority" was the second most common with 25 selections $(9.2 \%)$, followed by "No staff dedicated to interpretation" with 22 selections $(8.1 \%)$. 
Table 29 Challenges faced by survey respondents in interpretation development.

\begin{tabular}{|c|c|}
\hline Survey Choices & $\begin{array}{l}\text { Number of Responses } \\
\text { (overall percentage) }\end{array}$ \\
\hline Insufficient budget or resources & $\begin{array}{c}217 \\
(79.2 \%)\end{array}$ \\
\hline No staff dedicated to interpretation & $\begin{array}{c}100 \\
(36.5 \%)\end{array}$ \\
\hline Responsibilities among staff unclear & $\begin{array}{c}95 \\
(34.7 \%)\end{array}$ \\
\hline Insufficiently trained staff & $\begin{array}{c}93 \\
(33.9 \%)\end{array}$ \\
\hline Lack of an understanding of the role of interpretation & $\begin{array}{c}91 \\
(33.2 \%)\end{array}$ \\
\hline Interpretation is not a priority & $\begin{array}{c}91 \\
(33.2 \%)\end{array}$ \\
\hline Lack of understanding of audience and their motivations & $\begin{array}{c}89 \\
(32.5 \%)\end{array}$ \\
\hline Lack of training opportunities available for staff & $\begin{array}{c}88 \\
(32.1 \%)\end{array}$ \\
\hline $\begin{array}{l}\text { Staff struggles with how to make interpretation relevant } \\
\text { or interesting }\end{array}$ & $\begin{array}{c}86 \\
(31.4 \%)\end{array}$ \\
\hline $\begin{array}{l}\text { Garden staff perceive it to be obtrusive to visitor } \\
\text { experience }\end{array}$ & $\begin{array}{c}49 \\
(17.9 \%)\end{array}$ \\
\hline Does not fit the mission of the organization & $\begin{array}{c}17 \\
(6.2 \%)\end{array}$ \\
\hline None of the above & $\begin{array}{c}9 \\
(3.3 \%)\end{array}$ \\
\hline
\end{tabular}


Table 30 Biggest challenges faced by survey respondents in interpretation development.

\begin{tabular}{|c|c|}
\hline Survey Choices & $\begin{array}{c}\text { Number of Responses } \\
\text { (overall percentage) }\end{array}$ \\
\hline Insufficient budget or resources & $\begin{array}{c}126 \\
(46.5 \%)\end{array}$ \\
\hline Interpretation is not a priority & $\begin{array}{c}25 \\
(9.2 \%)\end{array}$ \\
\hline Other & $\begin{array}{c}23 \\
(8.5 \%)\end{array}$ \\
\hline No staff dedicated to interpretation & $\begin{array}{c}22 \\
(8.1 \%)\end{array}$ \\
\hline Lack of understanding of the role of interpretation & $\begin{array}{c}17 \\
(6.3 \%)\end{array}$ \\
\hline Responsibilities among staff unclear & $\begin{array}{c}12 \\
(4.4 \%)\end{array}$ \\
\hline Making interpretation relevant or interesting & $\begin{array}{c}11 \\
(4.1 \%)\end{array}$ \\
\hline Lack of understanding of audience and their motives & $\begin{array}{c}10 \\
(3.7 \%)\end{array}$ \\
\hline Insufficiently trained staff & $\begin{array}{c}9 \\
(3.3 \%)\end{array}$ \\
\hline Perceived obtrusive impact of interpretation & $\begin{array}{c}8 \\
(3.0 \%)\end{array}$ \\
\hline Lack of training opportunities available & $\begin{array}{c}7 \\
(2.6 \%)\end{array}$ \\
\hline Does not fit garden mission & $\begin{array}{c}1 \\
(0.4 \%)\end{array}$ \\
\hline Total & 271 \\
\hline
\end{tabular}

\section{Professional Development Organizations}

The most common professional development organizations related to interpretation in which survey participants were involved were the American Public Gardens Association (APGA) with $84.0 \%$ of respondents actively involved, American 
Alliance of Museums (AAM) with 19.6\%, and National Association for Interpretation (NAI) with $12.1 \%$ (Table 31).

Table 31 Professional development organizations related to interpretation in which 281 survey respondents are actively involved.

\begin{tabular}{|c|c|}
\hline Survey Choices & $\begin{array}{c}\text { Number of Responses } \\
\text { (overall percentage) }\end{array}$ \\
\hline American Public Gardens Association (APGA) & $236(84.0 \%)$ \\
\hline American Alliance of Museums (AAM) & $55(19.6 \%)$ \\
\hline National Association for Interpretation (NAI) & $34(12.1 \%)$ \\
\hline $\begin{array}{c}\text { North American Association for Environmental Education } \\
\text { (NAAEE) }\end{array}$ & $17(6.0 \%)$ \\
\hline National Association of Museum Exhibition (NAME) & $9(3.2 \%)$ \\
\hline Association of Zoological Horticulture (AZH) & $8(2.8 \%)$ \\
\hline Association of Zoos and Aquariums (AZA) & $7(2.5 \%)$ \\
\hline American Association of State and Local History (AASLH) & $6(2.1 \%)$ \\
\hline Association of Children's Museums (ACM) & $2(0.7 \%)$ \\
\hline Other & $34(12.1 \%)$ \\
\hline Not actively involved in any professional associations related to & $26(9.2 \%)$ \\
\hline interpretation
\end{tabular}

Survey participants were asked to rate the value of their involvement with the organizations of which they were active members on a Likert scale. For the purpose of statistical analysis, numerical values of 1 (very valuable) to 4 (not valuable for this purpose) were assigned to the responses. Participants were also asked to provide a text response describing what was valuable about their involvement with the professional 
development organization or how the organization could be more valuable (Appendix D).

The mean score for the American Public Garden Association was 2.63 (Table 32). Networking, learning from what other gardens are doing, and publications and the quarterly journal were the most common reasons given for why the APGA was valuable.

The mean score for the American Alliance of Museums was 2.76 (Table 33). Conferences, publications, newsletters, and online resources are common reasons given for why the AAM is valuable.

The National Association for Interpretation had the lowest mean score (rated most useful) of the three organizations at 1.91 (Table 34). This was significantly lower than the mean scores for APGA and AAM at a 99\% confidence interval in a two-tailed difference of means test. Common elements from responses about what was valuable about NAI include resources, certified training programs, publications, newsletters, and networking.

Table 32 How valuable survey respondents rated their involvement in APGA with regards to professional development in the field of interpretation.

\begin{tabular}{|c|c|c|}
\hline $\begin{array}{l}\text { Survey Choices } \\
\text { (numerical value) }\end{array}$ & \multicolumn{2}{|c|}{$\begin{array}{l}\text { Number of Responses } \\
\text { (overall percentage) }\end{array}$} \\
\hline Very valuable (1) & \multicolumn{2}{|c|}{$31(13.7 \%)$} \\
\hline Valuable (2) & \multicolumn{2}{|c|}{$66(29.1 \%)$} \\
\hline Somewhat valuable (3) & \multicolumn{2}{|c|}{$85(37.4 \%)$} \\
\hline Not valuable for this purpose (4) & \multicolumn{2}{|c|}{$45(19.8 \%)$} \\
\hline & Total & Mean \\
\hline & 227 & 2.63 \\
\hline
\end{tabular}


Table 33 How valuable survey respondents rated their involvement in AAM with regards to professional development in the field of interpretation.

\begin{tabular}{|c|c|c|}
\hline $\begin{array}{c}\text { Survey Choices } \\
\text { (numerical value) }\end{array}$ & \multicolumn{2}{|c|}{$\begin{array}{l}\text { Number of Responses } \\
\text { (overall percentage) }\end{array}$} \\
\hline Very valuable (1) & \multicolumn{2}{|c|}{$3(6.1 \%)$} \\
\hline Valuable (2) & \multicolumn{2}{|c|}{$18(36.7 \%)$} \\
\hline Somewhat valuable (3) & \multicolumn{2}{|c|}{$16(32.6 \%)$} \\
\hline Not valuable for this purpose (4) & \multicolumn{2}{|c|}{$12(24.5 \%)$} \\
\hline & Total & Mean \\
\hline & 49 & 2.76 \\
\hline
\end{tabular}

Table 34 How valuable survey respondents rated their involvement in NAI with regards to professional development in the field of interpretation.

\begin{tabular}{|c|c|c|}
\hline $\begin{array}{l}\text { Survey Choices } \\
\text { (numerical value) }\end{array}$ & $\begin{array}{l}\text { Number of Responses } \\
\text { (overall percentage }\end{array}$ & \\
\hline Very valuable (1) & $12(37.5 \%)$ & \\
\hline Valuable (2) & $11(34.4 \%)$ & \\
\hline Somewhat valuable (3) & $9(28.1 \%)$ & \\
\hline \multirow[t]{3}{*}{ Not valuable for this purpose (4) } & $0(0 \%)$ & \\
\hline & Total & Mean \\
\hline & 32 & 1.91 \\
\hline
\end{tabular}




\title{
Case Studies
}

\section{Monterey Bay Aquarium}

\author{
Background
}

The mission of the Monterey Bay Aquarium (MBA), which first opened in 1984 , is to inspire the conservation of oceans. The MBA consists of more than a dozen main exhibits, each with its own message or theme. Large portions of the individual exhibit elements have interactive components. The MBA also has numerous personal interpretation media in the form of daily shows and animal feedings, 15-minute presentations that run throughout the day in the auditorium, and interpretive guides at stations throughout the Aquarium.

\section{Volunteer Program and Training}

Monterey Bay Aquarium relies heavily on approximately 600 interpretive guide volunteers to help communicate their interpretive messages. The interpretive guide program is organized into three shifts per day. Volunteers rotate to different stations every half-hour throughout the shift following a schedule prepared by the Aquarium staff. Volunteers generally only work one shift per week, which when coupled with the rotations, discourages "burn out" and allows for more unique experiences (Covel, 2012).

Each volunteer shift begins with a formal update that usually includes a status review of exhibits. This time is also used to as an opportunity to train and educate volunteers. 
Historically, the MBA trained volunteers by having experts lecture about different topics. This method did not work well because visitors received either inconsistent messages or messages that just didn't connect with them (Covel, 2013). The format was subsequently changed to focus early volunteer training on understanding both the audience and personal interpretation practices. Volunteers learn why visitors come to the aquarium and how to recognize their needs and interests, which helps the volunteers facilitate the experiences specifically sought out by the visitors (Appendix E). After new volunteers are trained in personal interpretation methods, experienced guides mentor them. The MBA holds periodical training workshops for all volunteers.

\section{Exhibit Development and Planning Documents}

The exhibit development teams at Monterey Bay Aquarium consist of 10-15 people, including an exhibit developer with a fine arts or writing background, an exhibit designer, and, when relevant, a staff member from interpretation, animal husbandry, and/or education. Exhibit development is a 5-year process consisting of six phases. The first phase is forming the topic for the exhibit and front-end evaluation. The second phase involves concept development whereby detailed written walkthroughs are created, and formative evaluation takes place. In the third phase, production planning, detailed drawings of individual exhibit components are created and sent to contractors for bids. Exhibits are built in phase four, production, phase five is implementation, and remedial evaluation in phase six.

Programs involving a live interpreter (e.g. animal feedings) begin development with a "one page" or "treatment" that describes the program idea. After the Vice President of Exhibits and Guest Experience approves the treatment, multiple drafts of 
the scripts are created with different levels of approval. Programs were not fully scripted at the time of this case study, and live interpreters had flexibility in what the spoke about, particularly in the auditorium shows. The Aquarium was moving towards a system where interpreters followed a script more closely to improve program and message consistency (Bridal, 2012).

In the process of developing a new exhibit or program, documents are created that outline their primary, secondary, and tertiary messages and the goals (Appendix E). The Volunteer Manual also outlines the messages and goals for many of the longterm exhibits (Appendix E). While the MBA does not have an Interpretive Master Plan, the staff is aware of the primary interpretive goals of the organization through its mission "to inspire the conservation of oceans" and primarily the Monterey Bay area (Covey, 2013).

\section{Interpretive Sign Development at UC Davis Arboretum}

UC Davis Arboretum develops interpretive signage for gardens through a process referred to as Team Week or Team Exhibit Week. Team Week is a weeklong exercise for planning for the interpretive signage of a particular garden. Team Week can occur as much as once or twice a year or as little as once every two years. Staff involved in the Education department at the Arboretum and outside experts in fields related to the gardens theme participate in Team Week. For example, expert geologists were included in the development team of a new rock garden surrounding the Geology department's building. As a part of Team Week, training is provided in basic interpretation principals (e.g. visitor motivations in reading labels).

Prior to Team Week, Arboretum staff members conduct a preliminary survey of visitors and interview experts in the field to help define the topics for interpretive 
signs or exhibits. The survey tests visitor knowledge of the subject and explores topics of greatest interest to them. Information from surveys and interviews are used to create guiding documents for the interpretive sign development exercises. One team exercise includes creating headlines for the signs. Teams are given exhibit topics and headline goals such as "correct misconceptions" or "articulate questions visitors commonly have about exhibit content." Teams brainstorm to create a list of potential headlines and select the best for use in formative evaluation. Similar exercises are conducted to create interpretive sign text. The whole process includes repeated team member evaluations of interpretive messages and media.

Formative evaluation is conducted using mock-ups of interpretive signs, which are tested in the Arboretum along the main visitor path. Signs are evaluated for their attracting power (how many people stop at the sign) and holding power (how long they stay). Several different headlines are tested during evaluation. Visitors to events, such as the Arboretum plant sale, also evaluate signs through interviews with Arboretum staff.

\section{United Stated Botanic Garden}

\section{Background}

The United States Botanic Garden (USBG), located in Washington D.C., consists of a conservatory with 14 different permanent gardens and exhibits, and outdoor gardens in the three acre National Garden and two acre Bartholdi Park. Interpretation at USBG includes interpretive signage (both permanent and temporary handwritten signs), interpretive programs (e.g. family activities and children's 
programs), guided tours, self-guided tours and brochures, interpretive carts/displays (Discovery Cart), and temporary exhibits.

There are approximately 65 employees housed in four different divisions: Administration, Horticulture, Operations, and Public Programs. Staff members responsible for interpretation development are in the Public Programs department, although staff from departments such as Horticulture are also tapped for their expertise. Many staff members in Public Programs are active members of the American Alliance of Museums (AAM), and USBG is an accredited museum through AAM.

Interpretive Planning Documents

USBG has an Interpretive Master Plan (Appendix F) that was completed in October 1999. The plan consists primarily of an interpretive content outline that gives a communication goal and outlines desired messages, including one "Big Idea" message, for each garden or exhibit space. An overarching theme that connects the individual gardens and exhibits is addressed in the Mission Statement but not in the Interpretive Master Plan (Shimizu, 2012), which states, “demonstrating the aesthetic, cultural, economic, therapeutic, and ecological importance of plants to the well-being of humankind." According to the Education Programs Specialist, "Everything we do is based off of our Mission, so everything we do has to relate back to our Mission somehow" (Rhoads, 2012).

The Executive Director, Holly Shimizu, described the Interpretive Master Plan as, "incredibly useful as a guiding force in the Conservatory." A series of workshops was conducted with staff members to create the plan. This allowed input from the 
entire staff, an essential part of the process. As the plan was created thirteen years ago and much of the staff has changed since that time, the USBG is in need of a new, updated Interpretive Master Plan (Shimizu, 2012; Rhoads, 2012). When asked if there was anything she would do differently in the way the Interpretive Master Plan was developed, Holly Shimizu responded, "Yes. I would make it more dynamic. I would have multiple messages that can change throughout the seasons, the times. I like a lot of flexibility so one big change is the large heavy expensive signs; we're not doing that anymore. They are outdated. You know you have to be fresh. You have to change."

Interpretive planning documents are also created for each interpretive program (Appendix F) at USBG. The interpretive plans include "Big Idea" messages, goals and objectives, talking points, and background information (research). The "Big Idea" message is a theme statement and states the main message being communicated in a few short sentences.

Interpretive plans for programs are made available to public program volunteers, who supplement the training sessions. The Education Program Specialist, who is responsible for developing the public programs, has a Master's degree in Museum Studies and an undergraduate degree in Education.

\section{Volunteer/Docent and Staff Training}

USBG holds regular training sessions for new and continuing volunteer docents. Training for new docents used to be heavily focused on facts about the plants in the collection but this was later judged as too intimidating for new docents, and USBG visitors don't expect to leave as plant experts (Nelson, 2012). So, the Volunteer Coordinator, Maura Nelson, started training docents at USBG in informal 
education. Docents are trained to be comfortable with teaching and engaging people with objects. Two of the primary introductory classes provided are titled Museum Education 101 and Museum Audiences. New docents are also provided with a copy of a short text about museum learning and education, Museums: Places of Learning by George E. Hein and Mary Alexander (1998). Maura Nelson has a Master's Degree in Museum Studies and is involved in professional development through the American Alliance of Museums.

Staff members were recently granted overtime to attend the evening volunteer training sessions. Having staff at these sessions has been useful in providing a larger knowledge base for group exercises and discussions, and sometimes other staff members are asked to facilitate training workshops (Nelson, 2012).

\section{Chicago Botanic Garden}

The Chicago Botanic Garden (CBG) is a 385-acre, public garden that consists of 26 display gardens and four natural areas. The mission of the CBG is "to promote the enjoyments, understanding, and conservation of plants and the natural world." CBG provides a wide variety of interpretive media including interpretive signs (both permanent and temporary, hand-written signs), adult and family interpretive programs, guided tours, and docents.

During the 1990's, the CBG developed planning documents, or “Green Books," for the different gardens. Green Books outlined major themes, how the

gardens would be planted, and what type of programming would occur there. There was also a Green Book for interpretation that outlined the vernacular language that would be included on the signs, sizes, look, and how they would be posted. These 
documents had long lasting value, but the messages also became an inherent part of the daily activities (Webber, 2012).

Interpretive signs are kept brief, approximately 75 words or fewer. Each garden space has an interpretive sign at its entrance that clearly conveys the garden's theme or themes (Figure 4). Interpretive signs within the garden support the themes (Figure 5). CBG uses many handwritten signs as a result of anecdotal evidence that visitors are more likely to read handwritten signs (Figure 6).

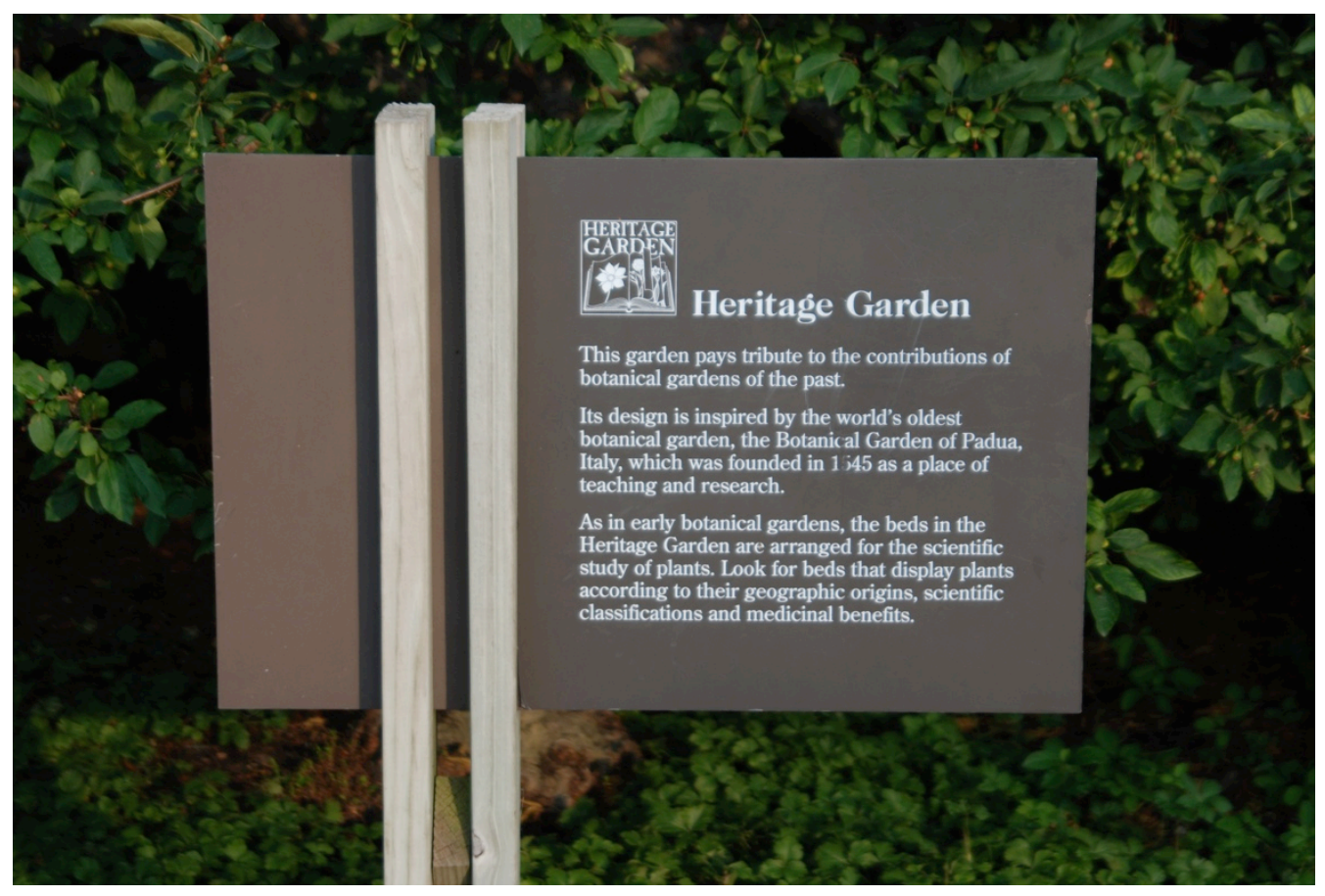

Figure 4 The sign at the entrance to the Heritage Garden at Chicago Botanic Garden explains the intent of the garden and introduces the concept of grouping plants for scientific study, the major theme of the garden. 


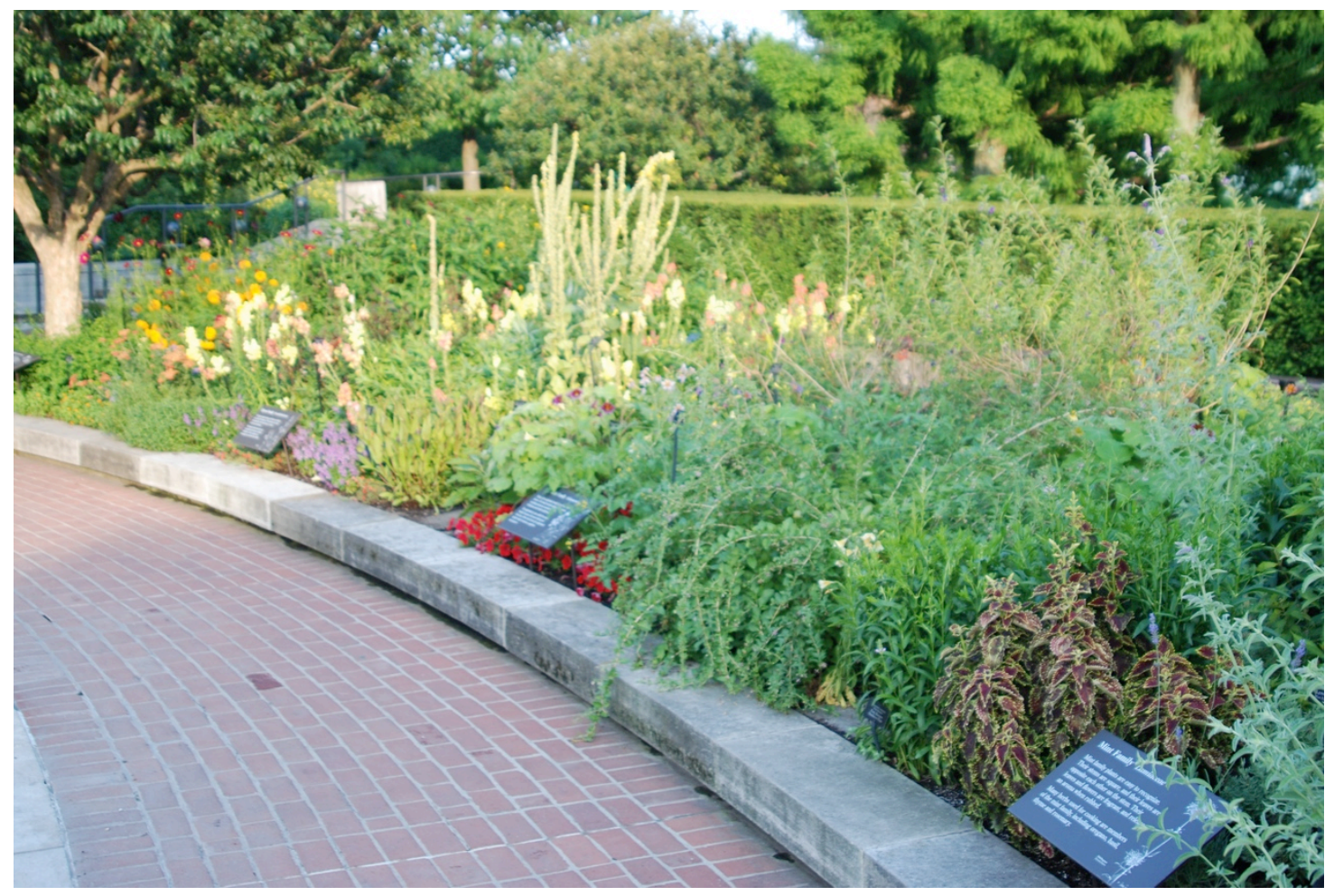

Figure 5 Plants within the Heritage Garden at Chicago Botanic Garden are arranged by geographic origins, medicinal benefits, or plant families. Interpretive signs identify each of the plant families displayed here and provide information about the shared characteristics of plants in that family.

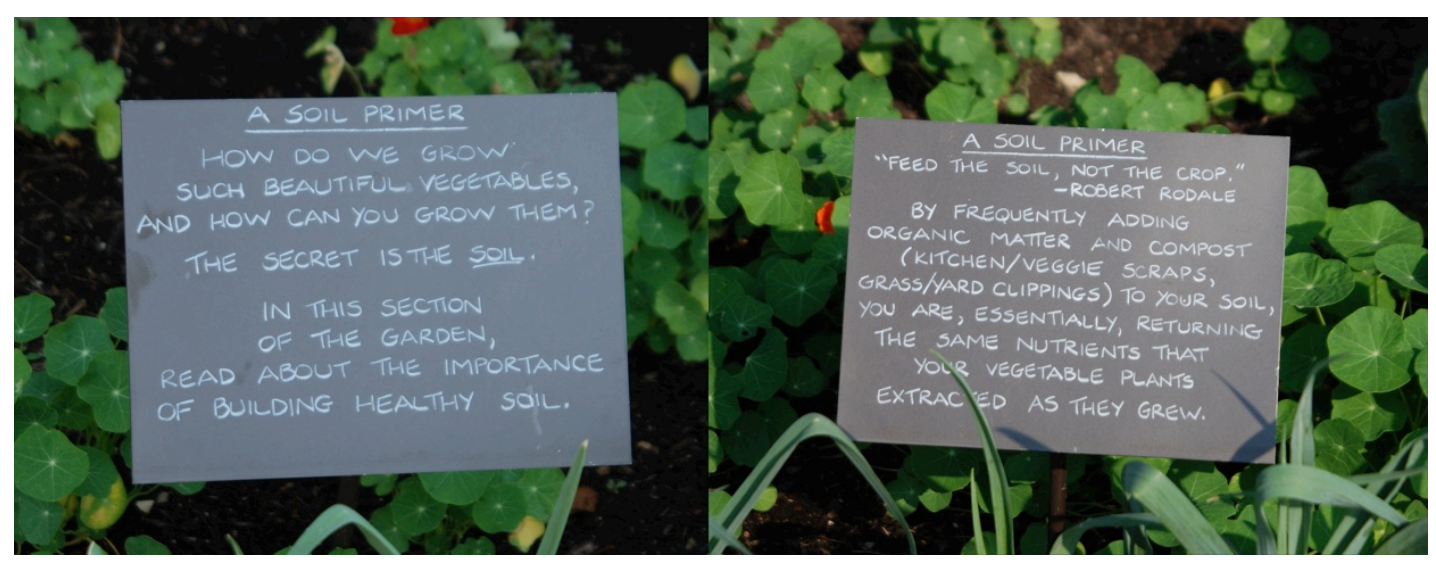

Figure 6 Multiple handwritten signs are placed throughout a garden at Chicago Botanic Garden with common themes. 


\section{Expert Interviews}

\section{Interview with Jennifer Rigby, Director of The Acorn Group}

Jennifer Rigby is an expert in interpretive planning. She has worked on many projects with public gardens and is a founding member of the National Association of Interpretation. The Acorn Group, established in 1990, provides services in interpretive planning and design.

Rigby defines interpretive planning as "an analysis of a site in order to determine what programs and what media best communicates the message" (Rigby, 2012). Analysis includes a complete study of the site including all the mechanics, budgetary concerns, traffic flow, and all the guiding documents of the organization. Every recommendation that is made can be justified by this research. Interpretive planners work as advocates for the visitor, so messages defined in the interpretive planning process must be framed in an understandable context for the visitor. Appropriate media is discussed only after every variable is determined.

Theme identification is one of the first tasks when developing an interpretive master plan; in fact, it should drive the entire process. Visitors should leave with a single overarching message; facts are not really important. The theme needs to be the single most compelling, relevant message that takes into consideration the organization's intended message. The goal is to achieve equilibrium between visitor needs and the organization's message. Media that constantly reinforces a driving message, either subtly or directly, is going to be successful. Large planning processes should be done with facilitated group exercises, and the theme comes from everyone's recommendations. Interpretive master plans should not sit on a shelf; they should constantly be revisited and re-evaluated. 
Goals and specific objectives are important components of interpretive planning projects. Objectives have to be very specific and measurable in order to provide a standard for evaluating interpretation.

Planning documents begin with a prospectus and proceed to a comprehensive master plan. Interpretive master plans are useful for fundraising and have been useful to include in grant solicitations.

Gardens and museums are relatively new to interpretive planning. It's not new to public parks. Interpretation is emotional; you're trying to touch the visitor's heart, so they go away with a different view of the resource.

\section{Interview with Casey Sclar, Executive Director of the American Public Gardens Association}

The American Public Gardens Association (APGA) is a non-profit organization for professionals, students, and volunteers in the field of public horticulture. The mission of APGA is "advancing public gardens as a force for positive change in their communities through national leadership, advocacy and innovation."

Casey Sclar defines interpretation as, "A process of engagement. How our visitors are engaged and relayed information. It can happen before they get to the garden certainly during and sometimes after the visiting. Not a full-blown educational program, though an educational program can be a part of that. If I were looking for a close synonym, I would probably call it engagement. Ideally it focuses in and attracts what somebody's already interested in and provides him or her a conduit to get that" (Sclar 2012). 
One of the ways APGA supports interpretation is through professional development meetings. Topical or regional meetings and the Annual Conference provide opportunities for members to learn from what other public gardens are doing and provide a conduit for the APGA to address professional development for its members. Sessions at the Annual Conference are often related to interpretation.

The APGA has 16 professional sections, which allow members to communicate and share information regarding a particular topic. While there is no professional organization related to interpretation specifically, each professional section could touch on interpretation in its own way.

Another method through which the APGA provides its members with interpretive tools is through its programs. Each program has interpretive toolboxes that provide public gardens with resources or best practices for interpretation of information provided through the program. Publications such as the quarterly journal and newsletters allow the APGA to communicate with its members about these programs. Social media and webinars provide further opportunities to communicate with members and provide members with professional development. 


\section{Chapter 5}

\section{DISCUSSION}

Although there is a significant amount of literature regarding best practices of interpretation and interpretation development, none could be found that analyzes to what extent public gardens are following these best practices, or what kind of results these practices are having on the interpretation and development processes. Each organization is unique in its interpretation needs and resources (Brochu, 2003), but the current research revealed certain planning and development practices that are yielding significant benefits for many public gardens. Our research indicated that only $41 \%$ of survey respondents were satisfied with the overall quality of interpretation at their organization, leaving room for improvement for the majority of public gardens. This can be surprising but it also allows for an understanding of the underlying causal reasons and leads to the development of recommendations for improvement.

\section{Educational Background}

Ham (1992) states that many interpreters enter their jobs without formal training or prior experience. Unsure of just how they should approach their roles as communicators, they often take a formal approach to education, even though it is not the role of interpreters to teach their audiences in the same way that they were taught in school. Survey results from the current research support Ham's findings, showing that only $15.6 \%$ of respondents had an academic degree or formal training in the fields of Interpretation or Museum Studies. Those who did were more likely to feel 
adequately trained in their interpretation responsibilities than those who did not. In fact, respondents in possession of a degree or formal training were 3.4 times more likely to agree or strongly agree with the statement, "I feel that I am adequately trained in best practices for my specific responsibilities in interpretation," than those who did not. Although there was no significant difference for individuals with formal training in the field of Education, the mean was slightly higher for them, which may highlight a difference between formal education and interpretation.

The mission of a public garden will often differ from the visitors' motivation for visiting. Therefore, it is the role of the interpreter to be the bridge between the organization's reason for existence and the visitor's reason for coming (AABGA, 2001). Our findings indicated that ideally, each public garden should have at least one staff member, or more for larger gardens, with formal education or training in a field related to interpretation, such as courses in Museum Studies or Interpretation or certification programs, such as the NAI's Certified Interpretive Guide Workshop. This person should promote the basic principals of interpretation and serve as an advocate for the interests of the visitor.

\section{Interpretive Planning Documents}

\section{Interpretive Master Plans and Interpretive Plans for Individual Gardens or Exhibits}

Our research indicated that interpretive master plans and interpretive plans for individual gardens or exhibits are providing significant benefits for public gardens. Public gardens with these types of interpretive planning documents were more likely to be satisfied with their interpretive planning process and the overall quality of interpretation and interpretive signage at their organization. They were also more 
likely to have interpretive messages that were clearly defined and create interpretation using themes and subthemes, i.e., core messages and supporting messages.

No previous study could be found that examines how valuable interpretive planning documents are for the organizations that created them. There is also no consensus regarding contents or level of detail for different types of interpretive plans, only general guidelines. An interpretive master planning process often focuses on the development of a single overarching theme or core message, and several supporting subthemes and the overarching interpretive goals and objectives of the organization (Veverka, 2011a; Brochu, 2003). Interpretive master plans sometimes go into more detail by outlining more specific interpretive messages, goals, and objectives for the individual gardens and exhibits of the public garden. So, as per our survey, an interpretive master plan could also have been included as "document(s) outlining desired messages and/or goals for individual gardens or exhibits" in the survey. For example, United States Botanic Garden's Interpretive Master Plan focused primarily on the interpretive messages, goals, and objectives for individual gardens and exhibits, without discussing the overarching message.

The present research indicated that interpretive plans for individual gardens and exhibits were rated significantly more useful than interpretive master plans. The level of detail in interpretive plans for individual gardens and exhibits is likely to make them more useful in the day-to-day perspective and more widely used across the organization. This is supported by the fact that several survey respondents thought their interpretive master plans could be more useful if they provided more detail. The interpretive master plan of United States Botanic Garden goes into detail for each 
garden and exhibit, but the present research found this is not the case with every interpretive master plan.

A primary purpose of an interpretive master plan is to outline the primary, overarching theme or core message for the organization and determine the overall objectives of interpretation (Veverka, 2011a). This can then be referenced and applied to interpretive plans for gardens and exhibits. Interpretive master plans may be perceived as less valuable if staff members lack understanding of the document's intended use or goals. Lack of a dedicated budget to support the interpretive master plan was also an issue identified in the present research. The budget and resources of an organization should be considered in the interpretive planning process to be sure that the objectives identified are achievable (Brochu, 2003). Therefore, when endeavoring to create an interpretive master plan, management should be careful to outline how it will be used and funded and make sure that all staff understands exactly what an interpretive master plan is and how it will be used, as well.

Case study results indicated that it is possible that the process of defining the overarching interpretive theme of an organization is more valuable than the interpretive master plan/prospectus itself. The intent should be that all staff be aware of and committed to the same interpretive themes and goals. Kristie Webber (2012), Director of Interpretive Programs at Chicago Botanic Garden, suggested that the message could become an inherent part of the day-to-day activities. The Monterey Bay Aquarium has done this well. They do not have an interpretive master plan, but the mission of inspiring conservation of the world's oceans outlines the interpretive goal of the organization. They also use interpretive planning methods when developing all programs and exhibits, which include conducting audience analysis, defining any 
resource considerations, and developing themes, goals, and objectives. All the programs and exhibits also support this conservation theme.

The best practices for interpretation development should include a broad interpretive theme supported by its interpretation throughout an organization, connecting all other interpretive messages like a thread (Brochu 2003). This is often accomplished with an interpretive master plan (Veverka, 2011a). Public gardens that have not identified their overarching interpretive theme and lack the resources to create a full interpretive master plan might consider other methods of determining what it will be. Case study results from this research indicate that an interpretive master planning document may not be the only means for determining a core interpretive theme or for sharing that theme across the organization. It might come from a simplified version of an interpretive master planning process or worked into the mission statement, vision statement, or organizational master plan.

Through this research's survey and case studies, there is evidence that creating interpretive planning documents for gardens and exhibits is a worthwhile endeavor. This type of interpretive plan was the most common among survey respondents but was still only reported by $47 \%$. According to survey respondents, these interpretive plans help to keep interpretive messages focused and consistent, which leads to a clearer message being delivered to the visitor. They also provide a starting place for interpretation and program development, which can lead to a savings of time and money.

For maximum effectiveness, interpretive messages defined in interpretive plans for gardens and exhibits should be threaded with a common, broad interpretive theme (Brochu, 2003). Therefore, an organization should first define what the core message 
or theme is for their organization, either through an interpretive master planning process or some other means, before creating interpretive plans for individual gardens and exhibits. Interpretive plans should also be periodically and concurrently reviewed and updated with staff changes; if not, our findings indicated that the value of interpretive plans, particularly interpretive master plans, was reduced.

\section{Interpretive Planning Consultants}

No garden staff has all the experience, skills, and facilities necessary for every project, and sometimes consultants are necessary to supplement staff expertise or provide dedicated labor (Connolly, 2011). Survey respondents who consulted with professional planners in developing interpretive plans for individual gardens or exhibits rated their plans significantly more valuable then those who didn't consult. Public garden leaders seem to value the input of consultants when developing these plans. Conversely, it does not seem that consulting with professional planners had any impact on how valuable interpretive master plans were rated. In fact, the mean value for those who did not consult was slightly better than those who did, though the difference was not significant. Some survey respondents who rated the master plan as "Somewhat valuable" or "Useless," commented that because their plan was written by consultants or lacked institutional buy-in, the document was less valuable.

Public gardens intending to create an interpretive master plan should still consider consulting with professional planners if they lack the skills in-house. These gardens should seek out planning firms having experience with the public garden arena who will understand the garden's mission and vision. The planning firm should also include all staff in the process, to build buy-in for the document upon its completion. Consultants and upper management should also clearly outline the process 
and intended results for all the stakeholders in the organization, so that results from the consultant match expectations of staff and volunteers.

\section{Interpretive Planning for Events and Daily Programing}

Overall, interpretive planning documents for events and daily programming were rated the most valuable of the four types of plans analyzed. These plans are likely used more than others, given their immediate value over the short term.

If a program is going to be truly interpretive, the messages delivered should connect the interests of the audience with the resources and mission of the organization. Developing themes is a great way to ensure that the interpretive messages will make this connection in a clear and focused way. According to Ward and Wilkinson (2006), the theme is a defining characteristic of interpretation, and its purpose is to outline the way interpreters connect the visitors to the resource. The interpretive themes, i.e. core messages, should be more specific but still fit within the context of a broader, less specific theme identified in one of the previously discussed types of documents or plans (Veverka, 2011b).

By creating a document from an interpretive planning process that includes a theme, sub-themes, and specific messages or storylines, information can be easily disseminated to staff and volunteers responsible for interpretive programs. This will help to ensure consistency in messaging. Going a step further by adding goals and objectives, program evaluation is simplified and measures of success are identified (Veverka, 2011a). 


\section{Sign Plans}

While $78 \%$ of survey respondents who had a sign plan rated it useful or very useful, it is interesting to note that there it made no difference in how they felt about the overall quality of their interpretive signage. Sign plans typically include an inventory of all interpretive, informative, and wayfinding signs and outline the appearance, location, and display of those signs (Brochu, 2003). Such a plan may be necessary to ensure signage uniformity. It can also be useful to outline pedestrian traffic via wayfinding signage, but it does not appear to have any impact on how public gardens' perceive the quality of their overall interpretive signage. Public gardens looking to invest in improved interpretive content of their signage may want to consider other options first, such as creating an interpretive plan for gardens, creating an interpretive development team for signage, or conducting front-end evaluation of interpretive messages.

\section{Staff and Volunteer Training}

Public gardens are unique among museums because staff who manage the resources on display and are highly knowledgeable, are often in a position to interact or care for the resources while interacting with visitors and answering their questions. For example, Longwood Gardens will often have a staff member in their water lily pool maintaining the Victorian water lilies during visitor hours. These staff will often interact with curious visitors while caring for the plants. Staff interactions have the potential to be highly memorable experiences for visitors (Pine II and Gilmore, 1999), but interacting with visitors of a variety of ages and backgrounds and answering questions in a way that relates to the visitor is not something that comes naturally to everyone. By training staff to recognize visitor motivations and to capitalize on the 
visitors' curiosity rather than telling them random facts, these interactive experiences can be greatly improved from the visitor's perspective.

Organizations that are satisfied with the overall quality of their interpretation are more likely to be training their staff and volunteers in personal interpretation techniques. Despite the fact that the large portion of survey respondents $(83.5 \%)$ indicated that their organization encouraged horticulture staff to interact with guests, only $18.7 \%$ indicated that horticulture staff were provided with training in personal interpretation. Instead, such training was more likely to be provided to volunteers and docents, as indicated by $68.0 \%$ of survey respondents. It is clear that providing this training to horticulture and other front-line staff would be highly beneficial, as it was for the United States Botanic Garden (Rhoades, 2012).

Training need not be limited to horticulture staff or staff with extensive knowledge of the resource. Any staff who potentially interacts with the public has the potential to improve the visitor experience. The Monterey Bay Aquarium only hires people for security who are comfortable with guest interaction and provides them with special training in first person interpretation. Many are Certified Interpretive Guides through the National Association for Interpretation. As a result, the security staff is not

only more comfortable interacting with guests, which allows them to be more effective at their primary duties, but are able to improve the visitor experience by creating memorable interactive experiences and addressing questions (Uretsky and Wright, 2013).

\section{Interpretation Development Teams}

While one-third of survey respondents were dissatisfied with the overall quality of interpretation at their organization, they were less satisfied with the overall 
quality of the interpretive signage, with $44 \%$ indicating they were not satisfied. On the other hand, survey respondents were overwhelmingly satisfied with the overall quality of guided tours at their organization, with only $11 \%$ not satisfied. Guided tours and interpretive signs were the most common types of interpretive media offered by public gardens, but since interpretive signage is not first-person interpretation, more visitors to public gardens likely experience it (Moscardo et al., 2007). Therefore, improving the quality of interpretive signage at public gardens in general would likely have a significant impact the overall quality of interpretation.

Public gardens looking to improve their interpretive signage should consider internal dedicated interpretation development teams. Brochu (2003) states that an interpretive planning process, "usually requires input from a number of people." This supports survey findings that those who were satisfied with quality of their interpretive signage were more likely to have a team dedicated to interpretation development. Those with such teams were 2.8 times more likely to strongly agree or agree with the statement, "I am satisfied with the quality of interpretive signage at my organization," than those who did not.

It is best to have an interpretive signage team composed of experts with a variety of skills. Rarely is the person who is most knowledgeable going to be the best person to write interpretive text, and the person most skilled at developing interpretation, written or otherwise, is not going to be an expert on every subject (Rand, 2010). This is why the U.C. Davis Arboretum consults experts who work with their internal, experienced teams when developing interpretive signage. These teams participate in intensive, weeklong workshops when developing interpretive signage but meet only about once per year. 
Our findings also indicate that public gardens with similar teams could be creating and reviewing interpretation on a more consistent basis to keep their products current and/or fresh. They may more likely to use handwritten signs or those that can be made quickly in house. They can also update these signs more frequently. Holly Shimizu (2012) said that interpretation at USBG traditionally used large, inflexible interpretive panels that needed to be replaced by interpretation that could be easily changed as seasons progressed or as plants came in and out of bloom. This sort of system would most likely require an interpretive development team with a variety of skills and knowledge in order to keep up to date and follow best practices for interpretive writing.

In addition to being more satisfied with interpretive signage quality, staff from organizations with a team specifically dedicated to interpretation were also more likely to be satisfied with the process by which they developed interpretation. They were also more likely to be using best practices related to interpretation development, such as developing interpretation using core messages or themes. They were also more likely to feel that their budget sufficiently supported interpretation, though just $27 \%$ of these survey respondents felt that it did.

Slightly fewer than half of survey respondents reported having an interpretation development team. This study has shown that encouraging their formation and use could improve the overall quality of interpretation at pubic gardens. Inadequate budget or resources could be barriers to creating interpretive development teams at some organizations. 


\section{Evaluation of Interpretation}

Survey respondents who were satisfied with the quality of their interpretive signage were also more likely to evaluate it, which can have a significant effect on the quality of interpretation. This was the case in the relationship between how satisfied survey respondents were with the quality of their interpretive signage and guided tours and whether or not they evaluated these forms of interpretation. Unfortunately, only $30 \%$ of survey respondents reported that their organization routinely conducted evaluation of interpretive media or messages. Visitor observations were also the most common method of conducting evaluation, reported by approximately $20 \%$ of survey respondents, and may not be the most effective method of conducting evaluation (McManus, 1994).

According to Tilden's (1957) first principal of interpretation, any interpretation that does not relate to the visitor will be sterile. Front-end evaluation is critical to understanding visitor interests in and knowledge of targeted subject matter for interpretation (Bitgood et al., 1997). Without this understanding, interpretation may not be relatable to visitors and engaging them could be futile (Woods and Moscardo, 1998). It may also be too complex for the average visitor or conversely, not complex enough. For example, the United States Botanic Garden, when designing its medicinal plant exhibit, wanted to approach interpretation from a traditional medicine point of view. When conducting front-end evaluation, they found that their guests were actually more interested in the subject of medicinal plants from a modern medicine perspective. By first conducting evaluation, they were able to provide more effective interpretation for their money. Only $20 \%$ of survey respondents indicated that their organization routinely conducted front-end, or preliminary, evaluation of interpretive media or messages. 
Evaluation also allows an organization to assess the effectiveness of its interpretive media and activities for interpretation improvement. Through defined goals and objectives, interpretive plans define what an organization wants to achieve with their interpretive activities (Merritt, 2008). Without evaluation, it would be impossible to determine if interpretive goals and objectives are being achieved, which would diminish the value of an interpretive plan.

Evaluation can be a challenge for even large organizations with significant resources (Merritt, 2008). Only 17\% of survey respondents indicated that their organization conducted summative evaluation of interpretive media or messages. Professional development organizations can improve an organization's evaluation practices, and the American Alliance of Museums provides its members with abundant resources related to evaluation.

\section{Insufficient Budget and Resources as Barriers to Interpretation Development}

According to Beck and Cable (1998), interpretive programs must be capable of attracting support- financial, volunteer, political, administrative- for the program to flourish. From our research, it appears that the interpretive programs of many public gardens are failing in this regard and an insufficient initial investment of resources is to blame. Although a large majority of survey respondents $(86.4 \%)$ agreed that interpretation was important to the mission of their organization, a mere $21.3 \%$ agreed that their budget sufficiently supported interpretation. Insufficient budgets or other resources for interpretation development was a challenge faced by $79.2 \%$ of survey respondents, and $46.5 \%$ indicated it was their biggest challenge. If interpretation is important to fulfilling a garden's mission, then it stands to reason that the budget should reflect this. 
Public gardens with limited resources should focus their efforts on staff training and professional development. Well-trained staff with knowledge of interpretive principles can produce interpretive plans, increase efficiency in interpretation development, and provide effective first person interpretation (NAI, 2012). Unfortunately, $42 \%$ of survey respondents did not feel their organization provided sufficient training or professional development. When resources are available, there are opportunities for public gardens to assist in providing professional development opportunities for public garden organizations. For instance, the Huntington Botanical Gardens is currently providing grant funded professional development workshops on the fundamentals of developing botanical exhibits. Informal educators at public gardens can apply to attend these free workshops that also cover travel and lodging expenses.

Ideally, interpretive planning should not be overlooked simply due to budgetary or staff resource concerns. Interpretive plans can provide good starting points for interpretation development, which can lead to long-term savings in time and resources (Veverka, 2011b). A well-developed interpretive plan can also be useful for fundraising or grant writing efforts (Brochu, 2003), though, despite their value, only $21 \%$ of survey respondents having interpretive plans at their organization reported that they had successfully secured a grant or financial donation using one. This finding suggests that public gardens are not fully utilizing their interpretive plans to raise and/or obtain outside support. Public gardens can also secure grants in order to complete interpretive plans. Paul J. Ciener Botanical Garden, a developing garden in Kernersville, N.C., hired a consultant to complete their Interpretive Master Plan using a grant from the Stanley Smith Horticulture Trust. Approximately, 24\% of survey 
respondents with interpretive plans reported using a grant to fund the creation of an interpretive plan.

\section{Professional Development Organizations}

Professional development organizations provide useful resources for information and training. Three professional development organizations related to interpretation dominated the active affiliations of survey respondents: the National Association for Interpretation (NAI), the American Public Gardens Association (APGA), and the American Alliance of Museums (AAM).

NAI, which was rated significantly more valuable than APGA and AAM, focuses on professional development for professionals involved in interpretation of natural and cultural heritage resources (NAI, 2013). Public garden professionals might find NAI a better fit than AAM, which serves a more diverse audience from all types of museums, because of the similarities in the interpreted resources. In addition to the National Workshop, International Conference, and certified training courses offered, NAI provides a membership magazine (Legacy), numerous books printed through InterpPress (NAI's publishing company), and blogs.

NAI is an untapped resource for most public gardens. Despite the fact that it was rated more highly than either APGA or AAM, only $12 \%$ of survey respondents indicated that they were actively involved in it, the lowest of the three groups. As a professional organization focused solely on interpretation, any public garden looking to improve the quality and effectiveness of their interpretive offerings is strongly encouraged to consider NAI for professional development resources. If more public gardens did, perhaps a professional section could be added to include public gardens 
and increase the networking opportunities through NAI. As it is, no professional section exists for public gardens, and the necessary demand is likely lacking.

Survey respondents rated both AAM and APGA as "Valuable" or "Very Valuable" by $42.8 \%$ of respondents. AAM was valued primarily for its significant resources related to interpretation, including publications, webinars, newsletters, journals, list serves, and email updates. AAM also has several Professional Networks related to different elements of interpretation (e.g. audience research and evaluation, exhibit development, and learning theories). Some survey respondents indicated that AAM and other types of museums provided more innovative and forward thinking ideas that seemed to be lacking in public gardens. Despite these benefits, participation in AAM is low with only $19.6 \%$ of respondents actively involved. This, combined with information from survey responses, seems to indicate that public gardens may not feel that AAM is as good of a fit for public gardens as it is for other types of museums. Lack of participation likely affects the overall value of AAM for public gardens by reducing opportunities for networking among public garden professionals, but research and publications done through AAM remains valuable.

Networking and learning from other public gardens were overwhelmingly the most common reasons given for why APGA was valuable, something that appeared to be lacking in NAI and AAM. The APGA Annual Conference was a primary source of these benefits, as were APGA's effort to provide its members with information about professional development workshops and symposia.

APGA has a number of professional sections, but none are specifically for interpreters. There is, however, a section for Education, which includes interpretation as part of its descriptions (APGA, 2013). Given the distinct differences between 
formal education and interpretation (Ham, 1992), having a professional section for interpreters would be beneficial for interpreters at public gardens and aid in the sharing of information and resources, increasing the value of APGA. The overall value would also likely be improved with more partnerships between APGA and other organizations with a stronger focus on interpretation. This could include crosspromotion of research, publications, and professional development events related to the art of interpretation.

\section{Summary}

From the current research, we can determine that public gardens following best practices for interpretation development as described by literature and past research are more likely to be satisfied with their interpretation. Current research also showed that the majority of public gardens are not utilizing these best practices, though some practices were more commonly utilized then others. No similar studies could be found that examined to what extent other types of museums followed best practices for interpretation development. Such a study would be useful for benchmarking public gardens against similar organizations.

Among the best practices shown to be valuable were:

- Training in interpretation for staff responsible for interpretation development

- The process interpretive planning

- Evaluation of interpretive messages and media

- Teams dedicated to interpretation development

- Training in personal interpretation for frontline staff and volunteers 
Interpretive plans were determined to be highly effective tools for interpretation development, but several pitfalls were identified that can potentially limit an interpretive plans value. In order to avoid these problems it is recommend that public gardens:

- Revise or update plans on a regular basis especially after staff changes.

- Take into consideration funding or incorporate a dedicated budget into the plan.

- Involve all staff and stakeholders in the planning processes for interpretive master plans and for gardens and exhibits.

- Before endeavoring to create an interpretive master plan, make sure all stakeholders fully understand how the interpretive planning process will be conducted and how the plan will be used.

Further study is recommended to determine additional best practices for interpretive planning for public gardens, particularly for interpretive master planning. This could include recommendations regarding the level of detail that should be included in interpretive plans. It could also include recommendations for best practices for how interpretive planning processes should be conducted.

In order to improve the quality of interpretation at public gardens as whole, the first step that should be taken is to improve staff training and professional development in interpretation. It is difficult to take an interpretive approach to communication or follow best practices for interpretation development without first having an understanding of what interpretation is. It is unclear from current research how well public garden leaders currently understand the differences between 
interpretation and information or formal education. However, the current research did show that few are entering the public horticulture field with any formal training in interpretation, so training must be provided or encouraged. While this may not be possible for every staff member involved in interpretation development, it is strongly recommended that each public garden have at least one staff member with training in interpretation. Staff members responsible for interpretation development are also strongly encouraged to use a process of interpretive planning in the development of interpretive media and messages. 


\section{REFERENCES}

American Association of Botanical Gardens and Arboreta. 2001, Reaching Out to the Garden Visitor. AABGA, Kennett Square, PA.

American Association of Museums, and Merritt, E.E. 2008, National Standards and Best Practices for U.S. Museums. American Association of Museums, Washington, DC.

American Public Gardens Association (APGA). 2013, "Education Professional Sections". APGA [online] available at http://www.publicgardens.org/sections/education-professional-section-0

Ballantyne R., Packer J., and Hughes K. 2008, "Environmental Awareness, Interests and Motives of Botanic Gardens Visitors: Implications for Interpretive Practice". Tour Manage Tourism Management, vol. 29, no. 3, pp. 439-444.

Beck, L., and Cable, T. 1998, Interpretation for the $21^{\text {st }}$ Century. Sagamore Publishing, Champaign, Il.

Bitgood, S. 1988, “A Comparison of Formal and Informal Learning”. Technical Report No. 88-10. Center for Social Design, Jacksonville, AL 36265.

Bitgood, S., and Shettel, H.H. 1997, "An Overview of Visitor Studies". JOURNAL OF MUSEUM EDUCATION, vol. 21, no. 3, pp. 6-10.

Bridal, T. October 2012, Personal Communication. Monterey Bay Aquarium.

Brochu, L., and Merriman, T. 2002, Personal Interpretation: Connecting Your Audience to Heritage Resources. InterpPress, Fort Collins, CO.

Brochu, L., and National Association for Interpretation 2003, Interpretive Planning: The 5-M Model for Successful Planning Projects. InterpPress, Fort Collins, CO.

Connolly, K. 2011, Interpreting Gardens to Visitors. In: Rakow, D and Lee, S., ed. 2011. Public Garden Management. John Wiley and Sons, Inc., Hoboken, New Jersey. Ch.17. 
Covel, J. October 2012, Personal Communication. Director of Interpretive Programs, Monterey Bay Aquarium.

Cowan, N. 2001, "The Magical Number 4 in Short-term Memory: A Reconsideration of Mental Storage Capacity". Behavioral and Brain Sciences. vol. 24, no. 1, pp. 87-114.

Creswell, J.W. 1994, Research Design: Qualitative and quantitative approaches. Sage Publications, Thousand Oaks, Calif.

Falk, J.H. 2006 "The Impact of Visit Motivation on Learning: Using Identity as a Construct to Understand the Visitor Experience". Curator: The Museum Journal, vol. 49, no. 2, pp. 151-166.

Falk, J. H., and Dierking, Lynn. 1992, The Museum Experience. Whalesback Books, Washington, D.C.

Falk, J. H., and Dierking, Lynn. 2000, Learning from Museums: Visitor Experiences and the Making of Meaning. Walnut Creek, CA: AltaMira Press, 2000, Chapters 1-4, pp. 1-67.

Falk, J.H., Koran, J.J., Dierking, L.D. and Dreblow, L. 2010, "Predicting Visitor Behavior". Curator: The Museum Journal. vol. 28, no. 4, pp. 249-258.

Falk, J. H., Reinhard, E. M., Vernon, C. L., Bronnenkant, K., Deans, N. L., Heimlich, J. E. 2007. Why Zoos and Aquariums Matter: Assessing the Impact of a Visit to a Zoo or Aquarium. Association of Zoos and Aquariums, Silver Spring, MD.

Falk, J.H., and Storksdieck, M. 2005, "Using the Contextual Model of Learning to Understand Visitor Learning from a Science Center Exhibition”. Science Education, 89, 744-778.

Graf, B. 1994, "Visitor Studies in Germany: Methods and Examples" in Routledge, London; New York, pp. 6-5.

Gross, M., and Zimmerman, R. 2002, "Park and Museum Interpretation: Helping Visitors Find Meaning”. CURATOR. Vol. 45, no. 4, pp. 265-276.

Ham, S.H. 1992, Environmental Interpretation: A practical guide for people with big ideas and small budgets. Fulcrum Pub., Golden, CO. 
Heimlich, J. E., and Storksdieck, M. 2007, “Changing Thinking about a Changing World". Southern African Journal of Environmental Education. No. 25, pp. 6375.

Hein, G.E. 1998, Learning in the Museum. Routledge, New York, NY.

Hein, G.E., and Alexander, M. 1998, Museums: Places of Learning. American Association of Museums, Washington, DC.

Helmich, M. 1997, Workbook for Planning Interpretive Projects in California State Parks.

Leftridge, A. 2006, Interpretive Writing. InterpPress, Fort Collins, CO.

McManus, P.M. 1994, "Oh, Yes, They Do: How Museum Visitors Read Labels and Interact with Exhibit Texts". Curator: The Museum Journal, vol. 32, no. 3, pp. 174-189.

Merriman, T. 2010, "Best Practices for Interpretation: Forging Emotional Connections", People, Plants, Collections: Making the Connection, Kennett Square, PA, Longwood Gardens.

Miles, R. 1993, "Grasping the Greased Pig: Evaluation of Educational Exhibits". in Science Museum, London, pp. -33 .

Miller, G.A. 1994, "The Magical Number Seven, Plus or Minus Two: Some Limits on Our Capacity for Processing Information". Psychological review, vol. 101, no. 2, pp. 343-52.

Moscardo, G., Ballantyne, R., and Hughes, K. 2007, Designing Interpretive Signs: Principles in Practice. Fulcrum Pub., Golden, CO.

National Association for Interpretation (NAI). 2009, "Standards and Practices for Interpretive Methods".

National Association for Interpretation (NAI). 2012, Certification Program: Handbook and Study Guide. Fort Collins, Co.

National Association of Interpretation (NAI). 2013, "Who We Are". NAI [online] available at http://www.interpnet.com/nai/About/Who_We_Are

Pine II, J., and Gilmore, J.H. 1999. The Experience Economy: Work is Theatre and Every Business is a Stage. Harvard Business School Press, Boston, MA. 
Rand, A., and Kiihne, R. 2010, Experts, Evaluators, and Explorers: Collaborating with Kids. In: McRainey, L., and Russick, J. ed. 2010, Connecting Kids to History with Museum Exhibitions. Left Coast Press, Inc., Walnut Creek, CA.

Rand, J. 2010, “Adventures in Label Land”, One Size Fits All?. Boston, MA, USS Constitution Museum.

Rhoads, L. July 2012, Personal Interview. Education Program Specialist, United States Botanical Garden.

Rigby, J. July 2012, Personal Interview. Director, The Acorn Group.

Sclar, C. December 2012, Personal Communication. Executive Director, American Public Gardens Association.

Shimizu, H. July 2012, Personal Interview. Executive Director, United States Botanical Garden.

Serrell, B. 1996, Exhibit Labels: An Interpretive Approach. Alta Mira Press, Walnut Creek.

Tilden, F. 1957, Interpreting Our Heritage; Principles and Practices for Visitor Services in Parks, Museums, and Historic Places. University of North Carolina Press, Chapel Hill.

Tofield, S., Coll, R., Vyle, B. and Bolstad, R. 2003, "Zoos as a Source of Free Choice Learning". Research in Science and Technological Education. vol. 21, no. 1, pp. 67--99.

Uretsky, T., and Wright, K. 2013, Safety and Security - The Park Ranger Model. [online] Available at: < http://www.iaapa.org/mobile/mobile-news/safety-andsecurity---the-park-ranger-model $>$ [Accessed 9 March 2013].

Veverka, J. 2011a, Interpretive Master Planning Volume One: Strategies for the New Millenium. MuseumsEtc, Edinburgh.

Veverka, J. 2011b, Interpretive Master Planning Volume Two: Selected Essays, Philosophy, Theory and Practice. MuseumsEtc, Edinburgh.

Ward, C.W., and Wilkinson, A.E. 2006, Conducting Meaningful Interpretation: A Field Guide for Success. Fulcrum Pub., Golden, CO. 
Webber, K. June 2013. Personal Interview. Director of Interpretive Programs, Chicago Botanic Garden.

Woods, B., and Moscardo, G. 1998, "Researching Interpretive Techniques in Tourism: An Evaluation of the Effectiveness of Pictorial Symbols in Reef Tourist Education". Progress in Tourism and Hospitality Research. pp. 320--33. 
Appendix A

HUMAN SUBJECTS REVIEW BOARD 


\section{Certification of Human Subjects Training}

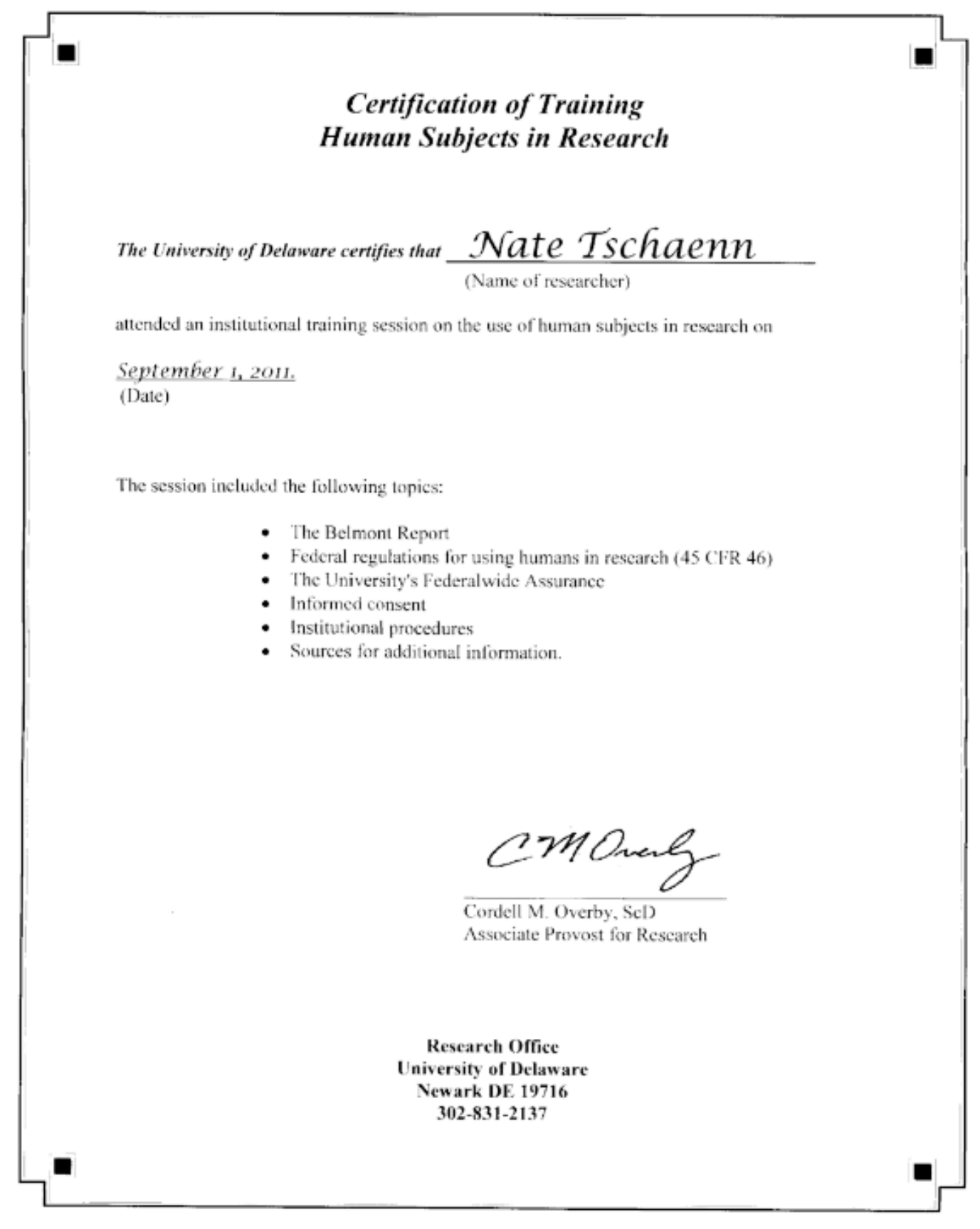




\section{Exemption Letter: Preliminary Survey}

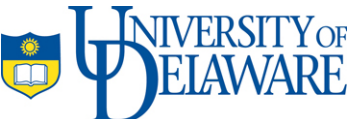

Research OfFice

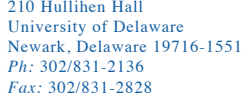

entihen Hall

Fax: 302/831-2828

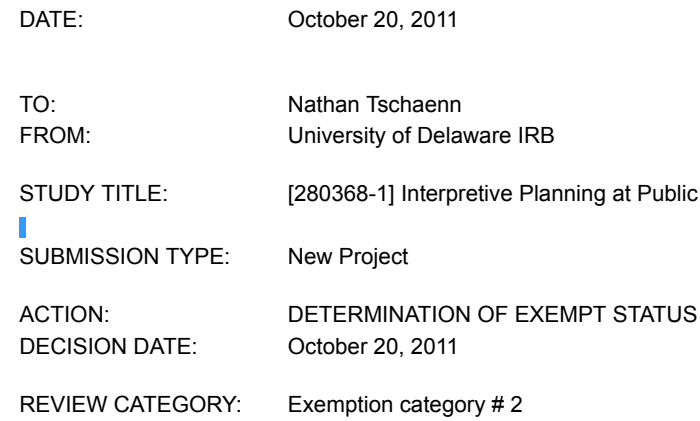

Thank you for your submission of New Project materials for this research study. The University of Delaware IRB has determined this project is EXEMPT FROM IRB REVIEW according to federal regulations.

We will put a copy of this correspondence on file in our office. Please remember to notify us if you make any substantial changes to the project.

If you have any questions, please contact Jody-Lynn Berg at (302) 831-1119 or jlberg@udel.edu. Please include your study title and reference number in all correspondence with this office. 


\section{Exemption Letter: APGA Survey, Case Studies, Expert Interviews}

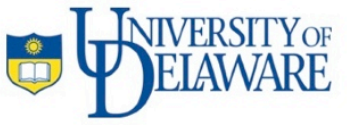

Research OfFice

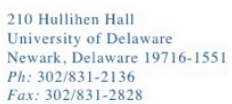

University of Delaw

Fax: $302 / 831-2828$

DATE:

October 1, 2012

TO:

Nathan Tschaenn

FROM:

University of Delaware IRB

STUDY TITLE:

[350911-2] Interpretive Planning Processes at Public Gardens

SUBMISSION TYPE:

ACTION:

DECISION DATE:

Amendment/Modification

DETERMINATION OF EXEMPT STATUS

October 1, 2012

REVIEW CATEGORY:

Thank you for your submission of Amendment/Modification materials for this research study. The

University of Delaware IRB has determined this project remains EXEMPT FROM IRB REVIEW according to federal regulations.

We will put a copy of this correspondence on file in our office. Please remember to notify us if you make any substantial changes to the project.

If you have any questions, please contact Jody-Lynn Berg at (302) 831-1119 or jlberg@udel.edu. Please include your study title and reference number in all correspondence with this office. 
Appendix B

INFORMED CONSENT FORM 


\title{
The Longwood Graduate Program, University of Delaware
}

\section{Informed Consent Form for Individual Interview}

\begin{abstract}
A University of Delaware graduate student is conducting research to investigate interpretive planning processes at public gardens in order to complete a Master's thesis. You have been selected to participate in this research because the researcher feels you can provide valuable insight to this study and help in identifying the current status and future potential for interpretive planning at public gardens.
\end{abstract}

You are in no way obligated to participate in this interview. The interview will be digital voice recorded only for reference during the research process. Audio recordings will be destroyed one year after the study is complete. Also, the researcher would like to potentially quote you; therefore, it is important that you are willing to be identified by name and position in the final report.

You reserve the right to refuse to answer any questions, and you can leave the interview at any time. You will not directly benefit from this research, but the feedback you provide will help develop a better understanding of interpretation at public gardens.

If you have questions about this research, please contact Nate Tschaenn, Longwood Graduate Fellow, by email at ntschaenn@gmail.com or Dr. Robert Lyons, Longwood Graduate Program Coordinator, by phone at (302) 831-1369. If you have any concerns about your rights as a participant, contact the Chair of the University of Delaware Human Subjects Review Board at (302) 831-2136.

If you agree to participate in this research, please print and sign your name below.

\section{Name of Subject (Please Print)}


Appendix C

PRELIMINARY SURVEY RESULTS 
Do you make decisions regarding the development of interpretive signage at your organization?

\begin{tabular}{|c|c|c|c|}
\hline Answer & Bar & Responses & \% \\
\hline Yes & & 388 & $78.2 \%$ \\
\hline No & & 78 & $15.7 \%$ \\
\hline Not sure & & 30 & $6.0 \%$ \\
\hline Total & & 496 & $100 \%$ \\
\hline
\end{tabular}

Does your organization's mission statement include an "education" component related to the general public?

\begin{tabular}{|c|c|c|c|}
\hline Answer & Bar & Responses & \% \\
\hline Yes & & 387 & $95.8 \%$ \\
\hline No & & 14 & $3.5 \%$ \\
\hline Not sure & & 3 & $0.7 \%$ \\
\hline Total & & 404 & $100 \%$ \\
\hline
\end{tabular}

Please rank how strongly you agree or disagree with the following statements.

\begin{tabular}{|c|c|c|c|c|c|c|c|}
\hline $\begin{array}{c}\text { Question } \\
\text { Qisagree }\end{array}$ & $\begin{array}{c}\text { Strongly } \\
\text { Disagree Undecided Agree }\end{array}$ & $\begin{array}{c}\text { Strongly } \\
\text { Agree }\end{array}$ & Responses Mean \\
\hline $\begin{array}{c}\text { The interpretative } \\
\text { signage at my } \\
\text { organization reflects } \\
\text { the educational } \\
\text { component of the } \\
\text { mission statement } \\
\text { well. }\end{array}$ & 15 & 45 & 52 & 180 & 70 & 362 & 3.7 \\
$\begin{array}{c}\text { The interpretive } \\
\text { signage at my } \\
\text { organization is } \\
\text { sufficient and } \\
\text { effective. }\end{array}$ & 31 & 141 & 60 & 110 & 17 & 359 & 2.8 \\
\hline $\begin{array}{c}\text { There is a well- } \\
\text { defined organizational } \\
\text { structure for the } \\
\text { development of }\end{array}$ & 46 & 126 & 52 & 100 & 37 & 361 & 2.9 \\
$\begin{array}{c}\text { interpretive signage at } \\
\text { my organization. }\end{array}$ & & & & & & & \\
\hline
\end{tabular}


Please rank the following methods used by your organization in order of importance with 1 being the most important. Please leave blank if not offered by your organization.

\begin{tabular}{|c|c|c|c|c|c|c|c|c|}
\hline Answer & $\mathbf{1}$ & $\mathbf{2}$ & $\mathbf{3}$ & $\mathbf{4}$ & $\mathbf{5}$ & $\mathbf{6}$ & Responses & Mean \\
\hline Guided tours & 77 & 104 & 63 & 51 & 23 & 4 & 322 & 2.5 \\
\hline Docents & 55 & 52 & 59 & 40 & 38 & 10 & 254 & 2.9 \\
\hline Interpretive signage & 70 & 57 & 76 & 71 & 44 & 13 & 331 & 3.0 \\
\hline Classes or lectures & 68 & 58 & 54 & 64 & 69 & 15 & 328 & 3.2 \\
\hline Brochures & 51 & 54 & 64 & 70 & 61 & 15 & 315 & 3.3 \\
\hline Orientation videos & 9 & 10 & 17 & 14 & 24 & 138 & 212 & 5.1 \\
\hline Total & 330 & 335 & 333 & 310 & 259 & 195 & - & - \\
\hline
\end{tabular}

Does your organization have an interpretive master plan?

\begin{tabular}{|c|c|c|c|}
\hline Answer & Bar & Responses & \% \\
\hline Yes & & 96 & $26.7 \%$ \\
\hline No & & 206 & $57.4 \%$ \\
\hline Not sure & & 57 & $15.9 \%$ \\
\hline Total & & 359 & $100 \%$ \\
\hline
\end{tabular}

Is there a mechanism in place to periodically review the interpretive master plan?

\begin{tabular}{|c|c|c|c|}
\hline Answer & Bar & Responses & \% \\
\hline Yes & & 43 & $45.7 \%$ \\
\hline No & & 32 & $34.0 \%$ \\
\hline Not sure & & 19 & $20.2 \%$ \\
\hline Total & & 94 & $100 \%$ \\
\hline
\end{tabular}

Does your organization have a method of reviewing interpretation in order to measure success?

\begin{tabular}{|c|c|c|c|}
\hline Answer & Bar & Responses & \% \\
\hline Yes & & 38 & $15.3 \%$ \\
\hline No & & 180 & $72.6 \%$ \\
\hline Not sure & & 30 & $12.1 \%$ \\
\hline Total & & 248 & $100 \%$ \\
\hline
\end{tabular}


Who is responsible for the development of interpretive signage at your organization? (Please check all that apply)

\begin{tabular}{|c|c|c|c|}
\hline Answer & Bar & Responses & $\%$ \\
\hline Executive Director & & 176 & $51.6 \%$ \\
\hline Director of Horticulture & & 174 & $51.0 \%$ \\
\hline Other Horticulture staff & & 143 & $41.9 \%$ \\
\hline Director of Education & & 182 & $53.4 \%$ \\
\hline Other Education staff & & 150 & $44.0 \%$ \\
\hline Director of Marketing & & 94 & $27.6 \%$ \\
\hline Other Marketing staff & & 63 & $18.5 \%$ \\
\hline Director of Guest Services & & 51 & $15.0 \%$ \\
\hline Other Guest Services staff & & 28 & $8.2 \%$ \\
\hline Curator & & 92 & $27.0 \%$ \\
\hline Exhibit planner/designer & & 98 & $28.7 \%$ \\
\hline Volunteers & & 57 & $16.7 \%$ \\
\hline Interns & & 32 & $9.4 \%$ \\
\hline Total & & 1340 & $100 \%$ \\
\hline
\end{tabular}


Appendix D

ADDITIONAL RESULTS FROM INTERPRETATION DEVELOPMENT SURVEY 
Responsibilities of survey respondents in the area of interpretation development.

\begin{tabular}{|c|c|c|c|}
\hline Answer & \multicolumn{2}{c|}{ Bar } & \multicolumn{2}{c|}{ Responses } & \% \\
\hline $\begin{array}{c}\text { Developing broad messages, ideas, or themes } \\
\text { for interpretation or interpretive programs }\end{array}$ & & 211 & $74.3 \%$ \\
\hline Developing written interpretation & & 207 & $72.9 \%$ \\
\hline Signage formatting and layout & & 183 & $64.4 \%$ \\
\hline Tour guide and docent training & & 163 & $57.4 \%$ \\
\hline Developing tour content or scripts & & 149 & $52.5 \%$ \\
\hline Reviewing or editing programs, scripts, etc. & & 148 & $52.1 \%$ \\
\hline Developing adult or family programming & & 148 & $52.1 \%$ \\
\hline Evaluation of interpretation & & 110 & $51.8 \%$ \\
\hline Design & & 93 & $38.7 \%$ \\
\hline Developing K-12 programming & & & $32.8 \%$ \\
\hline
\end{tabular}

Specific skill sets of interpretive development teams.

\begin{tabular}{|c|c|c|c|}
\hline Answer & Bar & Responses & $\%$ \\
\hline Content development & & 126 & $89.4 \%$ \\
\hline Program development & & 116 & $82.3 \%$ \\
\hline Interpretive writing & & 111 & $78.7 \%$ \\
\hline Editing & & 109 & $77.3 \%$ \\
\hline Horticulture & & 102 & $72.3 \%$ \\
\hline Graphic design & & 93 & $66.0 \%$ \\
\hline Teaching experience & & 90 & $63.8 \%$ \\
\hline Project management & & 80 & $56.7 \%$ \\
\hline Exhibit design & & 78 & $55.3 \%$ \\
\hline Lesson plan development & & 75 & $53.2 \%$ \\
\hline Evaluation & & 63 & $44.7 \%$ \\
\hline Curation & & 62 & $44.0 \%$ \\
\hline Landscape design & & 57 & $40.4 \%$ \\
\hline Master planning experience & & 49 & $34.8 \%$ \\
\hline Other & & 14 & $9.9 \%$ \\
\hline
\end{tabular}




\begin{tabular}{|c|c|c|c|c|c|c|c|c|c|}
\hline Statement & $\begin{array}{l}\text { Strongly } \\
\text { disagree }\end{array}$ & Disagree & $\begin{array}{l}\text { Neither } \\
\text { Agree nor } \\
\text { Disagree }\end{array}$ & Agree & $\begin{array}{c}\text { Strongly } \\
\text { Agree }\end{array}$ & Total & Mean & Variance & $\begin{array}{l}\text { Standard } \\
\text { deviation }\end{array}$ \\
\hline $\begin{array}{c}\text { I am satisfied with the process by } \\
\text { which interpretation is developed } \\
\text { at my organization. }\end{array}$ & 9 & 73 & 60 & 123 & 17 & 282 & 3.23 & 1.01 & 1.01 \\
\hline $\begin{array}{c}\text { The interpretive messages that my } \\
\text { organization strives to } \\
\text { communicate are clearly defined }\end{array}$ & 9 & 58 & 59 & 122 & 34 & 282 & 3.40 & 1.09 & 1.04 \\
\hline $\begin{array}{l}\text { The interpretation at my } \\
\text { organization is clear and concise. }\end{array}$ & 7 & 53 & 69 & 125 & 27 & 281 & 3.40 & .96 & .98 \\
\hline $\begin{array}{l}\text { My budget sufficiently supports } \\
\text { interpretation. }\end{array}$ & 50 & 106 & 61 & 51 & 9 & 281 & 2.48 & 1.19 & 1.09 \\
\hline $\begin{array}{l}\text { The interpretation at my } \\
\text { organization is created using } \\
\text { themes and supporting sub- } \\
\text { themes (i.e. core message and } \\
\text { supporting messages). }\end{array}$ & 10 & 34 & 60 & 132 & 44 & 280 & 3.59 & 1.02 & 1.01 \\
\hline $\begin{array}{l}\text { I feel that I am adequately trained } \\
\text { in best practices for my specific } \\
\text { responsibilities in interpretation. }\end{array}$ & 5 & 71 & 68 & 103 & 34 & 281 & 3.32 & 1.08 & 1.04 \\
\hline $\begin{array}{c}\text { My organization provides } \\
\text { sufficient training and/or } \\
\text { professional development in the } \\
\text { field of interpretation for related } \\
\text { staff and volunteers. }\end{array}$ & 31 & 88 & 82 & 68 & 12 & 281 & 2.79 & 1.13 & 1.06 \\
\hline $\begin{array}{l}\text { The interpretation at my } \\
\text { organization effectively connects } \\
\text { the interests of our visitors to the } \\
\text { resources of our organization. }\end{array}$ & 10 & 40 & 79 & 127 & 24 & 280 & 3.41 & .92 & .96 \\
\hline $\begin{array}{l}\text { Interpretation is important to the } \\
\text { mission of our organization. }\end{array}$ & 5 & 7 & 26 & 106 & 137 & 281 & 4.29 & .76 & .87 \\
\hline $\begin{array}{l}\text { I struggle with ways to interpret } \\
\text { complex issues like global climate } \\
\text { change, invasive species, etc. }\end{array}$ & 16 & 65 & 91 & 86 & 21 & 279 & 3.11 & 1.06 & 1.03 \\
\hline $\begin{array}{l}\text { I am satisfied with the overall } \\
\text { quality of interpretation at my } \\
\text { organization. }\end{array}$ & 15 & 78 & 70 & 100 & 15 & 278 & 3.08 & 1.07 & 1.03 \\
\hline $\begin{array}{l}\text { I am satisfied with the overall } \\
\text { quality of interpretive signage at } \\
\text { my organization. }\end{array}$ & 22 & 64 & 34 & 62 & 12 & 194 & 2.89 & 1.34 & 1.16 \\
\hline $\begin{array}{l}\text { I am satisfied with the quality of } \\
\text { the guided tours provided by my } \\
\text { organization. }\end{array}$ & 2 & 19 & 40 & 95 & 34 & 190 & 3.74 & .82 & .81 \\
\hline
\end{tabular}




\section{Please describe what is useful about the interpretive master plan or prospectus.}

The plan was put partially into place but that was 7 years ago. The interpretive signage that came out of the plan was a vast improvement.

sets the stage for ongoing projects instead of having to "reinvent the wheel" each time

Helps keep messaging and tone on track

phases interpretive projects within a prioritized, five year scope and it outlines how each recommendation (sign, brochure, exhibit, tour) works toward achieving established interpretive objectives and communicates interpretive themes outlined in the master plan.

Keeps us focused on our goals for the year and improvements year after year. setting themes and big ideas of each area.

Outline the directions for projects and help get everyone on the same page.

clearly delineates messaging and goals; indicates interpretive zones where info is concentrated

Overall layout and functions of various parts of the future garden; purposes of the garden.

Map for annual planning

Gives everyone goals to shoot for and helps in establishing priorities for new construction, landscape planning, land use, environmental concerns etc.

keeps us focused on the mission and aids in keeping our tours and signage coordinated Determines what messages we will convey in each area of the garden. It also determines what plants are a part of the collection.

Outside professional evaluation

Gives and overall framework related to various parts of the property, better directing our resources.

Clarifying how, where and design details for interpretations and other signage

There is always the Garden's Mission which must be a functional part in the interpretive agenda.

It clearly states the themes and core messages.

Makes the over all vision clear.

consistency in message and delivery

100 year plan

It helps us keep our focus on interpretive topics and content relevant only to our mission.

Consistency 


\section{Please describe what is useful about the interpretive master plan or prospectus (cont.).}

it's the roadmap for future development, whether it can be afforded presently or requires fund-raising to meet our objectives.

They have a good conceptual and historical understanding of the Garden.

It gives a framework and direction for docents to create their own talks

The master plan serves as a guiding "road map" for planning our educational and interpretive programs.

Gave us an interpretation focus for new areas opening at the Garden

It is a project-based tactical plan, based on our experiences and needs, rather than ideas and strategies.

everything is aligned, everyone knows the plan/strategic direction

Getting all departments to commit to a unified public experience and recognize interpretation falls to everyone.

Our interpretive media tell a coherent story. We don't grope for ideas or drift.

Gives us direction and focus

Allows room for updated academic research to make its way into daily practice, allows our org to reflect trends with various age groups, provides a direction for grant writing, lends credence to our org

The core messages and themes are right-on for Wyck. How to take the themes into spaces is not explicit, and a more detailed documented is needed to take it to the next step.

useful to know there is a clear idea of future plans

Gives broad themes and specific sub themes.

Provides direction, justification and clarity around decision making - of most value over the medium term

It helps define the important messages we wish to convey to visitors. Before the interpretive master plan, each department fashioned its own interpretive messages so we now present a more cohesive message.

Concrete direction

Provides clear information to disseminate to public and potential donors. 
Please describe how interpretive master plan or prospectus could be more useful. It was basically ignored after it was developed, partly due to staff changes, partly due to the fact that it was written by a consultant.

having the financial and human resources to actually implement the suggestions

The plan was created before the recession. We have not had the money to implement all the ideas. It is now 5 years old, and we have a new director, so we need to create a new plan.

More broad-based training among non education or interpretive staff (e.g., horticultural staff)

Having an organization budget allocation supporting MP proposals, rather than being dependent on donor resources or local revenue streams.

could have been more fully fleshed out, more storyboarding

Provide funding for the plan. Assign individual people with the responsibilities to accomplish the goals.

it could have institutional buy in

focus on mission; guidelines on how to reach specific audiences

It could be more specific regarding the mission of the garden.

The plan is 14 years old and is now very dated.

It was written 10+ years ago, and with changes/moves with staff, we are unable to locate the copy!

Could be updated. Update should be more inclusive of staff.

Condensed and shared more broadly across my organization

Lacks scientific rigor and rigorous editing

We are in the middle of deciding how to move forward to complete an interpretive plan. We have documented what we need and why, but have not yet completed a full interpretive plan.

Most of the team that created it are no longer with the organization; the interpretation program is now part of the Marketing Department, while the original plan was created in the Education Department. This difference does color the way the original plan is perceived and considered currently.

Drafted in 1999. Needs to be updated.

If people other than me read it.

Not sure, but I know it isn't as useful as hoped.

We are part of the park district; our district is so large (ice arenas to public gardens) that is sometimes hard to tie priorities to so many varied operations

If it could be implemented. Our plan is really the first phase in the planning process. 


\section{Please describe what is useful about having a document or documents outlining desired messages and/or goals for individual gardens or exhibits.}

consistent message

It helps frame the discussion staff have with visitors and press. It makes writing interpretation easier and ensures consistency of message.

Consistency of Message across the exhibition, throughout the Garden

It makes it easier to develop the exhibit if you know what content you want to include and how it fits into the overall interpretive master plan.

Development is guided by these documents. Also points out areas where interpretation is lacking or insufficient, giving us clear goals and areas to work on.

It allows the project to be focused on the topic of the exhibit.

Map for staff to be consistent with messaging and move the project forward

So staff is clear and on the same page with interpretation.

Documents must accompany the master plan for concise understanding and statement of Pros and Cons of each of it's components

Focus; ease of communicating goals

it gives focus to topics that are otherwise very broad in scope

Not sure how useful it has been.

Outside professional evaluation

same as above. BTW, "professional planning" is mostly done in-house, not contracted to an outside firm

Gardens help us tell our stories. They are more effective if we design gardens with our messages in mind. Documents containing our agreed upon and prioritized messages (themes) and goals provide focus and direction. They also help insure these goals, messages match up with long range plans for our whole organization (part of our Strategic Plan).

Ensure any new plantings or displays, tours, etc. support the messages and goals.

It enables other staff and volunteers, including future staff and volunteers, to understand goals of gardens and landscapes.

focus efforts. eliminate unneeded information.

It is valuable to describe goals for current staff and volunteers now and in the future. It is helpful in landscape design and in collection development.

Narrow the scope of the interpretation project and relates it to the rest of the Gardens' mission.

Consistency

helps put weight behind the important messages and ranks them accordingly

focus and lens for choosing text and visual images to convey message - must also consider visitor interests and questions 


\section{Please describe what is useful about having a document or documents outlining desired messages and/or goals for individual gardens or exhibits (cont.).}

Staff understands goals, helps focus ideas and keep on track

keeping staff focused, dividing up and assigning work

Keeping focus on the core big ideas

Makes sure that the ideas for interpretation are fully developed as well as clear and visible to stakeholders.

Keeps everyone on the same page and helps us all to work towards common goals, instead of guessing what the most important message points are.

It focuses my efforts and aligns them with the mission of the arboretum and interests of our visitors.

Maps out a process and goal

The document provides an outline for the development of interpretive materials and is a useful tool to share with those not directly involved in the development of interpretation who shape messages that go out to the public (marketing, development, PR)

Useful in educating the public and other specific audiences and fundraising

Provides a focus for interpretation

Delivering a consistent message

Makes developing content and style more effective

Consistency across departments about intended messages

Captures ideas and content that can be used in other ways

Some exhibits/gardens are more inclined to messaging than others. So the areas with messages help guide interpreters and staff

ensures everyone is on the same page

Particularly in planning new gardens, areas of interest it gives us the ability to design around interpretation. For existing gardens and areas of interest it guides the story to be told.

Objectives of gardens outlined so everyone is on the same page.

Enables everyone to be on the same page.

ultimately a clearer message

same as above

$i$ wrote them. they help me get buy in from my clients and stakeholders

keeps the organization on track and can be shared with the rest of the organization

We have an exhibit planning document only for our core exhibit, not every exhibit panel or site. We do plan every interpretive intervention with reference to our master plan. 
Please describe what is useful about having a document or documents outlining desired messages and/or goals for individual gardens or exhibits (cont.).

provides a framework for development of tours, exhibits, signage, programming that all staff and volunteers can follow...presents a cohesive message

Several garden areas were/are in need of renovation. We began this process by determining what messages we wanted the public to encounter. When then redesigned areas to fulfill specific interpretive themes.

With a plan the design of the garden can be guided to integrate with the signage and interpretive programs that utilize the site.

It enables us to communicate strategically and effectively to our stakeholders and community about our mission, our collection and our messages.

It helps us develop interpretive signs that communicate desired messages

All staff, volunteers are the same page and are aware of what message we send to our guests

It helps to integrate signage and interpretation among gardens/events/programs. It helps when it's time to generate PR and create website content.

I think that it is useful but I do not have direct experience with that team, so I'm not sure what is specifically useful.

Again, everyone is on the same page and not just "doing their own thing".

we can only achieve our interpretive goals if we know what they are

keeps the focus

Funding for plant relabeling project

Not having to start from scratch to figure out the purpose/audience of the garden. useful to know what is expected as the end product

Very much aids in priority setting during design, construction, and interpretation processes.

everyone has the same set of messages to work from, there's no ambiguity.

Curators, educators and science staff collaborated with a consultant on the messages for individual gardens/exhibits. Having individual documents can inform one that is over arching, some themes emerge.

Keeps message consistent. Facilitates transmission of message to public, volunteers, staff and media.

To keep messages on point with the mission of the garden

Professional firm may be consulted regarding specific messages and interpretation It provides a framework for decision making

Please describe how document or documents outlining desired messages and/or goals for individual gardens or exhibits could be more useful.

More specifics needed. 
I don't know if it would be.

what little we have informs the interpretation we offer our guests. we have a clear idea of where we want to go but lack the resources such as money and personnel to execute the entire plan.

I do not agree with the focus of the planning documents

Avoid sending out a convoluted message to the public

Having more budget and staffing support for expanding marketing vehicles. Our program intends to produce season based marketing vehicles as time and fiscal resources permit.

building a common vision and a common understanding of the engagement goals for our statewide organization and then trickle-down specifics for individual sites.

Would help to focus the ideal interpretive message for the desired sites in the garden.

The completed document sits on the shelf, lost in the day-to-day activities that take priority.

If it was up to date.

Have you ever consulted with a professional planning firm in the development of a sign plan?

\begin{tabular}{|c|c|}
\hline Survey Choices & $\begin{array}{c}\text { Number of Responses } \\
\text { (overall percentage) }\end{array}$ \\
\hline Yes & 37 \\
& $(39.0 \%)$ \\
\hline No & 41 \\
& $(43.2 \%)$ \\
\hline Not sure & 17 \\
\hline Total & $(17.9 \%)$ \\
\hline & 95 \\
& $(100 \%)$ \\
\hline
\end{tabular}

Usefulness ratings of a sign plan in their decision to consult with a professional planning firm. 


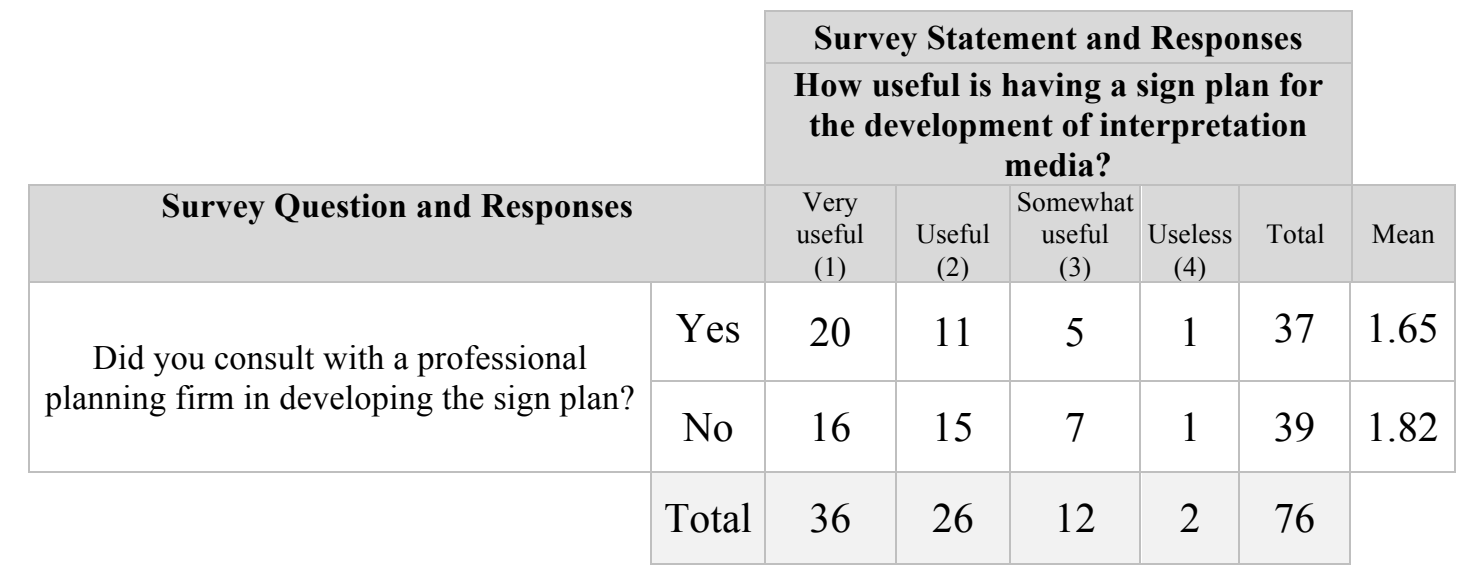

The degree to which 194 survey respondents agreed or disagreed with the statement "I am satisfied with the overall quality of interpretative signage at my organization with respect to whether or not they indicated that they had a sign plan at their organization.

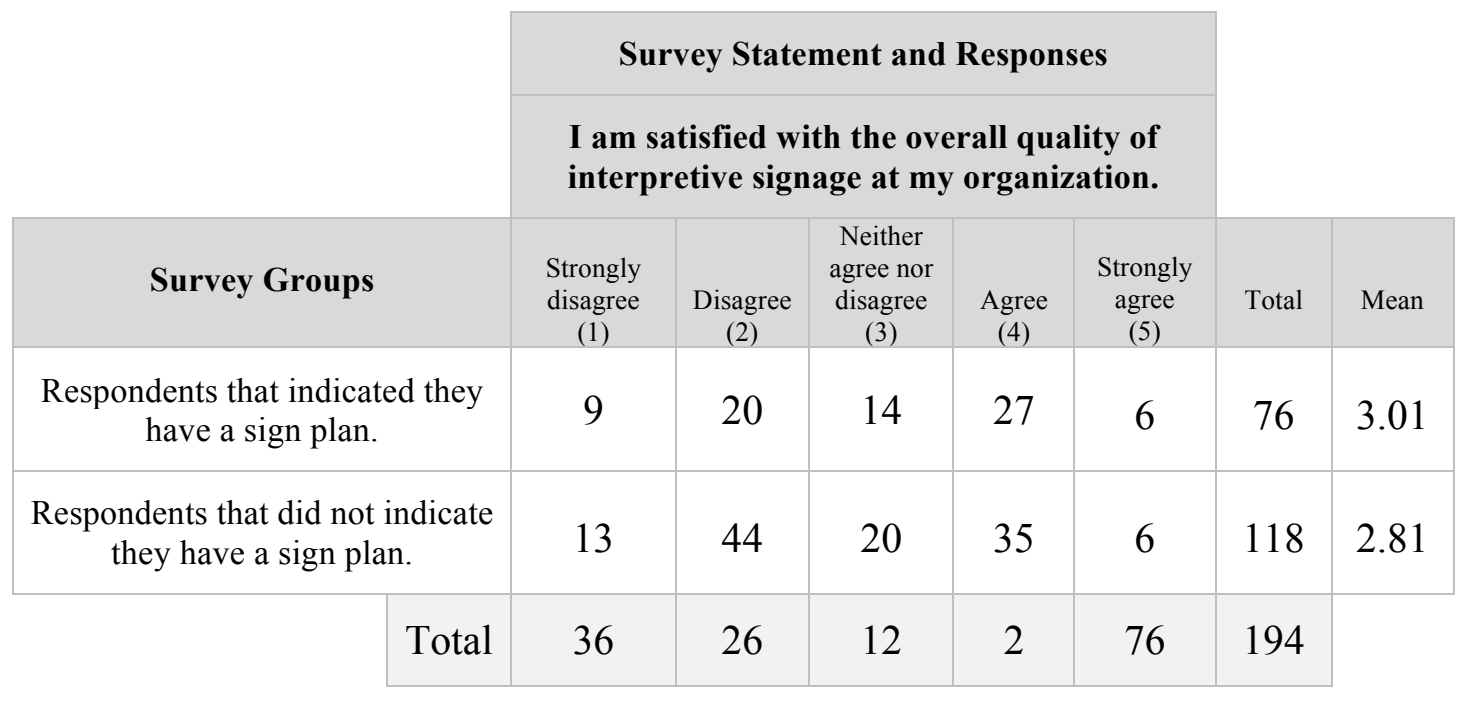


Does your organization develop goals and objectives when developing interpretation?

\begin{tabular}{|c|c|c|c|}
\hline Answer & Bar & Responses & \% \\
\hline Yes & & 185 & $62.7 \%$ \\
\hline No & & 64 & $21.7 \%$ \\
\hline Not sure & & 46 & $15.6 \%$ \\
\hline Total & & 295 & $100 \%$ \\
\hline
\end{tabular}

Does your organization develop a specific theme or core message when developing interpretation?

\begin{tabular}{|c|c|c|c|}
\hline Answer & Bar & Responses & \% \\
\hline Yes & & 224 & $75.7 \%$ \\
\hline No & & 35 & $11.8 \%$ \\
\hline Not sure & & 37 & $12.5 \%$ \\
\hline Total & & 296 & $100 \%$ \\
\hline
\end{tabular}




\section{"Other" response to biggest challenged faced in developing effective interpretation}

administration does not understand the importance of interpretation, and they are unclear about the differences between education and interpretation.

Struggles with how to provide interactive educational opportunities that do not require being staffed

Time

being seen as an afterthought rather than an integral part of developing a great garden; that translates into lack of funds. There is a lack of understanding about how much of an impact good interp can have on visitors and visitation - the Eden Project is a good example of a place where it is at the heart of all they do.

Not enough time or employees

insufficient staff and budget

Docent training should be more unified and focused.

not enough staff dedicated

presenting content in a user friendly and attractive format

collaboration between departments to develop interpretation does not function well

Poor turnout to many interpretive programs

limited staff - only 2 full time staff dedicated to interpretation with many projects to oversee

Clear and tractable messages for each program or exhibition not always clearly defined.

Inconsistency and incoherent approach

accessibility

Lack of staff and/or time to dedicate toward interpretation.

staff doing interpretation is a perfectionist and neither do they have the time to dedicate to interpretation (not the person's main job), therefore we get NOTHING out b/c it is never "perfect" vs. something, anything even though it's sorely needed!

Lack of long term planning for interpretive development

We have a challenge of helping all departments see how they are a part of the interpretive experience. Would love to have the financial resources to provide basic interpretive training to all the staff. The National Association for Interpretation's Certified Interpretive Host

Training would probably be very helpful if we could afford both the time and the money. A shorter basic course or suggested material resources that could be shared with all staff over a one day (or even half day) would be valuable.

adequate staff time 


\section{Comments on how APGA has been valuable or how it could be more valuable from}

those describing their involvement with APGA as "Very valuable" or "Valuable"

ability to network with other institutions; don't need to re-invent the wheel...

Annual conferences and symposia are valuable, but it would be great if there were more affordable

APGA is a great resource and allows professional like me see what other arboretum and public gardens managed.

APGA provides educational resources on improving interpretation and allows for staff to learn from other APGA gardens interpretation

As Volunteer Coordinator, I'm not really sufficiently familiar to comment.

Attending the annual conference allows opportunity to see what other gardens are doing. get lots of ideas and contacts.

Becoming acquainted both with what other gardens do, and also the various levels or extent of commitment to interp.

Botanic Gardens are a prototype for University Arboreta - although mission is somewhat different, we still do many of the same things and have similar goals in using the grounds for education laboratories and targeting non-horticulture audiences to become exposed to or better educated through interpretation

Certification of Collections, making them nationally recognized. Access to industry information at the APGA conference.

Conference sessions about interpretation, articles in publications, and contact with other professionals involved in interpretation.

Contacts with sister organizations

Contact with peer organizations is incredibly valuable.

Continuing staff education; networking

cross training horticulture/education people to present content in a marketable way or marketing people to be more familiar with horticulture/education

Design and Planning Conferences that have had interpretive signage presentations

great conferences but we have limited staff time and budgets for attendance; would love to have some on-line webinars or courses

great to see what and how other organizations are facing same or similar issues

Helpful resources and it is interesting to learn what other gardens are doing at their facility

I have just started working here and have had a tiny bit of involvement with APGA. We will be hosting the conference this year, so I will have more information at that point. 


\section{Comments on how APGA has been valuable or how it could be more valuable from those describing their involvement with APGA as "Very valuable" or "Valuable" \\ (cont.)}

I learned about the whole notion of interpretive planning from APGA. I'd like to see more articles and online resources on interpretation. Webinars?

Interactions with other universities going through similar experiences.

Interact with other professionals, special conference sessions, visit other Gardens to see what is being done.

interpretive master planning symposium, sessions at APGA conference

Learning how other organizations get their messages across to the public and what is important to get across to the public. Involvement with BGED for specific ideas, comments, questions.

list serve is very helpful, good online resources, more APGA workshop sessions on interpretation

Many times the annual conferences include workshops on interpretation and the visitor experience which is always helpful, in addition the APGA staff are very knowledgeable and friendly making it easy to go to them for advice.

Meeting others with similar issues and hearing presentations at conferences, also consultants we have met at trade shows

my only knowledge of the theory of interpretation and current trends comes from the APGA and my independent research and study

Networking; resources available on website;

Networking with other public garden professionals is very important and invaluable.

Newsletter sharing stories of other gardens projects and conferences, workshops, training resources.

only limited number of staff are able to partake in the APGA programs due to budgeting.

Our focus is very specific at our organization, and APGA helps me to get broader perspectives and expertise outside of our skill set.

Plant labeling discussions on the Listserve

pre conference workshops targeted at interpretation; offering training on a regional basis for interpreters

Professional development of the organization has meant we have done some good projects but some garden area remain weak. APGA provides good exchange of ideas and even some free graphics to use,

Programs at their meetings are helpful to me

Quarterly journal, library, source of information for master planning 


\section{Comments on how APGA has been valuable or how it could be more valuable from those describing their involvement with APGA as "Very valuable" or "Valuable" \\ (cont.)}

Reciprocal memberships to visit other gardens and the APGA publications for ideas

Resource Library from many yeas ago was helpful, regional and national conferences

Seeing interpretive signs at other Arboreta

Sessions on interpretation at annual meeting are very valuable.

sharing ideas with other gardens and hearing what works with specific audiences

Since the Vallarta Botanical Gardens is a Mexican organization, we could greatly benefit from materials from the APGA in Spanish.

Strategic design workshop

The annual conference is our greatest source of professional development and I always learn about new programming, ideas and visitor services, however; I would like to see APGA connect on a more global level with AAM to realize that gardens are part of all cultural institutions.

The education section has been very productive. (I am no longer an active member as a result of my current position.) Use more webinars.

The interpretive staff has not been involved with APGA, money for interpretive conferences has been available only for NAI. In the past APGA representatives have come from horticulture staff. Our organization is changing and breaking down these separating distinctions which should allow for wonderful cross--pollination and greater integration of gardens and our interpretive messages.

The marketing talks at the annual conference.

The networking experiences.

The opportunity to interact with other professionals in the field and learn from their experiences

The sharing of knowledge and experience of other members.

Training programs have been very helpful

Understanding the importance/potential of our interaction with the ( funding) Public. As a Community College with a tie in to Horticulture and work force development there are many potentials for partnerships, but with the lack of objectives in the filed of interpretation, we are severely under utilized.

use as a benchmark, conferences

we are able to see what other gardens are doing and review and follow trends in interpretation 


\section{Comments on how APGA has been valuable or how it could be more valuable from those describing their involvement with APGA as "Very valuable" or "Valuable" \\ (cont.)}

We are very involved in NPGD. If they provided additional funding for collateral materials and media buys for the event and continued promotion of public gardens, that would be wonderful.

webinars, conferences, networking opportunities, newsletters, resources available

We don't have the budget to be actively involved, but information, available through APGA, is helpful in interpretive development.

We just singed up so have not explored all yet

workshops at conference, webinar, workshops on topics

workshops on interpretation at the annual conference would be great... 


\section{Comments on how APGA has been valuable or how it could be more valuable from those describing their involvement with APGA as "Somewhat valuable" or "Not valuable"}

Accessibility via online web courses on topics featured at annual symposium

Additional regional conferences dedicated to education

APGA conferences. Applied for but was turned down for Huntington workshop

APGA does not strike me an organization that promotes education

APGA does provide many resources, including symposia, workshops, etc. that help advance the objectives of public gardens.

APGA is valuable in highlighting the need for accessible, relevant interpretation and interpretive planning.

Attended one interpretive planning workshop

attend sessions in national conference

Being a UK garden our involvement with the APGA is limited, we have made some useful contacts and hope to keep a reasonable flow of ideas going.

Being made aware of free APGA resources regarding interpretation would make APGA more valuable. Public Garden publication articles are sometimes helpful. Local interpretation workshops would be useful.

Budget does not permit attendance at national meetings. An active on-line forum to discuss different approaches to interpretation and their success would be helpful.

Conferences (Phoenix and LA) on sustainability were useful. Would appreciate regional help in interpretation models.

Connecting our organization to many resources.

Connecting with colleagues at other gardens. However, I find much more cutting edge interpretive ideas and techniques at other types of institutions besides public gardens.

Enewsletters and Public Garden magazine has good info, generates ideas.

Gives us a sounding board and examples of how others are developing interpretation in their gardens

good resources

Have not been particularly involved as we are quite isolated geographically and limited in resources. But have attended some of the professional development programs

Have recently become member of APGA and have not yet explored resources available.

Helpful sessions at conferences 


\section{Comments on how APGA has been valuable or how it could be more valuable from those describing their involvement with APGA as "Somewhat valuable" or "Not valuable" (cont.)}

helps to keep me connected to other gardens and horticultural related information sources

I am new to the organization and have not yet tapped its resources

I attended a conference on volunteer management that was valuable. Have not attended anything pertaining to interpretation.

I feel APGA is lacking in innovative interpretive ideas for gardens. Need more inspiring ideas/designs/concepts for reaching a broader spectrum of audiences.

I have not had the opportunity to see what the APGA offers in this regard. I am not that active with the APGA, but am a member through my employment

Interesting and informative what other institutions are doing.

I perceive APGA to be a networking opportunity for administrators, less relevant to frontline interpreters.

It may be more valuable for other staff than it is for me. I simply send them news about the Gardens and new staff.

I wear many hats in my job. APGA allows me to address all my responsibilities at one meeting.

keeping up with current issues

Look outside to experts in education and interpretation to bring in best practices from the museum field.

magazine; access to info on line

meeting with the historic gardens group

More affordable training/ continuing ed

More direct discussion about this topic

More help with a dynamic passive interpretation program. With a mix of repeat and destination visitation gardens have to balance classic content with dynamic experiences all within a budget and time frame

more mini-conferences that relate to interpretation (how-to, evaluation, writing techniques, creating a plan)

More webinars, local chapters in major metropolitan areas so we can meet in person more 


\section{Comments on how APGA has been valuable or how it could be more valuable from those describing their involvement with APGA as "Somewhat valuable" or "Not valuable" (cont.)}

My involvement in APGA helped me make a professional connection that has involved me in a recently awarded NSF grant to develop a smartphone app game to engage youth.

my involvement in APGA volunteer mgt talks/lists and Volunteer Interactions has been valuable; same thing for interpretation would be exciting

national conference is valuable but interpretation is not a priority for the organization network

Networking, information. networking, visiting gardens

Networking and National Conference are best benefits.

Networking with other garden managers

online resources, access to webinars

participating in annual conferences as a presenter and as an audience member

Perhaps more programs

Public Garden Directory listing

quarterly publication

Reading about interpretation in the APGA Public Garden magazine and also learning from talks at APGA conferences.

Resources, contacts, Historic Landscapes Conference

Sharing interpretation planning documents, templates and training materials between member organizations

staff training

The conferences often have an element of interpretation that is helpful; online resources are valuable

The most valuable is seeing what other people and institutions have come up with at their home facilities.

There have been valuable presentations and sessions in conferences, articles, and discussion with peers and interpretation professionals.

We learned of a interpretation workshop taking place at another botanical garden in which I will participate

Would love to see more interpretive planning sessions/workshops for directors 


\section{Comments on how NAI has been valuable or how it could be more valuable from those describing their involvement with NAI as "Very valuable" or "Valuable"}

Attending my first workshop in November. Webinars have been great. Currently working on Certified Heritage Interpreter program.

I took trainings through NAI to train others to be interpretive tour guides. This really helped me understand and value the process of interpretation and how taking this process when creating any form of interpretation will result in high quality interpretation.

Training is most valuable

Our volunteer coordinator attends workshops conducted by NAI and shares that knowledge with guides and volunteers

I have been trained as an interpreter through them and find their newsletter and forum interesting and useful

Connecting with other interpreters, learning about latest technology, on-site visits exploration of techniques during conferences. Regional involvement.

It's wonderful to be able to talk to other professionals about how they solve some of the interpretation issues at their site.

I have used many of the CIG training ideas/handouts to train my staff.

NAI has allowed me to become an effective interpreter through training, certification, support, etc.

Through their publications- research papers and books

Contacts through the organization are a valuable resource.

training, newsletters, resources available

As the staff naturalist, I look to NAI for my professional development and to stay current with the interpretive field.

NAI's interpreter training program really helps to illustrate the goals, objectives, and themes that are important to a public program. Furthermore, it illustrates the needs for addressing multiple styles of learners though your interpretation. Everyone learns differently, so your interpretive signage should cater to these audiences.

The network of helpful individuals, the certified levels of training, the conferences, the resources that support our staff training efforts and our broaden opportunities to be a part of larger discussions on shared goals and visions. NAI has given our organization effective tools for planning, evaluation, training staff, and volunteers. The network of fellow interpretive trainers and planners has been an incredible resource. I can call up a number of these interpreters to bounce off ideas, share resources, partner in training efforts and so much more. 
Comments on how NAI has been valuable or how it could be more valuable from those describing their involvement with NAI as "Very valuable" or "Valuable" (cont.)

I am CIT certified, and have presented CIG curriculum for 11 years. Again, more webinars, since travel is prohibitive due to lack of funds.

trainings, certifications, newsletters, regional meetings, journal, books

NAI offers plenty of ideas to spark programming plans.

excellent resources, training opportunities, online resources, workshops

Comments on how NAI has been valuable or how it could be more valuable from those describing their involvement with NAI as "Somewhat valuable" or "Not valuable for this purpose"

online webinars on interpretive strategies

Could be more valuable by being more locally available in their trainings. Frankly, they need more chapters, with more autonomy

I find a couple of the blogs useful (media) and the magazine is often useful Interesting and informative as to signage technology and interpretation methods. 


\section{Comments on how AAM has been valuable or how it could be more valuable from those describing their involvement with AAM as "Very valuable" or "Valuable"}

Receive weekly emails with updates about developments in museum education, including interpretation

AAM provides more resources and sessions on pertinent interpretation topics.

exhibits at conferences to see what is new

publications, conferences, newsletters, list serves connect me to a larger conversation

AAM offers webinars and resources (professional development material as well as vendor lists) that are very useful.

Certification has helped us focus on important missions, including interpretation.

General info contains good info and ideas

publications, conferences...

online resources

AAM presents a wide variety of ideas that are innovative and forward thinking. Many interpretive ideas born at historic sites, history museums, art museums, etc. are applicable to gardens.

AAM certification has enabled us to justify our collections.

Publications and recommended reading have been valuable

Again, as discussed above, I think the connection between gardens and museums is critical for professionals to realize global audience trends and resources.

sessions at national conference, webcasts, books, newsletters, journal

this is my go-to for most interpretive quests...excellent materials, list serve, online resources...just wish I could attend some conferences. 
Comments on how AAM has been valuable or how it could be more valuable from those describing their involvement with AAM as "Somewhat valuable" or "Not valuable for this purpose"

Email updates are helpful, as well as grant opportunities

Usually go to APGA as a resource first since it more my direct peers in the museum world.

Workshops and seminars at Annual Conference have proven helpful

I'm really not all that involved but can be through institutional membership.

if there was more focus on bringing interpretive developers/designers to the table.

use as a benchmark, conferences

Contacts made at annual meeting are valuable.

Cut budgets prevent opportunity to be fully engaged with professional organizations during recent years i.e. travel to meetings and/or prof. dev. opportunities

helped us complete a self study in the area of Public Dimension- how about a self-study for Interpretation (Are you getting your message out??)

online resources are valuable

Benchmarking and networking.

How valuable is your involvement with NAME in regards to professional development in the field of interpretation?

\begin{tabular}{|c|c|c|c|c|}
\hline Value & Answer & Bar & Responses & $\%$ \\
\hline 1 & Very valuable & & 1 & $25 \%$ \\
\hline 2 & Valuable & & 2 & $50 \%$ \\
\hline 3 & Somewhat valuable & & 0 & $0 \%$ \\
\hline 4 & Not valuable for this purpose & & 1 & $25 \%$ \\
\hline & & Total & 4 & $100 \%$ \\
\hline
\end{tabular}

How valuable is your involvement with NAAEE in regards to professional development in the field of interpretation?

\begin{tabular}{|c|c|c|c|c|}
\hline Value & Answer & Bar & Responses & $\mathbf{\%}$ \\
\hline 1 & Very valuable & & 1 & $8.3 \%$ \\
\hline 2 & Valuable & & 4 & $33.3 \%$ \\
\hline 3 & Somewhat valuable & & 4 & $33.3 \%$ \\
\hline 4 & Not valuable for this purpose & & 3 & $25 \%$ \\
\hline
\end{tabular}




\section{Comments on how NAAEE has been valuable or how it could be more valuable}

brand new, can't yet evaluate

I love this organization. I love their forum and their emails; lots of great articles and very useful in informing me of grant opportunities, professional development, etc.

Information about grant opportunities most valuable; conference fees too high which inhibits attendance

Available lesson plans and curriculum.

Publications, local conferences

online resources and training

good materials and resources, used NAAEE a lot initially when building program, but I now find superior local resources.

I went to the affiliate workshop this year and to the rest of the conference. I made good connections, got wonderful suggestions for myself and for my affiliate.

How valuable is your involvement with ACM in regards to professional development in the field of interpretation?

\begin{tabular}{|c|c|c|c|c|}
\hline Value & Answer & Bar & Responses & $\mathbf{\%}$ \\
\hline 1 & Very valuable & & 0 & $0 \%$ \\
\hline 2 & Valuable & & 0 & $0 \%$ \\
\hline 3 & Somewhat valuable & & 0 & $0 \%$ \\
\hline 4 & Not valuable for this purpose & & 1 & $100 \%$ \\
\hline
\end{tabular}

How valuable is your involvement with AASLH in regards to professional development in the field of interpretation?

\begin{tabular}{|c|c|c|c|c|}
\hline Value & Answer & Bar & Responses & $\%$ \\
\hline 1 & Very valuable & & 3 & $60 \%$ \\
\hline 2 & Valuable & & 0 & $0 \%$ \\
\hline 3 & Somewhat valuable & & 2 & $40 \%$ \\
\hline 4 & Not valuable for this purpose & & 0 & $0 \%$ \\
\hline
\end{tabular}

How valuable is your involvement with AZA in regards to professional development in the field of interpretation? 


\begin{tabular}{|c|c|c|c|c|}
\hline Value & Answer & Bar & Responses & $\%$ \\
\hline 1 & Very valuable & & 1 & $14.3 \%$ \\
\hline 2 & Valuable & & 2 & $28.6 \%$ \\
\hline 3 & Somewhat valuable & & 3 & $42.9 \%$ \\
\hline 4 & Not valuable for this purpose & & 1 & $14.3 \%$ \\
\hline
\end{tabular}

How valuable is your involvement with AZH in regards to professional development in the field of interpretation?

\begin{tabular}{|c|c|c|c|c|}
\hline Value & Answer & Bar & Responses & $\%$ \\
\hline 1 & Very valuable & & 1 & $12.5 \%$ \\
\hline 2 & Valuable & & 4 & $50.0 \%$ \\
\hline 3 & Somewhat valuable & & 2 & $25.0 \%$ \\
\hline 4 & Not valuable for this purpose & & 1 & $12.5 \%$ \\
\hline & & Total & 8 & $100 \%$ \\
\hline
\end{tabular}




\title{
Appendix E
}

\section{MONTEREY BAY AQUARIUM DOCUMENTS}

\author{
Documents courtesy of: \\ Monterey Bay Aquarium \\ 886 Cannery Row, Monterey, CA 93940
}




\section{Volunteer Manual excerpt "What is Interpretation?"}

M O N TEREY B A Y A Q U A R I U M

\section{WHAT IS \\ INTERPRETATION?}

Here are $\mathbf{3}$ ways of interpreting the same animal.

What do you think of them?

Approach 1:

Visitor: What's that?

Guide: A gumboot chiton.

Visitor: Oh.

Approach 2:

Visitor: What's that?

Guide: A gumboot chiton. Like other chitons it has 8 valves or plates. Unlike other chitons, the gumboot chiton's plates are under the mantle. They look like these butterfly-shaped shells.

Visitor: Oh.

Guide: A gumboot chiton is a kind of mollusc. It lives on the rocks along the coast and grazes on algae.

Visitor: Hmmm.

Guide: Molluscs are a group of animals that includes snails, clams and so forth.

Visitor: Oh, a snail! Thank you.

\section{Approach 3:}

Visitor: Yuck, what's that?

Guide: It does look a little weird but it's related to snails, like an abalone. Let me show you something. If I turn it over you can see its gills, mouth and foot. Go ahead and touch it.

Visitor: Oooh. What does it do?

Guide: It scrapes plants (algae) off rocks. In its mouth is a ribbonlike file covered with teeth, called a radula. We also know algae live on it and small pea crabs use it as a home. Can you see one living in its gills?

Visitor: Oh yeah. If it's like a snail, where's its shell?

Guide: It has 8 butterfly-shaped shells, or plates, along the back. You can't see them because they're covered by the mantle, but you can feel them.

They look like this (showing a chiton plate). Have you ever seen shells like these on the beach?

Visitor: Yeah, I always wondered what those were. So can you eat it?

Guide: I'm not sure. I've never tried one. I've heard it's tough and tasteless. The Indians that lived in Monterey ate it. Archaeologists have found the shells in Indian middens, or junk piles. There's a small snail that rasps holes in its skin and flesh. As far as I know, large predators like otters don't eat it.

Visitor: What'd you call it?

Guide: It's a gumboot chiton-the largest chiton in the world. If you've done any tide pooling you may be more familiar with the lined shore chiton. Have you ever seen one of these (showing a lined shore chiton) on the rocks?

And so on.

Good interpretation capitalizes on curiosity and helps visitors see meanings and relationships rather than simply learning facts. It involves listening, sharing and seeing through the visitors' eyes, acting on feedback, having fun, learning and teaching. In the 1950s, Freeman Tilden wrote a book on the fundamentals of interpretation. Since then Interpreting Our Heritage has become the basic guide to interpretation. 


\section{Volunteer Manual excerpt "What is Interpretation?” (cont.)}

M O N T E RE Y B A Y A Q U A R I U M

Here are Tilden's 6 principles of interpretation:

- Interpretation that doesn't relate to the visitor is sterile. (Start the interpretation with visitors' reactions.)

- Interpretation is revelation based upon information. Information, as such, is not interpretation. (Watch for an "oh!”)

- Interpretation is an art, which combines many arts, whether the materials presented are scientific, historical, architectural or otherwise. (Let your talents show.)

- The chief aim of interpretation is not instruction, but provocation. (Ask questions as well as answer them.)

- Interpretation should aim to present a whole rather than a part. (Show visitors the forest as well as the trees.)

- Interpretation for children should follow a fundamentally different approach than interpretation for adults. (Instead of giving a diluted adult presentation, develop a hands-on, experiential children's presentation.)

\section{TIPS FOR EFFECTIVE INTERPRETATION}

These tips apply to short interactions with visitors at various exhibit stations as well as to more extended presentations, such as exhibit discoveries, tours and narrations. Think of how you might adapt these interpretive techniques to the various scenarios in which guides interact with visitors.

\section{Before beginning}

- Be prepared. Have a theme or focus and questioning strategies in mind before the presentation.

- Try to assess the audience's interests, capabilities and level of knowledge. This is especially important before a tour.
- Meet the participants. It's easier to interpret for people you know.

- Neither overestimate the visitors' background nor underestimate their intelligence.

\section{At the start}

- During the introduction, give the audience an overview of your theme or focus.

\section{From start to finish}

- Be friendly, warm and enthusiastic. Enthusiasm rubs off on the audience, as will disinterest, passiveness or inhibition.

- Add anecdotes to a factual presentation. Throw in some personal examples of things that are important to you. "I was amazed to find out that this sea hare can get to weigh 15 pounds in its 1-year life span! This has always been one of my favorite animals."

- Pronounce words clearly and speak loud enough for everyone to hear. Avoid competing with other noises.

- Use body motion for emphasis, like pointing or gesturing to explain. Avoid distracting motions or body attitudes like folded arms, hands in pockets, rocking or slouching.

- Be accurate and honest. Feel free to say, "I don't know."

- Be flexible. Capitalize on visitors' spontaneous interests or questions.

- Repeat questions from the audience.

- Encourage audience participation. Ask questions and credit visitors' responses and questions.

- Ask some open-ended questions that stimulate discussion and lead the audience to a new discovery. 


\title{
Volunteer Manual excerpt "What is Interpretation?” (pg. 10-11) (cont.)
}

\author{
M O N T E RE Y B A Y A Q U A R I U M
}

- Allow time for visitors to respond to your question before moving on. Don't lavish praise on the first "correct" answer; it stifles responses from others who may have a different contribution.

- Avoid sarcastic or mocking comments.

\section{At each stop or with each new group}

- Face the audience when speaking to them. Try to be visible to each visitor.

- Avoid blocking the view or separating the audience.

- Make eye contact with each member of the audience.

- Vary your speaking rate for emphasis and feeling.

- Vary the amount of talking per stop, topic, etc.

- Do what you want the audience to do, like bending over to look at something more closely or picking up an interesting animal.

- Encourage visitors to use several senses (seeing, hearing, touch and smell) during the presentation.

- Know when to be silent.

- Watch for and respond to audience feedback. Verbal contributions, questions, a head nod (not the sleepy kind), laughter and applause indicate the audience is with you.

- Fidgeting, blank stares or apparent confusion indicate that the audience isn't interested in or comprehending what you are saying.

- Use transitions to connect one topic (or place) to another.

\section{In the end}

- Conclude your presentation. Summarize major points and congenially release the audience.
Suggest other exhibits that might interest them or that they shouldn't miss.

\section{QUESTIONS AND RESPONSES}

As an Aquarium Guide, you are the aquarium's major contact with the public. You can greatly enhance the visitor's enjoyment, education and overall impression of the aquarium by interpreting what is here. We have discussed what interpretation is, but how do you do it? The keys to interpretation are questions and responses.

Here are a few ways to get your interpreting rolling. Can you think of any others?

\section{The hook-an attention-grabbing fact}

Visitor: What's that?

Guide: That's a sea star relative called a brittle star. It's called a brittle star because its legs are very brittle and come off if something (or someone) pulls too hard! This is a brittle star's way of escaping from predators-its leg soon re-grows.

\section{The shift-a different point of view}

Visitor: This starfish won't come loose!

Guide: That's because it's holding tight with hundreds of little suction cups called tube feet. If you were a sea star living on the rocks pounded by waves, wouldn't holding on as tightly as this sea star does help you?

The transfer-a send-off to a related exhibit Visitor: How do these starfish reproduce?

Guide: Males release sperm and females release eggs into the sea. A fertilized egg develops into a small swimming larva and feeds on tiny plankton. This larva eventually settles down and changes into a young sea star. If you would like to learn more about reproduction of some ocean animals, visit the moon jelly exhibit at the exit from the Splash Zone. 


\section{Volunteer Manual excerpt for Kelp Forest exhibit}

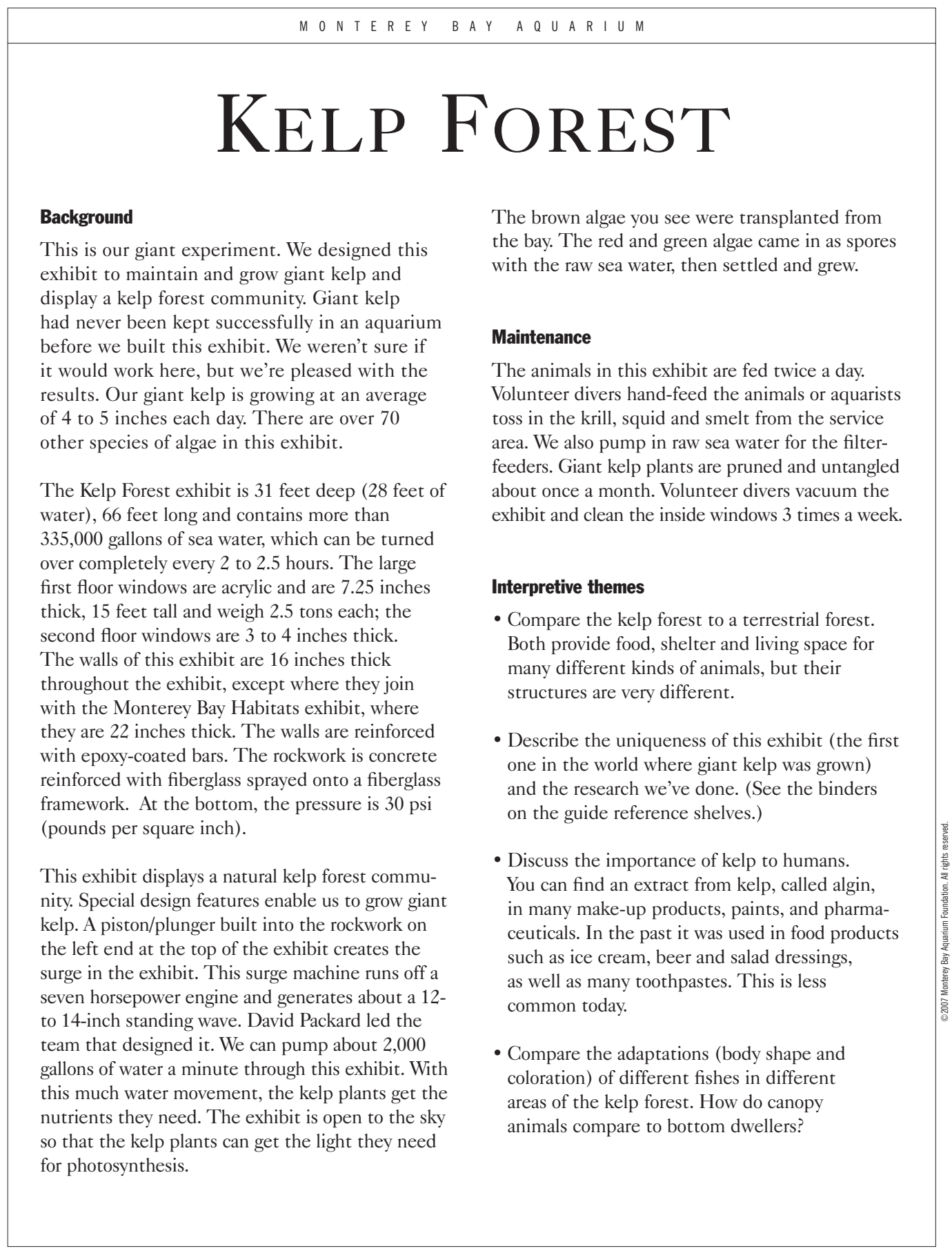




\section{Volunteer Manual excerpt for Kelp Forest exhibit (cont.)}

\begin{tabular}{|c|c|}
\hline MON T E R E Y B & $Y \quad A Q Q \cup A R \perp \cup M$ \\
\hline $\begin{array}{l}\text { - Watch and discuss schooling. Do schools have } \\
\text { leaders? Describe the use and importance of } \\
\text { the lateral line, a fish's sixth sense. } \\
\text { - Use the sardines to introduce the history of this } \\
\text { site and the canning industry. }\end{array}$ & $\begin{array}{l}\text { Guide positioning } \\
\text { Step over the railing and position yourself at the } \\
\text { corner of a window (so you're not blocking people's } \\
\text { views into the exhibit). From here you can talk for } \\
\text { a couple of minutes to a group or just answer } \\
\text { individual questions. }\end{array}$ \\
\hline $\begin{array}{l}\text { - Describe what it's like to dive in a kelp forest and } \\
\text { explain that the visitor is "diving" without getting } \\
\text { wet. There are often divers in this exhibit, so you } \\
\text { can use them to lead to a scuba discussion. }\end{array}$ & $\begin{array}{l}\text { Aids for starting conversations } \\
\text { - Eavesdrop and answer questions or help } \\
\text { clarify misinformation. Example: }\end{array}$ \\
\hline $\begin{array}{l}\text { - Compare vertical with horizontal rock faces and } \\
\text { the diversity of algae/invertebrates found there. }\end{array}$ & $\begin{array}{l}\text { Visitor: I wonder what's causing the } \\
\text { plant movement. }\end{array}$ \\
\hline $\begin{array}{l}\text { Conservation messages } \\
\text { - The kelp forest grows very close to the shore, at } \\
\text { the ocean's edge. It provides food, shelter and a } \\
\text { living space to many animals, all the way from } \\
\text { the rocky substrate where the kelp is anchored to } \\
\text { the canopy at the ocean's surface. The California } \\
\text { sea otter spends a great deal of time in the kelp } \\
\text { forest. Many juvenile fish find refuge among the } \\
\text { kelp blades. Since the kelp forest grows so close } \\
\text { to the ocean's edge, it can be easily impacted by } \\
\text { many of our activities on the land. Remember } \\
\text { that storm drains flow to the ocean. }\end{array}$ & $\begin{array}{l}\text { Eavesdropping guide: A special wave machine was } \\
\text { built to move the water in this exhibit. It's a pis- } \\
\text { ton that moves the water. The plants need } \\
\text { the motion... } \\
\text { - Say "hello" and smile. } \\
\text { - Ask someone a question, such as "Have you ever } \\
\text { eaten sardines?" } \\
\text { - Walk up to a group of people and, if you're not } \\
\text { interrupting their conversation, say "This is what } \\
\text { a scuba diver sees while diving in a kelp forest. If } \\
\text { you have any questions about this exhibit, I'll be } \\
\text { happy to answer them." }\end{array}$ \\
\hline $\begin{array}{l}\text { - We can help take care of the kelp forest by mak- } \\
\text { ing some simple choices: keeping our cars in } \\
\text { good working order so that oil doesn't drip onto } \\
\text { driveways and roadways; using nontoxic products } \\
\text { in our homes and gardens; placing trash in proper } \\
\text { receptacles; washing our cars at a car wash or on a } \\
\text { grassy surface. } \\
\text { - Rockfish, so prominent in this exhibit, have been } \\
\text { seriously overfished. When we eat red snapper or } \\
\text { rock cod, what we're really eating is rockfish. } \\
\text { Most rockfish are in the red zone of the Seafood } \\
\text { Watch Card. We can help them by choosing } \\
\text { seafood from the green zone of the card. }\end{array}$ & $\begin{array}{l}\text { Dealing with problems } \\
\text { If someone goes under or over the railing or reach- } \\
\text { es across to touch the window, let them know the } \\
\text { railing is there to protect the windows, which } \\
\text { scratch easily. Explain that "the windows are } \\
\text { acrylic and scratch easily, so please don't touch." } \\
\text { This is a good opportunity to interpret the win- } \\
\text { dows and why we use acrylic instead of glass. }\end{array}$ \\
\hline
\end{tabular}




\section{Volunteer Manual excerpt for Kelp Forest exhibit (cont.)}

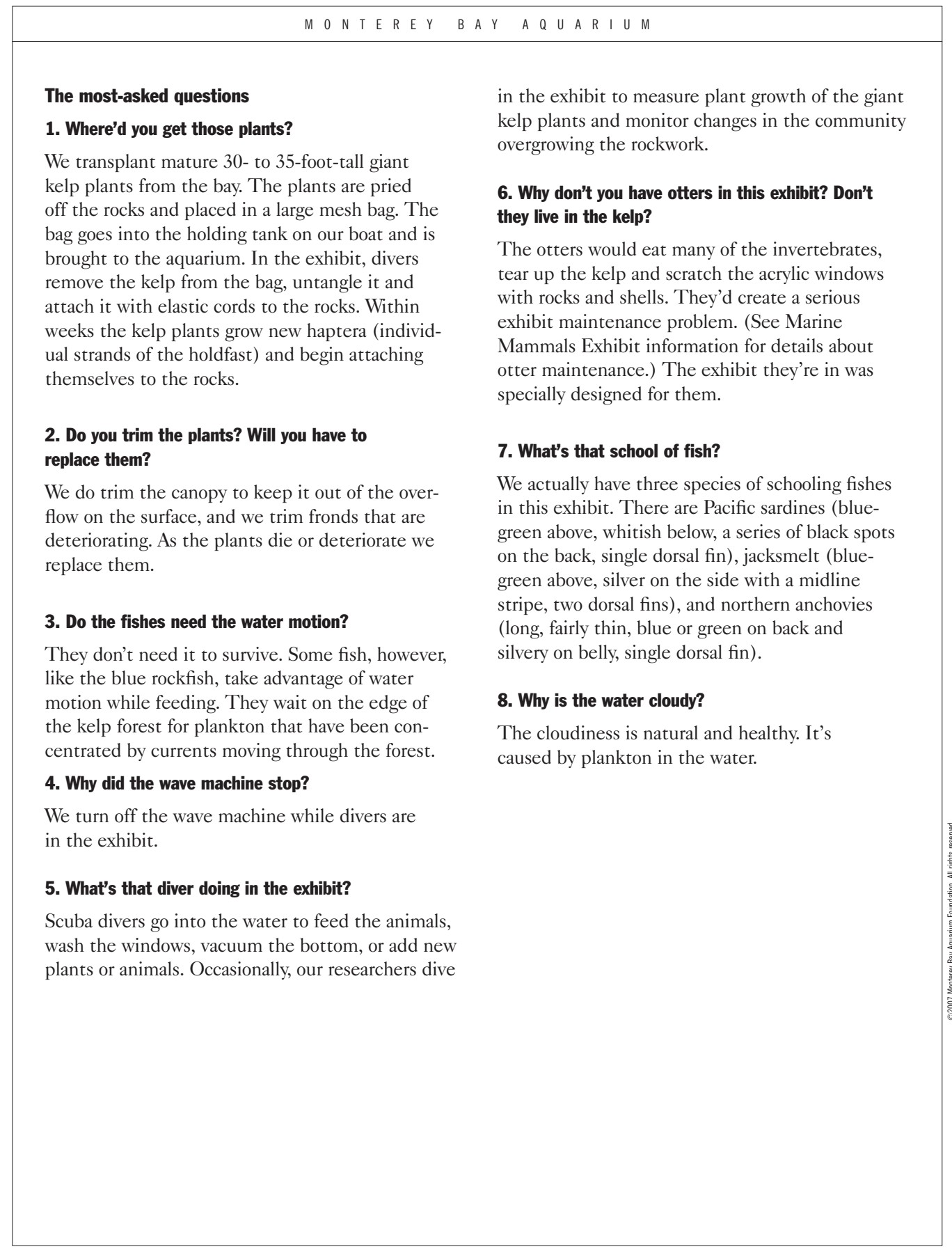

KELP FOREST 5.4 


\title{
Appendix F \\ UNITED STATES BOTANIC GARDEN INTERVIEW AND DOCUMENTS
}

\author{
Documents courtesy of: \\ United States Botanic Garden \\ 100 Maryland Avenue, SW, Washington, DC 20001
}


Excerpt from United States Botanic Garden Interpretive Master Plan

\section{THE GARDEN PRIMEVAL}

\section{Discussion:}

The display will represent a "snapshot" of the primeval forest as it might have appeared in the mid-Jurassic (150mya) period of the Mesozoic Era. Plants will not be grouped according to relative age, but rather the display will focus on those qualities that will insure an enjoyable sensory experience. It is important for the visitor to experience the dense, green, flower-less, humid, foggy character of this forest. The design for the house is laid out such that standing water (necessary for horsetails) is in the middle of the house. A large portion of the masonry wall is dedicated to the fern collection. Both ends of the house are to be densely planted with a forest-like collection of plants.

Props: Footprints of dinosaurs, fossils, fog, and sounds (insects, amphibians, reptiles) will add significantly to the visitor experience. Fossils, if used in the landscape, should be in the Paleozoic Era. Gigantic insects, dinosaur models, dinosaur nests will compete with the plants and dilute the message. Fossils of Mesozoic plants/animals could be used in the signs. The use of artificial plants is not necessary to meet the communication goal and might detract from the living collection.

Draw distinction between the signage (representing the present) and the landscape exhibit (representing the past).

\section{Communication Goal:}

Ancient forests, without flowering plants, were very different from the forests we have today.

Message: (Layout Plan - 3 signs total) [TGP.BI] Big Idea - Where are the flowers? Club mosses, horsetails, ferns, and gymnosperms - all plants that lack flowers, dominated ancient primeval forests of 150 million years ago. How did these plants reproduce?

[TGP.IG.1] Virtually all primitive seedless plants like ferns and clubmosses require water to complete their life cycle. When climates were moist, this presented no problem. But during the Mesozoic Era, the climate began to dry, and many primitive plants, represented here as fossils, went extinct. Unlike seed plants, which use air, water, or insects as a means of transport, the reproductive cells of seedless plants propel themselves across soil and leaf surfaces using flagella and other means adapted for movement in fluids. Without moist surfaces, reproduction fails. 


\section{Excerpt from United States Botanic Garden Interpretive Master Plan (cont.)}

[TGP.IG.2] During the Mesozoic, an era of increasing aridity, the four groups of plants known collectively as the gymnosperms arose and dominated the landscape. Unlike the ferns, these plants had pollen that could be dispersed by wind and propagules (seeds); both could withstand dryness. Representatives of all of the gymnosperm groups - the cycads, ginkgoes, conifers, and gnetophytes - can be seen here. The gingko and dawn redwood arose during this period, and we regard them as "living fossils" that have miraculously survived into the present.

[TGP.IG.3] Why are today's landscapes so different from this? Many other gingkos, cycads, and gnetophytes are now extinct. They were replaced by the flowering plants in a long pageant of evolution that began about 90 million years ago. Similarly, mammals, birds, and more diminutive reptiles have replaced dinosaurs. Why? Changing conditions, both climatic and ecological have favored the rise of plants and animals with new traits (adaptations) more suited to their environment.

[TGP.IG.4] Where did flowers come from? Flowering plants offered three advantages over the gymnosperms: first, their water-conducting tissues are more efficient; second, their seeds develop within a protective structure; and third, flowers and fruits offer many ways for animals to play a part in promoting the plant's reproduction through pollination and seed dispersal. These advantages resulted in rapid rates of evolution and diversification, allowing the flowering plants to invade and adapts to many new habitats. [This message could be in an audio/docent/discovery/cart format.] 


\section{Excerpt from interpretive planning document for discovery cart program (page 1 of 7)}

\section{Conifer Discovery Cart}

The Big Idea:

As the winter season approaches, and deciduous trees lie dormant, people begin to consider the evergreen options around them. Many conclude that all evergreens are pines, however this is no so! The Conifer discovery cart will aide the visitor in determining the difference between a pine, a fir and a spruce tree. It will impart knowledge about each member of the family Pinaceae and the historical and cultural impact of these plants.

\section{Goals \& Objectives:}

After interacting with the Conifer Discovery Cart, the visitor will be better able to:

1. Identify defining characteristics of evergreen trees;

2. Distinguish between pines, firs and spruces;

3. Understand the role evergreen trees play in winter traditions; and

4. Demonstrate the aesthetic, cultural, economic, therapeutic, and ecological importance of plants to the well-being of humankind.

\section{Talking Points:}

1. Evergreen trees have been a part of winter traditions for thousands of years.

2. Evergreens have specific adaptations that allow them to survive throughout the winter season.

3. Not all conifers are the same (aka - not all Christmas trees are pines). Pines, firs and spruces all have distinctive characteristics that make them easily identifiable to the keen observer.

\section{Background Information:}

\section{Traditions}

The winter solstice is celebrated on the shortest day of the year: December $21^{\text {st }}$. Well before Christianity, some 3,000-4,000 years ago, Europeans (particularly Druids) acknowledged the day with seasonal rituals and celebrations using plants. It was considered the "birthday" of the new sun, about to begin its return journey toward earth (and, thus, lengthening days).

An important part of these celebrations was the use of evergreens (firs, pines, spruces, boxwood, holly \& holly berries, and mistletoe). These plants were thought to hold the secrets of life and to insure that life would endure through the winter. Use of evergreens was a way these early people could act to insure that spring would come again, and that deciduous trees and shrubs would grow again.

Two early holidays used trees as important symbols:

- Feast of Adam \& Eve: This holiday was first celebrated on December $24^{\text {th }}$ in AD 337; during the celebration, a fir tree, called a 'paradise tree,' was decorated with red apples

- Saturnalia: The Roman festival of Saturnalia was celebrated with trees festooned with trinkets and topped with an image of the sun god. Saturn was the Roman God of Agriculture and Saturnalia was held on the winter solstice, and then reckoned on December 25 in the Julian calendar. (The astronomical solstice occurs on or about December 21.)

We have continued to mold and modify these traditions to suit modern tastes:

- Use of greens more indoors now than in colonial times

- Christmas tree

- From the ancient German and Scandinavian practice of placing evergreen trees outside their doors or on their roofs to hasten spring.

- May also be borrowed from a Celtic spring equinox tradition associated with putting an evergreen tree on/in front of the house to welcome the coming of spring.

- Having an evergreen tree indoors may have begun in the 1600s in Germany.

- Popularized in Great Britain during the reign of Queen Victoria and her husband Prince Albert. 


\section{Excerpt from interpretive planning document for discovery cart program (page 5 of 7 )}

\section{Activities:}

\section{Conifer Conundrum}

Goal:

After completing the Conifer Conundrum activity, the visitor will be better able to:

1. Identify defining characteristics of evergreen trees;

2. Distinguish between pines, firs and spruces;

3. Highlight misnomers, with specific attention to the Douglas fir; and

4. Demonstrate the aesthetic, cultural, economic, therapeutic, and ecological importance of plants to the well-being of humankind.

Materials Needed:

Conifer Conundrum Graphic Displays: Pine Key, Fir Key, Spruce Key

Physical (cuttings \& cones) and/or Photo Examples of Pines, Firs \& Spruces

Procedures:

1. Set up cart with Conifer Conundrum Game

a. Show a photo/display a cutting from a pine, fir or spruce.

b. Encourage visitors to guess which type of conifer they are viewing. Why did they choose that type of conifer?

2. Educate visitors as to the distinguishing features of pines, firs and spruces - show samples of all three to highlight distinguishing characteristics.

3. Discuss misnomers - Douglas fir, Princess pine, Norfolk Island pine

4. Encourage visitors to take a moment to observe them the next time they pass a conifer to test their investigative skills! 


\section{Excerpt from interpretive planning document for discovery cart program (page 6 of 7)}

\section{Survivor: Evergreen Edition}

Goal:

After completing the Survivor: Evergreen Edition activity, the visitor will be better able to:

1. Identify defining characteristics of evergreen trees; and

2. Demonstrate the aesthetic, cultural, economic, therapeutic, and ecological importance of plants to the well-being of humankind.

Materials Needed:

Survivor: Evergreen Edition board \& cards

Physical and/or Photo Examples of Pines, Firs \& Spruces

Procedures:

1. Game - in order to survive the winter, you must choose specific adaptations for specific situations. What you choose to do determines if you survive the winter season!

a. Evergreen adaptations (situational reason):

i. Cuticle (Surface): Waxy or Smooth?

1. Waxy cuticle!

Why:

a. Reduces evapotranspiration from leaf surface

b. Water beads off leaf instead of sitting on leaf

c. More durable

ii. Stomata (Breathing Pores): On Top-side or Bottom-side of Leaf?

1. Stomata lined up in pits on the underside of the leaf!

Why:

a. Wind flows over the pit and stomata are shielded

b. Less wind at the molecular level - similar to experience of lying in a ditch during a tornado...

iii. Spines: Yes or No?

1. Spines!

Why:

a. Dissuades herbivores/protection

iv. Sap: Thick or Thin?

1. Thick sap!

Why:

a. Reduces freezing temperature - similar to putting salt on a sidewalk in the winter to reduce ice

v. Sap: Toxic/Distasteful or Non-toxic/Tasty?

1. Sap with toxic, distasteful or noxious secondary compounds (conifer aerosols like turpentine and buxin or taxine, both poisonous)!

Why:

a. Deters herbivores

vi. Leaf Size: Large or Small?

1. Small leaf size (needles)!

Why:

a. Reduces wind resistance

b. Reduces evapotranspiration

vii. Shape: Square or Pyramid?

1. Pyramidal growth form!

Why:

a. Assists in the shedding of snow and ice

2. As visitors choose their adaptations, encourage them to think about why each adaptation would help an evergreen in the winter. Explain why each adaptation helps the evergreen survive the winter season. 
Excerpt of Interview with Holly Shimizu, Executive Director of United States Botanic Garden

How well are public gardens doing at training there are employees at interpretation.

Not well, not well. I mean not well enough. I'm just giving you my opinion.

It really hit me recently when we were interviewing for a position in public programs and one of the people that we interviewed was an interpreter. She is officially an interpreter and it really hit me; I want an interpreter here. I want the job title, the job expectation and a full time commitment to interpretation. So yesterday I was at the Capitol visitor center and their training specialist went to some great training called certified interpretive host. And what that is, is half customer service and half interpretation and I want to do that for our staff. It's not for the full time interpreter type. It's not for the people that know that they are already supposed to be involved in it. It's really for like the gardener, the laborer, the maintenance mechanic who may not realize that they are an interpreter as well, if some says "what's that plant?" they may not know but they can be polite and say "Oh, if you go right there, they can help you with that."

I have a copy of your Interpretive Master Plan, and I thought you might be the best one to talk to about it. I just wondered if you had any thoughts about it. Whether it was useful or how it came about that you thought you needed to have one done.

Well the Interpretive Master Plan is incredibly useful to us because we were given an incredible opportunity when the conservatory was shut down for major renovation. And so it was closed for four years, so most of the Botanical Garden was shut. So that enabled the staff to really work on this. And a firm was hired, Rodney Robinson Architects and they were really good at listening and facilitating so they conducted a series of workshops and sort of guided the process so we were able to get input from everybody, the whole staff. Of course, as you already know, that's essential. So we considered the horticultural aspects with the educational aspects with the practical and the scientific and all the different things. So it's been our guiding force essentially in the conservatory. But now we are ready to do a new one because we know what has worked and what hasn't worked and what happens over time is you lose it. Staff changes. People don't read it. You forget what it is and you always have people who have other ideas, who don't see it as it is written or described in that master plan. So, I would say, especially in our case, gardeners. They get their own take on it and how they want it to be. So they are making changes and it is really changing a lot over time so you kind of need the interpretation police, in a way to come in and say, "Come on we need to work together." You know, public programs working with horticulture is always a challenge. And we've been pretty good at it, better than a lot of gardens. But not always agreeing on what we want the messages to be and what we want the plant 
collections to be to support each of the greenhouses and what we want them to be about. So we lose focus a lot.

So the Interpretive Master Plan that I have didn't mention an overall or overarching message or theme that connects the entire interpretation at the sight. Is there an overarching theme perhaps in the mission?

There is. Yes we support the mission. We love our mission and that is really to focus on the five importance's of plants. Atheistic, cultural, beauty, so we do a lot with plants and literature, art, architecture and so forth. Economic. So we do a lot with economic plants. Then therapeutic/medicinal plants is important and then the environmental aspects of plants. So everything supports that overall. But then each of the twelve glasshouses has its own message. Kristine Flannagen was really in charge of this interpretive master plan. I did not work here at that time. So I'm really speaking for here. I hope I'm reflecting here because she really led this. I would say that the interpretation here at the botanical garden is really a reflection of her and her mission. She's a scientist but she's a gardener; she loves plants; she loves education and reaching the public. So she was able to come up with a lot of these ideas and she had it layered with the big message and different levels of interpretation for each of the houses. But honestly, I know that they are not effectively received unless you have a tour guide. To me people get things based on their own interest or reasons.

Circling back to our Interpretive Master Plan, I think it is old now. It's time to revisit and we are doing this. It's time to do new interpretive signs and be able to change them.

Is there anything you would do differently with the way the interpretive plan was put together? I guess you weren't here for the last one but is there anything that you would change about the plan in general?

Yes. I would make it more dynamic. I would have multiple messages that can change throughout the seasons, the times. I like a lot of flexibility so one big change is the large heavy expensive signs; we're not doing that anymore. They're outdated. You know you have to be fresh. You have to change.

I sort of have the opinion that we attract a lot of people that are really good at formal education to public gardens for classes or things like that but it is a totally different thing reaching the average visitor.

That's right. I agree. It is different. And I have shifted my interests in what we do and the focus of what I want for our garden and that is informal education. I don't want the formal education. We live in a town where there is so much formal education. There are too many choices. What we have is an opportunity with the walk-in visitor. It's 
enormous. We get over a million visitors and we get them even if we don't try because of where we are located. And I look at this as a huge gift. We have been given a wonderful opportunity to look at it as you walk in. You care less, and I think our challenge is to give you something that will make you look, understand, or be inspired by. That's really my goal, and I think that we can do that person by person. I want to have people available to meet and greet the walk-in visitor. It could be through a discovery cart or a "ask me questions." You know, respecting people that don't want to talk to anyone. That's ok. I don't want to bother them. But I want to be available in a warm friendly way because what we do remember is the stories people tell us.

\section{Yeah a lot of places are doing hand-written signs for that sort of thing.}

Right we do those as well. I always go back to, my preferred method is live. Is a person because I think that tends to be what we remember?

So you are going to try to get this interpretive trainer for your staff?

Yeah so I found out just yesterday. So she went to the National Association of Interpretation annual meeting and what she wants to bring back to the Capitol Visitor Center is this concept of Certified Interpreter Host. And it would be training for our staff.

It would be nice to have someone brought to a botanical garden for one of these programs. It's rather expensive to send people to these workshops.

It is expensive. I want to have somebody brought here.

I think a public garden needs to host some of these training workshops. They are always at nature centers, public parks, or places like that.

I know. I know.

And I don't think we are involved, really. We need to be involved more with NAI.

We need to. We need to get staff involved. We are making progress but in the mindset that we are all interpreters, every one of us. Even if you are the janitor, you are still and interpreter. You accept that that is part of what you are doing here.

A lot of people in our public programs department were saying to me, "We need a classroom and we need an auditorium," and my answer to that is most places around here have classrooms or they have auditoriums what they don't have is all these great plants. Our gardens are our classrooms and that's how I want to think about it. We 
need to use our living plants. That's what we are about. We are about living plants. So let's consider all our public spaces as our classrooms.

I've even convinced a lot of the people that have said to me, "Well, we need to follow the school guide lines and the testing...." and I said "No, we are not doing that."

What we need to do is what the schools aren't doing. They don't teach natural history. They don't teach about what kind of geology, and soil, and plants. What about where you live? They don't learn about that. That way what we offer is a connection to the environment.

\section{So this year was Savage Gardens, does every year have some sort of theme?}

Yes every year has a different theme. Last year was Plant Families. I didn't think it reached the public very well. We had done it a number of years ago and made it really good. Last year it was flat.

\section{Did you try to connect to your family like your family tree or something?}

When we were successful with it we did. We connected it to family- your cousins, your aunts and uncles. We really made it human and we really mad it fun. This time for whatever reason it was too scientific and we were trying to teach you about monocots and dicots and gymnosperms and angiosperms. People don't want to know about that. It's not interesting to them.

\section{Yeah you have to find a balance between visitor interests and what you want to communicate.}

Right. And we had too much information. It was definitely not one I recommend unless you can lighten it. Make it fun.

\section{What about preliminary evaluation? Do you ever test out ideas on the visitors?}

Yes we've done that. Here's an example which is kind of an extensive example that when we were trying to decide how to focus our medicinal glass house exhibit and initially we wanted to do it as a shaman from a rain forest all of that kind of magical stuff. Then we found out through surveying visitors what they wanted was really modern. Much more relevant, what plants are used for medicines, what plants are used over-the-counter, all these sort of things. That's what they want to know. So that affected the way we do house. So that was a good thing. It totally surprised us. 